\title{
Developmental explanation and the ontogeny of birdsong: Nature/nurture redux
}

\author{
Timothy D. Johnston \\ Department of Psychology, University of North Carolina at Greensboro, \\ Greensboro, N. C. 27412-5001
}

\begin{abstract}
Despite several decades of criticism, dichotomous thinking about behavioral development (the view that the behavioral phenotype can be partitioned into inherited and acquired components) remains widespread and influential. This is particularly true in study of birdsong development, where it has become increasingly common to diagnose songs, elements of songs, or precursors of songs (song templates) as either innate or learned on the basis of isolation-rearing experiments. The theory of sensory templates has encouraged both the dichotomous approach (by providing a role for genetic blueprints to guide song learning) and an emphasis on structural rather than functional aspects of song development. As a result, potentially important lines of investigation have been overlooked and the interpretation of existing data is often flawed. Evidence for a genetic origin of behavioral differences is frequently interpreted as evidence for the genetic determination of behavioral characters. The technique of isolation rearing remains the methodology of choice for many investigators, despite the fact that it offers only a rather crude analysis of the contribution of experience to song development and provides no information at all about genetic contributions to development. The latter could in principle be elucidated by the application of developmental-genetic techniques, but it is unlikely that these can easily be applied to the study of birdsong. Because developmental questions are so often posed in terms of the learned-innate dichotomy, "experience" istaken to be synonymous with "learning" and the possible role of nonobvious contributions to song development has largely been ignored. An alternative approach, based on Daniel Lehrman's interactionist theory of development, permits a more thorough appreciation of the problems that have yet to be addressed, and provides a more secure conceptual foundation for theories of song development.
\end{abstract}

Keywords: behavior genetics; birdsong; development; early experience; innateness; interactionism; isolation rearing; learning; nature/nurture; sensory template; song learning

\section{Introduction}

In the introduction to a recent review of the birdsong literature, Konishi (1985) wrote:

The study of birdsong has made significant contributions to the development of modern ethology. Concepts such as species-specificity in animal signals, innate predispositions in learning, and sensory templates for motor development were put forth first in birdsong research. ... Also, it was the study of song development that elevated the much debated issue of instinct versus learning from the realm of semantic discourse and confusion to an experimentally tractable subject. (p. 125)

No one who is familar with the research literature on Birdsong could argue with the first part of this quotation. The study of song has been an important focus of research on animal behavior for many years — it is a fascinating and theoretically productive field that has produced some important insights, not only for ethologists, but also for workers in many other areas of the behavioral sciences. The second part of Konishi's statement, however, is more questionable. Research on song development has certainly produced a wealth of data on such problems as specificity of song learning, sensitive periods, social versus sensory influences, species differences in learning mechanisms, and the neural bases of learning. But despite the many important contributions that it has made, much of this work is marred by an unfortunate adherence to a theoretical viewpoint that is widely regarded as inadequate to the analysis of behavioral development. As a result, theories of song development rest on shaky conceptual foundations and the interpretation of many experimental data remains theoretically suspect. The study of song development is still deeply influenced by both explicit and implicit allegiance to an outmoded view of behavioral development that seeks to attribute elements of behavior separately to one of two sources: genetic information and environmental information. It is, of course, commonly supposed that such dichotomous thinking has been eradicated from the study of development, and that the frequent use of phrases such as innate behavior, genetic determination, and hard-wired behavior patterns is to be understood only as a linguistic convenience. I have argued elsewhere (Johnston 1987) that this is not at all true. The assimilation of interactionist 
template (Kroodsma 1984; Marler \& Pickert 1984; Marler \& Sherman 1983; 1985). Most of this recent research has posed the same question as the earlier work of Marler and Konishi: How much of this structure is innate and how much is learned? My argument here is that posing that question has resulted in serious conceptual inadequacies in the literature on song development. Before discussing the problems inherent in such an approach and offering some suggestions for a more productive alternative, let me show that the issue of innate-versus-acquired aspects of song structure is, and always has been, a central topic in research on song development.

\section{Distinguishing innate and acquired components of song and the song template}

The idea that song development can be understood by distinguishing innate from acquired songs (or elements of songs) is surprisingly widespread in the literature and has been for the past 20 or more years. Most often, conclusions about innateness are reached on the basis of experiments involving isolation rearing (the deprivation experiment urged by Lorenz 1965; see further below), but cross-fostering (rearing of young by adults of another species) and tutoring with nonconspecific songs have also been widely used techniques. From these experiments, four general groups of conclusions have been reached about the innate and learned contributions to song development.

1. Song as a whole is either Innate or learned. When isolation rearing and cross-fostering failed to change the vocal behavior of doves (Streptopelia spp.), Lade and Thorpe (1964) concluded that "the songs of doves must be considered to be genetically encoded in some way" ( $p$. 366). Thorpe (1964) considered isolation rearing to be especially valuable for the study of song development because it permits us to study "the way in which behaviour patterns of great complexity are genetically coded and controlled" (p. 155). Twenty years later, Kroodsma (1984) reared flycatchers in isolation and, finding no differences between the songs of wild and isolated birds, concluded that: "Songs of the alder flycatcher (Empidonax alnorum) and willow flycatcher (Empidonax traillii) are innate" (p. 13; the quoted sentence is the title of Kroodsma's article).

Differences among species in the "degree of innateness" of song have been widely recognized. Marler (1967) compared song development in several species of sparrows, "some of which display the transmission of vocal behavior by tradition [i.e., learning] while others have the apparently more common method of direct genetic transmission" (pp. 231-32). Kroodsma and Pickert (1984b) pointed out that "the songs of some suboscines are innate. ... in sharp contrast to the oscines, where vocal learning is the rule" (p. 395). Finally, Marler and Sherman (1985) compared song development in isolation-reared swamp and song sparrows (Melospiza georgiana and $M$. melodia) and concluded that "genotypic control over gross song structure is less rigid in the swamp sparrow than in the song sparrow" (p. 69).
2. Elements of song are either innate or learned. In his classic defense of the learned-innate dichotomy, Lorenz (1965) proposed that even when whole patterns of behavior (such as song) cannot be diagnosed as either learned or innate, it will always be possible to distinguish learned from innate elements of the behavior. Lorenz's position (the so-called intercalation of learned and innate behavior) is widely represented in the study of song development. Rowley and Chapman (1986) introduce a study of the effects of cross-fostering on several patterns of behavior in cockatoos (Cacatua spp.) by forcefully restating Lorenz's view: "Since behaviour is part innate and part learned it is important to recognize those aspects of behaviour that have been transmitted genetically and those which have been acquired through the individual's experience of life" (p. 1). That recognition, they suggest, can be accomplished by the technique of cross-fostering, which "can help identify whether an element of behaviour is innate or learned" (p. 12). Cross-fostered young "often show certain species-specific behaviour patterns which must be innate as they could not have been learnt from their behaviourally alien foster-parents" (p. 13).

Guttinger (1979; 1981; Guttinger et al. 1978) has studied song development in several finch species and their hybrids and writes that his primary aim is to understand "how a genetically determined program controls speciesspecific behaviour activities which also contains [sic] learnt patterns" (Guttinger 1979, p. 286). Marler (1963), citing Poulson's (1954) study of song development in the linnet (Carduelis cannabina), noted that "pitch and timbre [of the song] seemed to be innate, but the rhythm and melody were not" (p. 237). When Lemon and Scott (1966) reared cardinals (Richmondena cardinalis) in isolation, they found different effects on two syllable types and concluded that "unlike the complex syllables, simple syllables may have some innate basis since they develop in isolated birds" (p. 196; cf. Dittus \& Lemon 1969, p. 530).

The distinction between learned and innate elements has generally been made on the basis of isolation rearing, but similarities in song structure between birds with different (even though unknown) rearing histories may also be attributed to innate influences. Marler and Pickert (1984) described a number of similarities in songs from widely separated populations of the swamp sparrow and on that basis concluded that the species has "an innate repertoire of note types, with a species-specific morphology that is genetically controlled" (p. 686). (Several conceptual errors involved in taking such similarities in behavior to imply genetic determination are discussed in section IV, below.)

3. Birds have innate songs that can be modified by learning. Reports in the older literature sometimes concluded that some birds have an innate song, but that this song can be modified or elaborated by learning. That conclusion was usually based on the finding that isolation-reared birds sing a song that is similar to, but less complex than, the song of wild birds. Thus Thorpe (1964) distinguished the "innate," or "primary," song of buntings (Emberiza spp.) from elaborations of this song produced by imita- 
tion, and Marler (1963) noted that "some of the birds with an inherited song nevertheless modify it by learning in nature" (p. 234). This formulation is less common now than it was, although the song of birds reared in auditory isolation is still sometimes referred to as "innate song" (for example, by Marler \& Sherman 1983).

\section{The template or blueprint for song development may be} innate or learned. Often, learned and innate contributions to song development are discussed in terms of the sensory template or blueprint, rather than the song itself. In the chapter that first introduced the template concept, Marler (1963) wrote: "The two most obvious ways in which such [genetic] control could operate are either by an inherited pattern of motor input to the sound producing organs, or by an inherited auditory 'template' to which the animal would match the sounds produced, as a result of hearing its own voice" (p. 233). The same distinction was also made, in almost identical language, by Marler and Sherman (1983, p. 517). Kroodsma (1985) found that isolated eastern phoebes (Sayornis phoebe) develop the same two song types as do wild birds and concluded from this that the species has an "innate song template" (p. 27). Searcy and Marler (1987) played the song of isolation-reared male song sparrows (Melospiza melodia) to wild males and females and found a stronger response than to the song of deafened birds. They interpreted these results as "further evidence for innate auditory templates" (p. 509) that must involve "genetically programmed specifications" for song (p. 517). Shiovitz (1975), discussing the role of learning in song recognition by the indigo bunting (Passerina cyanea), noted that birds must learn species-specific song and suggested that "learning can be restricted to conspecific figures [i.e., syllables] if an innate species-specific cue ... is present" in the song (p. 169). Dooling and Searcy (1980) measured the cardiac response of young swamp sparrows to conspecific and heterospecific song and interpreted their results as evidence "for innate perceptual biases as a basis for selective learning" ( $p$. 505). Indeed, almost every mention of selective vocal learning assumes some kind of "innate perceptual bias," so closely have the two ideas become linked.

Some authors have discussed differences among species in the degree of genetic specification of song by the song template. Konishi (1978b) pointed out that "the extent to which the innate template can guide normal song development varies from species to species" (pp. 297-98). In their study of song development in the marsh wren (Cistothorus palustris), Kroodsma and Pickert (1984b) remark that selectivity in song learning is made possible by the innate song template, but they point out that in species with large repertoires (like the wren) "genetic encoding of all the information necessary to restrict learning to conspecific song models would become increasingly difficult" (p. 395).

Clearly, the attempt to recognize innate elements of song, or to distinguish between innate and learned contributions to song development, is a prominent component of current research in the area. The preceding examples, taken from publications spanning almost 25 years and written by many different authors working on a wide range of species, show that the learned-innate distinction is not just characteristic of a few individuals working on the fringes of the area, but pervades the thinking of some of the most productive and influential researchers on song development.

\section{Ill. Sources of information in behavioral development: The learned-innate controversy}

In the review paper cited earlier, Konishi (1985) remarked that "it was the study of song development that elevated the much debated issue of instinct versus learning from the realm of semantic discourse and confusion to an experimentally tractable subject" (p. 125). And yet it was precisely the distinction between innate and acquired components of behavior that provided the source of the confusion to which Konishi refers and that, as we have just seen, still characterizes much of the research in song development. How much "elevation," then, has actually been achieved by the study of song development? The answer to that question must be "very little," and the unfortunate consequence is that serious conceptual inadequancies about behavioral development continue to be propagated by the very discipline that is perhaps best equipped to dispel them.

Although debate over the issue of learned and inherited contributions to behavior has a very long history (see Oppenheim 1982), the debate between Konrad Lorenz and Daniel Lehrman during the period from 1953 to 1970 served to bring the issues involved into sharp focus for behavioral biologists. That debate involved a number of points of disagreement, the most important of which was how one should understand the problem of analyzing the development of behavior. In articulating his influential theory of instinct during the 1930s and 1940s, Lorenz $(1935 ; 1937)$ had argued that behavior could be divided into the two categories of learned and innate. Learned behavior, according to Lorenz, depends on the animal's experience, and its development can be attributed to the environment of rearing; innate behavior depends on the animal's genetic inheritance and can be attributed to the activity of its genes. For Lorenz, the two categories are both exclusive and exhaustive: $A l l$ behavior can be unambiguously assigned to one or the other category, provided that the correct descriptive units are used. In order to determine whether a particular unit of behavior is learned or innate, Lorenz proposed to use the technique of deprivation rearing. If an animal is reared from birth or hatching without the opportunity to learn the behavior in question, and still the behavior develops normally, then it is innate. If the behavior does not develop normally, then it is learned.

In his well-known critique of Lorenz's theory of instinct, Lehrman (1953) argued that the learned-innate dichotomy was entirely inadequate to the task of analyzing the development of behavior. He pointed out that attributing behavior to the genes simple avoids the problem of explaining its development, since the genes clearly do not contain the behavior itself. Furthermore, he argued, the deprivation experiment does not eliminate 
appropriate and inappropriate interpretations of data on the origin of differences in behavior.

Does all of this mean that differences in behavior are of no interest or relevance to the study of behavioral development? Clearly, that cannot be the case. The demonstration of differences between experimental and control groups is the foundation on which the analysis of behavioral development must rest. The problem is that comparing the songs of, say, swamp and song sparrows reared under identical conditions (Marler \& Sherman 1983; 1985) cannot reveal any of the detail that we need in order to understand how genes contribute to development. The conclusions that can be drawn from such an experiment are precisely parallel to those that could be drawn from a hypothetical experiment that described behavioral differences between genetically similar animals reared in different environments, in the absence of any information about what environmental differences were involved. We would know that the environment affected the development of the behavior under study (although we could hardly have been in any doubt about that to begin with) but would be at a complete loss as to how the environment produced the observed effect. Only by specifying the environmental factors that differentiated the groups, the times during development when those differences were in effect, and all the other things that go into specifying the independent variables in a selective rearing experiment could we hope to make any developmental sense out of the results.

The same requirements apply to studies of the genetic contribution to behavioral development. Unless we can specify what genetic differences obtain between two groups of animals, we cannot possibly give a developmental interpretation to any behavioral differences that we find. In the case of different species, the genetic differences that exist are likely to be so large (or, at any rate, so unspecifiable) as to prevent even a small degree of precision in explicating the genetic contributions to development. The use of species differences in the study of behavioral epigenetics (Marler \& Sherman 1985) limits our conclusions to the unhelpful platitude that "genes affect behavior." Only by systematic and precise manipulation of genetic structure and activity, for example by the careful use of single-gene mutants and genetic chimeras (Stent 1981), can any useful substance be added. Techniques such as these, of course, belong in the province of geneticists and developmental biologists, not of ethologists and other students of animal behavior. That is not to say that ethologists cannot apply those techniques to the study of behavioral development, but, when they do, their activities will look much more like developmental genetics than ethology. However, until very much more is known about the genetics of songbird species, and mutations affecting song development are identified and isolated on constant genetic backgrounds, the application of those techniques to elucidating the genetic contribution to song development will be impossible.

\section{Basis for an interactionist approach to the study of song development}

If the innate-learned dichotomy is not an acceptable basis for the analysis of behavioral development, what then? The alternative approach is to follow the lead of Lehrman (1953; 1970) and others (Bateson 1987; Gottlieb 1976 1983; Kuo 1922; 1924; Lerner 1978; Oyama 1982; 1985; Schneirla 1966; see Johnston 1987) and consider all behavior to arise in development from interactions within and between the organism and its environment. How would such a view influence the experimental analysis of song development, and what new insights might it provide? This section briefly describes the interactionist approach to development, with special reference to the development of birdsong. Later sections of the paper consider more specifically how the interactionist approach both alters our interpretation of current experimental results and suggests new experiments.

Two misinterpretations of interactionist writings have contributed to the rather limited impact of these ideas, despite the lip service that is often paid to the insights that they provide. First, although Lehrman (1953), in perhaps the most influential statement of the interactionist position, said clearly that development involves an interaction between the organism and its environment, the interaction in question is often taken to be between the organism's genes and its environment (e.g., Fox 1970). Because the environment of the genes and the environment of the organism are quite different, the meaning of the term interaction in this formulation is elusive. It is not clear what kind of behavioral research follows from accepting the interpretation that development involves a "gene-environment interaction," beyond a recognition of the obvious and entirely uncontroversial point that genes and environment both contribute to the development of behavior.

The second misinterpretation follows directly from the first: If development is (erroneously) interpreted as a gene-environment interaction, then a research methodology (Lehrman's selective rearing experiment) that does not directly examine genetic contributions to development will inevitably be seen as reflecting an extreme environmentalist bias in which the genes are denied any role in development. Thus those who think, correctly, that something must be said about genetic contributions to development are drawn to the old dichotomous position, which seems to provide more scope for talking about genetic involvement in development. Unfortunately, the conceptual inadequacies inherent in the old view inevitably result in the attribution of some aspects of the phenotype (either behavior itself or some precursor of behavior, such as a template) directly to the genes. A better approach might be to attempt a rearticulation of the interactionist view to accommodate the need to acknowledge the genetic contribution to development more explicitly. Such an acknowledgment is in fact made explicitly by proponents of the interactionist view, such as Lehrman (1953; 1970), Schneirla (1966), Gottlieb (1976), Bateson (1987), and others, and has recently been discussed at length by Oyama (1985). It is sufficiently un- 
familiar, however, that a further restatement may be worthwhile.

It is helpful at this point to recall Lehrman's original formulation of the interactionist view of development: "The problem of development is the problem of the development of new structures and activity patterns from the resolution of the interaction of existing structures and patterns, within the organism and its internal environment, and between the organism and its external environment" (Lehrman 1953, p. 345; emphasis added). The elements that participate in these interactions make up a "developmental ecosystem" (Johnston 1982) or "developmental niche" (Werner \& Gilliam 1984; West \& King 1987) within which species-typical behavior develops; they include gene products, hormones, patterns of neural activity, nutrients, anatomical structures (both neural and nonneural), physical variables (such as temperature, salinity, $\mathrm{pH}$, and gravity), self-produced stimulation, sensory experience, social interactions, and a host of other potential contributors to the development of the organism. Some of these elements (such as anatomical structures) depend on previous developmental interactions for their characteristics and all the elements may undergo extensive changes throughout the course of development. The interactionist view is that no aspect of the phenotype can be attributed to one of these elements - all aspects of the phenotype depend on interactions among many of them, and the purpose of a developmental analysis is to determine which elements interact in what ways to give rise to particular aspects of the phenotype. Typically, this is done by selectively manipulating one or a few elements and observing the effects of these manipulations on development. Elements in the external postnatal environment are the most accessible, and Lehrman's original argument was largely based on analyzing the contribution of environmental factors to behavioral development. Even 35 years later, the external postnatal environment continues to receive the greatest amount of attention, but the roles of prenatal factors (DeCasper \& Fifer 1980; DeCasper \& Spence 1986; Gottlieb 1971; 1981; Vince 1979), self-stimulation (Gottlieb 1981; Wallman 1979), diet (Castro \& Rudy 1987; Ottinger \& Tanabae 1969), and hormones (Whitsett \& Vandenbergh 1978) have also been investigated.

Genetic manipulations are particularly difficult to achieve with any degree of precision - it is not possible, for example, to prevent a specific gene from being transcribed during a specific period of development in a specific organ or tissue. The external environment can, of course, be manipulated in that way and a very large experimental literature (including that on song development) testifies to the important effects of environmental influences on behavioral development. However, the interactionist approach lends itself just as readily to accounting for genetic contributions to development as it does to accounting for environmental ones. In some species, such as mice, crickets, and fruit flies, wide ranges of single-gene mutations have been described, many of them with potent effects on the behavioral phenotype (e.g., Bentley 1975; Konopka 1979; Quinn \& Greenspan 1984; Rothenbuhler 1967; Sidman et al. 1965). These mutations, especially when combined with techniques for forming genetic mosaics, provide one means of investigating genetic influences on development, as reviewed by Stent (1981). Unfortunately, the finding that a singlegene mutation affects some behavior may be presented as evidence that the behavior in question is genetically specified, or developmentally controlled by the genes. As Stent suggests, single-gene mutations should be seen as tools that may be used to uncover the ways in which genes influence behavior in the course of development, not as evidence for "genetic control."

The interactionist approach thus accommodates the role of genetic influences as well as that of experience. The manipulations it proposes (such as Lehrman's selective rearing experiment, or the technically very demanding experiments on gene action described by Stent) involve altering one or more putative influences on development, whether environmental or genetic, and determining the behavioral effects of those manipulations. What it resists is any attempt to attribute any aspects of the behavioral phenotype directly to particular influences, such as environmental information, genetic programs, and the like. The concern of ethologists with specifying the genetic contributions to development is entirely appropriate, but the interactionist approach accommodates such contributions just as it does those of experience. In the case of birdsong, the problem at present is more a practical than a conceptual one: We simply do not have the means to manipulate genetic activity in song birds with the degree of precision needed to say anything very useful about genetic contributions to song development. Until it becomes possible to induce single-gene mutations that affect song development and begin to trace the action of the genes involved, our knowledge of genetic contributions to song development must remain virtually nil. Of course we must bear the genetic contribution in mind, but we can do that and still reject claims that the genes must be found to specify some aspects of the phenotype, such as a blueprint for song learning or some aspects of the structure of a song template. As was pointed out long ago (Kuo 1922; Lehrman 1953), such claims merely obscure the developmental work that is being left undone, and they do so in two ways: They deflect attention from the possibility that forms of experience other than learning contribute to song development (see section VI, below); and they make it unlikely that the tools of.genetic analysis will ever be applied to the task of elucidating genetic contributions to song development because of the mistaken assumption that this contribution can be revealed by the relatively simple technique of isolation rearing.

Given that technical limitations currently preclude the kinds of experimental manipulations that would permit the direct investigation of genetic contributions to song development, what specific contributions might the interactionist approach make to research in this area? Much current research on song development is limited in the two respects discussed at the beginning of this paper. First, by subscribing to a dichotomous view of development, researchers have ignored the potential contribution of experiential influences that are not obvious sources of information for song development. Second, by focusing largely on the structural aspects of song, they 
may overlook important functional components of song development. Once these two limitations are recognized, some largely unexplored lines of experimental investigation become apparent that might provide important insights into the development of song. The next two sections sketch out these research directions.

\section{Nonobvious experiential contributions to song development: Beyond song learning}

Because most studies of song development have adopted a dichotomous approach, they have sought experiential contributions to development that appear, prima facie, to be "informative" to the nestling, following Lorenz's (1965) distinction between genetic and environmental .sources of information" for development (Johnston 1987). The most obvious such contribution is hearing the song itself, and so the role of imitation, or modeling, of song has been a primary focus of research. The interactionist approach rejects Lorenz's sources-of-information metaphor (Johnston 1987) and takes a different view of experiential contributions to song development. In particular, it emphasizes the role of nonobvious factors in development.

One of Lehrman's (1953) original criticisms of the learned-innate dichotomy was that it grants experiential status only to the most obvious kinds of experience: observation, imitation, trial-and-error learning, and so forth. Lehrman pointed out that this approach leaves unanalyzed a wide range of possible effects of experience that do not bear such an obvious relationship to the behavior under study, a point also made earlier by Kuo (1922). An example of such nonobvious experiential contributions to behavioral development is provided by Gottlieb's (1981) studies of the perceptual specificity of ducklings' responses to the maternal call of their species. In two species (the mallard, Anas platyrhynchos, and the wood duck, Aix sponsa) Gottlieb has shown that auditory experience with the calls of embryos or hatchlings is necessary for the usual specificity of response to the maternal call to develop (Gottlieb 1980a; 1980b; 1984). Another example comes from Wallman's (1979) study of the development of young chicks' response to mealworms. Chicks with normal visual experience readily peck at and eat mealworms, but chicks that have been denied the opportunity to see their own toes (which had been either covered or painted) for the first 2 days after hatching do not.

Clearly, there are a number of nonobvious sources of experience available to developing songbirds, but their possible role in song development has largely been overlooked, with one exception, namely, the effects of social context on the process of song learning. Quite early in the study of song development, Immelmann (1969) showed that zebra finch (Taeniopygia guttata) nestlings will learn songs sung by a heterospecific foster father in preference to tape-recorded conspecific songs, suggesting that social bonds might play an important role in song learning in that species. Similar results have more recently been obtained by Baptista and Petrinovich (1984; 1986; Petrinovich \& Baptista 1987), who found that whitecrowned sparrows, previously thought to be capable of learning only conspecific song (Marler 1970a), can also learn heterospecific song if it is sung by a live song tutor. Live tutoring also seems to extend the sensitive period for song learning (Petrinovich \& Baptista 1987), and these results suggest an interesting developmental interaction between song learning and the social context in which that learning occurs (see Payne 1981; Pepperberg 1985). Another example of the importance of social factors in song development comes from the studies of West and King (1985a; West et al. 1981a) on the cowbird (Molothrus ater), a nest parasite. In that species, the imitation of song models does not appear to play an important role in the development of song. Instead, social interactions among males are necessary for the normal development of species-typical song structure and function (West \& King 1980; West et al. 1979), and interactions between males and females underlie the development of population-typical song dialects (King \& West 1983; 1987; King et al. 1980).

All these studies indicate the potential importance of experience other than hearing song itself for the normal development of song, and they suggest that it may be worthwhile to consider other nonobvious contributions to song development as well. Such contributions might include the following:

i. Self-produced calls both prenatally and postnatally

ii. Calls of siblings both prenatally and postnatally

iii. Calls (not song) of parents and other conspecifics

iv. Nonvocal social stimulation from siblings

v. Nonvocal social stimulation from parents

vi. Conspecific song heard prenatally or in early postnatal life

In some birds and mammals, prenatal and early postnatal auditory experience is known to play an important role in the development of behavior (DeCasper \& Spence 1986; Gottlieb 1971; Vince 1979). The auditory system of songbirds may be less well developed at hatching than is that of precocial birds, but Khayutin (1985) has shown a remarkably specific auditory sensitivity to conspecific calls in nestlings of several altricial species (the pied flycatcher, Ficedula hypoleuca; the great tit, Pam major; and the redstart, Phoenicurus phoenicurus) at least as young as 2 days old, using auditory evoked potentials to calls and other stimuli. Some of Kayutin's data suggest that auditory sensitivity to calls may be present prenatally, even in these altricial species (Khayutin 1985, p. 126).

Although song learning (in the sense of imitation of song themes or syllables) is unlikely to occur so early in life, such very early auditory sensitivity may well make a less obvious contribution to song development. The selectivity of song learning discussed earlier in connection with the notion of a blueprint for learning might have its origins in very early experience (including prenatal experience) with conspecific calls, either those of parents or of self and siblings. Several studies have reported considerable vocal activity in young nestlings of many species (e. g. , Howes-Jones 1984; Muller \& Smith 1978; Thompson \& Rice 1970; Wilkinson 1980), suggesting the relatively rich environment of species-typical sounds experienced from very early in life. Such calls are not prima facie "informative," in the sense used by Lorenz (1965) and criticized elsewhere (Johnston 1987), but they are 
part of the developmental niche (Johnston 1982; West \& King 1987) of the young bird and their contribution to song development cannot be excluded a priori. In particular, they may provide experience that is sufficiently species-specific to attune the young bird to some acoustic features of conspecific song and thus provide the basis for selective vocal learning later in life.

In some early discussions of the song template (e.g., Mader 1970a; Nottebohm 1968) it was pointed out that the developmental origins of this hypothetical structure were unknown, and the suggestion was made that very early auditory experience might play a role in its development. The importance of early experience (other than song) has been emphasized only very occasionally in the more recent literature (for example, by Lanyon 1979), however, and the tendency to consider as innate any abilities that do not depend on song learning has become widespread, as documented in an earlier section. When subjects in song-learning experiments are taken from the wild as 5- to 10-day-old nestlings, as is common, the role of early auditory experience in their development cannot be ruled out. When birds are hand-reared from the egg, greater control over their early experience is obtained, but systematic comparison of results from hand-reared and wild-reared birds is made virtually impossible by the very wide variation both in the species studied and in other aspects of experimental methodology (see Kroodsma, 1977, for a discussion of similar concerns). From the interactionist perspective, the role of early auditory experience other than song in song development remains unspecified.

The role in song development of nonvocal social interactions, either between nestlings and parents or among siblings, also merits consideration. Work on the cowbird discussed above (West et al. 1981a) has shown that, in this species, social interactions other than hearing song play the most important role in song development. Even where imitation of song plays a preeminent role, as in the white-crowned sparrow and the zebra finch, social factors may also be important (Baptista \& Petrinovich 1984; 1986; Immelmann 1969). Studies of zebra and Bengalese finches have revealed that species differences in interactions within broods are important to the normal development of sexual preferences (Kruijt et al. 1983; ten Cate 1982; 1984; 1985). If species-typical social interactions are part of the developmental niche within which normal song development occurs, they may provide part of the experience on which that development normally depends, a point also raised in passing by Konishi (1964).

\section{Functional outcomes of song development}

Because the concept of the song template is so thoroughly imbued with structural associations, its importance in the study of birdsong has encouraged an emphasis on the structural aspects of song development. According to the template theory, a young bird starting to sing matches the structure of its song against the structure specified by the template and adjusts its output accordingly (section IIA, above). During the earlier (nestling) stage of song development, the template may act as a blueprint for learning, permitting the identification of conspecific songs on the basis of their structural features. This structural emphasis is reflected in the approach generally used to assess the effects of interfering with song development, which is to examine sound spectrograms of experimental song and compare them (either visually or statistically) with spectrograms of the song of wild-reared or control birds. In most cases, this is done without reference to two important questions: (1) What are the functionally significant aspects of song structure in the species under study? and (2) How has experimental rearing affected the efficacy of song as a signal for social communication?

Functional issues in the study of birdsong have, of course, long been a focus of research interest. The description of learned song dialects in many species (Baker \& Cunningham 1985) has raised questions about the evolutionary consequences of song learning, but those questions have not directly addressed the developmental origins of song function in the individual. It has been known for years that different structural features of song carry information about species (Becker 1982) and individual (Beer 1970) identity; the song features that carry different kinds of information vary widely among species. Playback studies have shown that although some features of the song can be manipulated without interfering with its signal function, others must be left intact if the song is to remain effective as a territorial display, courtship signal, or signal for individual recognition. For example, Emlen (1972) found that altering the syntactic arrangement of notes in the song of the indigo bunting (Passerina cynaea) did not reduce its effectiveness in species recognition, but that altering the intervals between notes or changing the acoustic structure of individual notes in the song did interfere with its communicative function. In other species, different features of the song are important for the communication of species distinctiveness (see Becker 1982, for a review).

It is apparent from functional analyses of birdsong that abnormalities in certain structural features of a song may have more important functional consequences than abnormalities in others. An important set of developmental questions that has been largely overlooked by the structural emphasis encouraged by the template theory concerns how various kinds of rearing experience contribute to the functional development of song in different species. A number of such questions might be posed, including the following.

\section{Are the structurally normal songs of tutored, laborato- ry-reared birds also functionally normal? Many studies} have shown that when young birds are exposed to tape recordings of their species-typical song, they develop songs as adults that are structurally similar (as assessed by spectrographic comparisons) to the songs of wild-reared birds. In fact, tape-tutored birds are generally used as a control group in studies of song development. West's results show that important functional differences exist between the structurally very similar songs of socially reared and isolation-reared cowbirds, suggesting that the same may be true in other species as well. In that context, it may be worth recalling that tape tutoring and social tutoring (which is closer to the normal situation in which song develops) affect song learning in the white-crowned 
sparrow in very different ways (Baptista $\&$ Petrinovich 1984; 1986; Petrinovich \& Baptista 1987). Socially tutored birds can learn heterospecific songs that tape-tutored birds cannot; they can also learn songs outside the sensitive period for song learning shown by tape-tutored birds (Baptista \& Petrinovich 1984; Marler 1970a). Since social tutoring is apparently a more potent form of song experience than tape tutoring, might it also produce a functionally more effective song? If so, we would be forced to conclude that the presence of a social tutor makes some nonobvious functional contribution to song development that should be investigated.

2. To what extent does isolation rearing result in the development of song that is nonfunctional? The isolate song of many species is structurally very impoverished, lacking most of the species-typical organization of notes, syllables, and song themes. It might be thought that such disorganized song would be completely nonfunctional, and playback of isolate song from a very small number of individuals in one or two species (Shiovitz 1975; Lanyon 1979) has tended to confirm that impression. However, Searcy et al. (1985) found that territorial male swamp and song sparrows both responded more to the isolate song of conspecifics than to the normal song of heterospecifics, suggesting that at least some functional specificity develops despite isolation rearing. Nonetheless, both species also responded more to normal than to isolate songs of their own species, indicating the importance of song experience to the development of functionally normal song. The results of this study are especially interesting because they confirm that song-sparrow song does not develop normally in isolation, as previously thought (Mulligan 1966). Kroodsma (1977) showed that the song of isolation-reared song sparrows differs structurally from normal song, and the data of Searcy et al. (1985) provide a functional confirmation of Kroodsma's analysis. Somewhat different results were obtained in another species by Spitler-Nabors and Baker (1987), who found that female white-crowned sparrows do not distinguish between the isolate song of their own and another species. The difference between the two species may indicate different functional effects of isolation rearing in Melospiza and in Zonotrichia, or it may be due to the different response measures used in the two experiments (territorial response in the case of Melospiza, courtship displays in the case of Zonotrichia; but see Searcy \& Marler 1987).

An interesting counterpoint to these studies of isolate song in sparrows is provided by West and King's (1980; 1985a) studies of song development in the cowbird (see also section VI, above). Cowbirds are nest parasites whose song development was long thought to be quite independent of early song experience (Mayr 1974; Lehrman 1974), as might be expected in a species whose young do not have the opportunity to hear conspecific song during early life. The song of the male cowbird (females do not sing) functions primarily as a courtship signal and its functional analysis has been greatly facilitated by the fact that females respond to the song by adopting a stereotyped copulatory posture (West et al. 1979). The response provides a bioassay for the potency of male song - the more potent (i.e. , functionally effective) the song, the greater the proportion of females that will respond with the copulatory posture. Females respond as readily to song playback as to the presence of a live male, permitting functional assessment of the song alone, uncontaminated by other aspects of the courting male's behavior. If male cowbirds are reared in social isolation, their courtship song is more potent than the songs of socially reared or wild-caught males (King \& West 1977; West et al. 1979; West \& King 1980). Acoustic analyses of normal and isolate song, coupled with playbacks of song recordings that had been altered in various ways, revealed that the critical difference between the normal and isolate songs was in the relative amplitude of the interphrase unit (IPU), a brief burst of sound that occurs near the middle of the song (West et al. 1979). In isolate males, the amplitude of the IPU is large in relation to the introductory phrase, and it is this increased relative amplitude that is responsible for the greater potency of isolate song.

Apart from the studies just discussed, little attention has been paid to the functional consequences of isolation rearing for song development. The widespread tendency in the Birdsong literature to categorize songs or song elements as either learned or innate has strongly encouraged the interpretation that a seriously disordered song indicates the adaptive necessity of song learning, without which (it is presumed) functional song will not develop. To the extent that isolate song is functionally effective (Searcy et al. 1985; Searcy \& Marler 1987) or structurally normal (Kroodsma 1984; Marler \& Sherman 1985), this is often said to indicate the existence of "genetically specified song structure. " Both the developmental origins of song structure in isolated birds and the degree to which that structure is functionally effective need to be addressed more carefully in the study of song development.

It should be noted that isolation rearing is only one experi nental technique that might be used to investigate the functional aspects of song development and, like other versions of the deprivation experiment, it is seriously limited in the information it can provide. Because the conceptual orientation in the study of song development has involved attempts to partition the song into learned and innate elements (following the logic of Lorenz's deprivation rearing), there has been little or no motivation to devise other rearing techniques that would give more precise information about the contributions of experience to song development. Although functional analyses of the effects of isolation rearing would be welcome, the interactionist view suggests a different and more selective analysis, such as might be provided by the following question.

\section{Does exposure to functionally significant features of song play an especially critical role in song develop-} ment? Gottlieb's (1981) studies of auditory perceptual development in ducklings were mentioned earlier in connection with possible nonobvious contributions of experience to song development. In those studies, normal perceptual development has been shown to be especially dependent on exposure to the critical acoustic features that underlie species-typical perceptual sensitivity in later life. In mallard ducklings (Anas platyrhynchos), the normal preference for the maternal call depends mainly on the repetition rate of notes in the 
call - calls pulsed at the normal rate of 4 notes/sec are preferred over either slowed (2 notes/sec) or quickened (6 notes/sec) calls. The development of this preference depends on prenatal exposure to the embryonic call, which, to be effective, must also be pulsed at its normal rate of about 4 notes/sec - exposure to either faster or slower rates has no effect on perceptual development (Gottlieb 1980a). In the wood duck (A ix sponsa) similar findings have been reported. In this species, frequency modulation (FM) of the notes in the call is the critical acoustic feature for species recognition and hatchlings must be exposed to sibling calls that have the appropriate FM. Stimulation with artificially altered FMs is not effective (Gottlieb 1980b).

Although Gottlieb's experiments concern the development of perceptual specificity, and most work on birdsong has concerned song production, his findings raise the intriguing possibility that normal song development might be especially dependent on exposure to the functionally significant features of song for that species. As discussed earlier (section IIB), several studies have shown that, in some species, conspecific song is more readily learned than heterospecific song. Indeed, selective learning of song was one of the primary contributions to the development of template theory in birdsong research (Marler 1976). However, little attention has been paid to the acoustic features of conspecific song that make it more easy to learn than heterospecific song. A functional perspective on song development provides grounds for suggesting that nestlings may be especially sensitive to the functionally important acoustic features of song and will only, or preferentially, learn songs that include those features. Studies of song learning in two species of sparrow support that suggestion.

The songs of adult song and swamp sparrows differ in both the structure of notes and syllables and the temporal organization of syllables into phrases and songs. By playing back normal and altered recordings of song to territorial male swamp and song sparrows, Peters et al. (1980) showed that syllable morphology, but not temporal organization, is important for species recognition in the swamp sparrow; both syllable morphology and temporal organization are important in the song sparrow. According to the hypothesis outlined above, selective vocal learning in the swamp sparrow should depend on syllable morphology and not on temporal organization, whereas learning in the song sparrow should depend on both these acoustic features. Studies of both species confirm that prediction. Using artificially constructed tape recordings, Marler and Peters (1977) found that young male swamp sparrows will learn song consisting of conspecific (swampsparrow) syllables, even if they are organized into patterns characteristic of heterospecific (song-sparrow) song. They will not learn song-sparrow syllables, regardless of their temporal organization. Song sparrows also preferentially learn song consisting of conspecific (song-sparrow) syllables, but they will learn heterospecific (swamp-sparrow) syllables if they are organized into temporal patterns characteristic of conspecific song (Marler \& Peters 1988). The interaction between syllable morphology and temporal organization for song learning in the song sparrow is complex. For example, repetition of a heterospecific syllable (in the "trill" phrase of a two-part song) seems to increase the likelihood that the syllable will be learned, but not if the song consists solely of repetitions of the syllable in the absence of other song phrases (Marler \& Peters 1988). The overall impression gained from the studies of these two species confirms the hypothesis that acoustic features of song that are functionally important during adulthood also play an important role during early learning of song. The hypothesis could be further tested with other species in which functionally important song features have been identified (Becker 1982; Peters et al. 1980).

An interesting correspondence between functionally significant song features and preferential song learning has been demonstrated in the Carolina wren (Thryothorus ludovicianus) by Morton et al. (1986). As is the case in other avian species (Morton 1975), the structure of Carolina wren song is well adapted for transmission through the habitat in which the species lives. Indeed, wren populations sing songs that seem to be specifically adapted to the transmission requirements of local environments (Gish \& Morton 1981). Morton et al. (1986) found that young wrens will learn to sing undegraded conspecific songs in preference to the same songs that have been artificially degraded to simulate the effects of transmission through vegetation. Their study suggests that preferential song learning in the Carolina wren depends on precisely those features of the song that permit it to function as a long-distance acoustic signal.

\section{Conclusion}

The study of birdsong development has been, and will remain, an important and influential research focus in behavioral biology. However, as long as so many of its practitioners continue to embrace the untenable view that elements of behavior can be attributed separately to genetic and environmental sources of information, its influence will not be a progressive one. By continuing the search for learned and innate elements or precursors of song, many students of song development are keeping alive an invidious distinction that should have been laid to rest decades ago. In fact, it is repeated with monotonous regularity in textbooks and review articles that the learned-innate distinction is a relic of the past and that there is no longer any need to point out its inadequacies and misleading implications. Unhappily, that is not so, for the distinction continues to motivate and inform this large and influential body of research literature (and see Johnston 1987). As a result, not only is the dichotomous view of development perpetuated, but potentially important avenues of research on song development are obscured (sections VI and VII, above). Contrary to Konishi's (1985) claim, the study of song development has not made the issue of learned versus innate behavior into "an experimentally tractable subject" - it has only served to perpetuate the confusion to which that distinction gives rise.

\section{ACKNOWLEDGMENTS}

Preparation of this paper was supported in part by funds from the Research Council of the University of North Carolina at Greensboro. I thank Cheryl Logan, Peter Marler, David Miller, and Susan Oyama for instructive comments and suggestions on various drafts of the manuscript. Discussions with Gilbert Gott- 
lieb have greatly increased my appreciation of many of the theoretical issues discussed in this article.

\section{NOTE}

1. It is entirely possible that some of the "innate differences" described in Experiment I and some of the "acquired differences" described in Experiment II would be exactly the same. Changes in environment can sometimes have the same phenotypic effects as certain changes in genotype, a finding that has given rise to the concepts of phenocopy in genetics and ecophenotype in ecology and evolution. Phenocopies and ecophenotypes are often construed as environmental copies or imitations of phenotypes that are normally genetically determined, another illustration of the tendency to categorize phenotypes as being either genetically or environmentally determined (Oyama 1981).

\section{Open Peer Commentary}

Commentaries submitted by the qualified professional readership of this journal will be considered for publication in a later issue as Continuing Commentary on this article. Integrative overviews and syntheses are especially encouraged.

\section{Singing down a blind alley}

\section{John Alcock \\ Department of Zoology, Arizona State University, Tempe, Ariz. 85287}

Timothy Johnston advances two major claims in his attempt to breathe new life into the old Lorenz-Lehrman argument. The first is that many students of birdsong are still confused about the interdependence of genes and environment in behavioral development. The second is that the failure to adopt Lehrman's "interactionist theory of development" has had serious and damaging consequences for the study of birdsong. I am not persuaded on either count.

At the heart of Johnston's argument is a deep antipathy toward such words as "innate" and -instinct." He apparently feels that researchers who use these words believe that behavior can be "genetically determined" in the sense of developing without any environmental input. There is no doubt that some birdsong researchers really do use the I-words, but are they so naive as not to realize the interactive nature of development? I think not.

Konishi's (1985) review, which Johnston cites at the outset as a key example of a paper based on dichotomous thinking, contains an explicit discussion (p. 135) of what "innate" means to birdsong researchers. An innate song or an innate song template is a distinctive song or specific neural substrate for song production that reliably develops in the absence of certain acoustical experiential inputs, namely, exposure to conspecific song and (for some researchers) exposure to auditory feedback from selfproduced songs. There is no debate that in some species these acoustical experiences have large effects on adult song, but in others they have little or no effect. The results of isolation experiments are to some degree dichotomous. Either listening to conspecific song has a developmental effect or it does not. To label one category learned and the other innate acknowledges the reality of these results and in no way implies acceptance of the proposition that innate behavior is "genetically determined" whereas learned behavior is not.
Furthermore, the general use of "innate" as a synonym for "developmentally resilient" or "developmentally buffered against certain kinds of experience" performs a useful service that is not advanced by interactionist lingo. Lehrman's interactionist hypothesis is that the development of a behavior pattern is dependent on an overwhelmingly complex interaction between genes and environment and between the products of preceding gene-environment interactions in the developing organism and its internal and external environment. Doesn't this imply that development will be affected by a nearly infinite range of interactive influences? If this were true, there should be immense variation in the outcomes of developmental processes within species, given that all individuals inevitably experience different environments and possess different genes. But despite their unique interactive developmental histories, song sparrows almost always sing song-sparrow songs, and even when reared in acoustical isolation from their fellows, they sing songs that exhibit distinctive elements of the fundamental song-sparrow pattern. This is an intriguing result, and it suggests that not all developmental outcomes are equally probable and not every potential experiential influence on development has equal impact.

I will go further. Lehrman's interactionist theory of development has been available for researchers to use for 25 years, and there have been and continue to be ardent advocates of its conceptual validity. Why then have there been so few productive research applications of the theory? Is it simply the slavish adherence of biologists to dichotomous thinking? Or could it be that the "theory" is so general and vague that it fails to generate useful testable hypotheses? After having criticized previous studies in the light of interactionist theory, Johnston's research suggestions strike me as decidedly nonrevolutionary. He concludes that it would be a good idea to check for additional subtle experiential influences on the development of birdsong. No one will stand in the way of researchers interested in these t not specify how this avenue of research will overturn or even substantially modify the current view of birdsong development as presented in Konishi's review.

Johnston also claims that the dichotomous view of birdsong development has taken attention away from the functional analysis of birdsong. This claim is based on a failure to discriminate between proximate and ultimate causation in biology. Johnston complains that researchers who experimentally investigate the development of birdsong focus "on the form of adult song, rather than on its function," as if one type of study necessarily precluded the other. Studying the effects of certain kinds of experience on the developing form of birdsong qualifies as proximate research, an exploration into the mechanisms within individuals that underlie the behavior of interest. No one suggests that this work cannot or should not be informed by an understanding of functional/evolutionary questions, but questions of proximate mechanism and ultimate function deal with separate aspects of a trait and complement rather than compete with one another.

The interactionist "theory" of behavioral development uses a proximate level of analysis and therefore cannot be inherently more evolutionary or functional than alternative proximate approaches to the development of birdying. To study questions of function, one uses various evolutionary approaches that are entirely different from those used to answer proximate questions. Studies of birdsong development not conducted under the aegis of interactionist theory have revealed many differences between species and many special features of the process of song acquisition. Some of these characteristics have been analyzed from a functional perspective; others (some identified by Johnston) remain to be explored. But to suggest that previous proximate studies of birdsong have impeded research on the 
functional significance of birdsong is to misread the goals of proximate and ultimate studies of behavior.

The study of the ontogeny of birdsong is far from complete, but a great deal has been learned about the process by researchers who include - innate" in their vocabulary. I am skeptical that abolishing the word and replacing it with a different terminology will yield major new research approaches to the fascinating problem of birdsong development.

\section{Birdsong and the "problem" of nature and nurture: Endless chirping about inadequate evidence or merely singing the blues about inevitable biases in, and limitations of, human inference?}

\author{
Marc Bekoff \\ Department of Environmental, Population, and Organismic Biology, \\ University of Colorado, Boulder, Colo. 80309-0334
}

Johnston's target article, in which he slides smoothly from a consideration of the ontogeny of birdsong to development in general, strikes me as being timely and provocative; provocative both in addressing important issues and also in being a bit too ad hominem for my taste. Having been greatly influenced by Daniel Lehrman, it is a shame that Johnston did not take to heart Lehrman's (1970, p. 46) admonition that personal attacks should not be part of intellectual discussions among people who disagree. His "I'm right and you're wrong" attitude often conveyed by unnecessary "pedantic posturing" (Gould 1988) and datajamming (Bekoff 1981; 1988) is not only counterproductive and unfair but also premature. It is probable that it will always be premature to advocate exclusively one or another position because of the impossibility of demonstrating that the development of all behavior in diverse species will be explainable by a single theory. Furthermore, when humans study nonhumans, they inevitably incompletely understand them and their inferences cannot be perfect (Byers \& Bekoff 1986). Thus, the best way to proceed is to put forth alternative hypotheses and then test each one systematically (Bateson 1978; Hacking 1965; Miller 1987; Murray 1986; Platt 1964; Quinn \& Dunham 1983) to present as "strong inference" as possible (Platt 1964).

Although I believe that there never will be strong or perhaps even weak agreement among "dichotomists," "interactionists," those that take middle ground, or among scientists interested in the development of behavior in general (Oyama 1988a; 1988b; Plomin 1988a; 1988b), lively debates are healthy and inevitable. Like the continued controversy over sociobiology (Kitcher 1985; 1987 - which is not totally unrelated to the present essay), it is in the interest of the disputants to keep the debates alive (Segerstrale 1986). The discussions do not necessarily continue because of a failure to communicate, but rather because people are people and like to cling to ideas that are dear to them (Loehle 1987).

Now, what about the evidence supporting a single theory of development? Kitcher's (1985) book Vaulting ambition: Sociobiology and the quest for human nature (see also Kitcher 1987) stresses that the major question that one needs to consider in a critical evaluation of a field is "How good is the evidence?" Of course, people disagree in their judgments of what is "good evidence." The question of evidence is critical to Johnston's argument. He argues (with respect to birdsong but it is certainly applicable to other areas) that "potentially important lines of investigation have been overlooked and the interpretation of existing data is often flawed." He also summarily dismisses the techniques of isolation rearing. Now, how objective is he being?
If important lines of investigation have been overlooked, is it not premature to conclude that a single explanation of available data is absolutely correct? And, even if the interpretation of some available data is incorrect, is it still not possible that future investigations will result in the accumulation of data that support earlier "incorrect" explanations of previously poor evidence? At the moment, I just do not see why the "dichotomous" way of looking at things constitutes "reliance on an outdated and inadequate view of development."

Johnston also writes that "if the innate-learned dichotomy is not an acceptable basis for the analysis of behavioral development, what then?" Note now that "birdsong" becomes translated to "development in general." He suggests that we adopt the interactionists' perspective "and consider all [my emphasis] behavior to arise in development from interactions within and between the organism and its environment." Elementary consideration of Karl Popper's (1959) and others' writings tells us that we cannot know something about all of anything, but that we can know that not all of anything is possible.

Another area that Johnston considers concerns "units of selection." He discusses alternative views in which supposed interactions occur between "genes and the environment" or between "organisms and the environment," preferring the latter because it is easier to fit in with his point of view. But it is not entirely clear that there is a correct view of units of selection. To wit, philosophers still have not come up with one answer despite deep and usually objective consideration of the issues (Brandon 1982; Mitchell 1987 and references therein; Sober $1980 ; 1984)$. Mitchell (1987) concludes that "the question of the unit of selection turns out to be ill-formed" (p. 352) because more than one entity can be involved in the evolution of traits by natural selection. Sober (1984) is also unable to come up with a totally acceptable unit and writes that he is thus "able to alienate reductionists and antireductionists alike" (p. 215). And, Rosenberg (1985) writes, "But organisms are not the units of selection" (p. 139), and then later on states, "The individual organism is of course the immediate (but perhaps not sole) unit of selection" (p. 205). [ See also Ghiselin: "Categories, Life and Thinking" BBS 4(2) 1981. ]

Now, just because philosophers cannot come up with a simple resolution to the problem of "units of selection" this does not mean a solution is impossible. Rather, their dilemma simply makes it clear that there are alternative points of view and that the one a person chooses is most likely to be the one that fits in best with his view of the world (Loehle 1987).

In summary, there is nothing inherently wrong with the interactionist point of view and the underlying assumptions necessary for its acceptance. What is disconcerting is Johnston's (sometimes ad hoc) sweeping dismissal of alternative explanations of development. His insistence that the interactionist perspective will be applicable to all behavior is, in my opinion, misleading, myopic, premature, and philosophically unsound. Furthermore, Johnston does not offer any clear-cut experiments that could be used to assess unambiguously his or the dichotomists' view in all situations. I would like to have read about hypothetico-deductive experiments that would conclusively show that the interactionists' point of view is the only tenable explanation for the development of all behavior. Also, a presentation of the types of data needed to reject alternative points of view would have been welcome.

Last, why Johnston accuses others of "keeping alive an invidious distinction that should have been laid to rest decades ago" is unclear to me. Is he also not discriminating unfairly and expressing his views too strongly? After all, all of the data are not yet in, and never will he.

\section{ACKNOWLEDGMENT}

I thank Anne Bekoff for comments on this piece. 


\section{Developmental creationism}

\section{Gordon M. Burghardt}

Departments of Psychology and Zoology, University of Tennessee, Knoxville, Tenn. 37996-0900

Johnston, by his detailed analysis of birdsong research, hopes to once again discredit the view that genes can specify or control "any aspects of the behavioral phenotype." His message is couched in an attack on "dichotomous thinking," in which "innate" is equated with genetically determined and "learning" is equated with experience. Johnston argues that this can lead to faulty interpretations and loose thinking. I agree. Where I part company is in the view that this is currently a major problem only present in the kind of studies criticized.

The early ethologists pointed out that a good deal of behavior should be considered a phenotypic character that is as much a part of an animal's evolutionary heritage as its morphology and physiology. "To use the term innate in reference to structure or behavior is a shorthand way of referring to phenomena which we consider to be shaped and influenced strongly, although perhaps indirectly, by specific genetic information" (Burghardt 1973, p. 361). In other words, the innateness concept includes an ultimate aspect that needs to be considered in any proximate analysis. Developmental studies of all phenotypic characters need to take into account life history, ecology, and genetics as well as form and function (Burghardt 1977; 1988).

It is clear that the term innate is used in different senses and that these can cause confusion (Lehrman 1970). This is also true of terms such as communication, learning, and experience. Arnold (1981) suggested using the term "congenital" to refer to behavior present at birth (thus not prejudging the role of heredity), "ontogenetically stable" to refer to characters apparently resistant to change, and "heritable" to refer to the role of genetics in explaining phenotypic variation in a given population in a specified environment. This is useful but it cannot be strictly applied to the birdsong work since the behavior is not present at birth. Hence we still have the problem of "maturation" versus "experience" (Schneirla 1965). In any event, initial genetic channeling and postconception modifiability are not incompatible (Burghardt 1977).

To argue that a heritability of 1.0 is identical to innateness as determined by studies of individual development is questionable. Having five digits on a hand can be considered an innate character specified by genetic information. Yet in a diverse genetic population of human beings or iguanas, phenotypic variability in the number of digits will be nil and calculated heritabilities zero. Thus the innate differences and heritability approaches do not always get at what others mean by the term innate.

Nonetheless, whereas the detailed answers derived from individual developmental studies and genetic studies may differ, an essential congruence will usually be found (Burghardt 1973). Thus, species-typical and apparently adaptive behaviors found to be congenital in newborn animals (such as chemically based prey preferences in snakes, Burghardt 1977; Arnold 1981) will almost always be shown to be heritable and under a strong degree of genetic influence. Are not probabilities and generalization major aspects of science?

It is interesting that concepts on the nurture side of the dichotomy do not receive the same intense censure as those on the nature side (Burghardt 1973; 1977). The even-handed appearing "pox" on both innate and learned (which goes back to both Kuo 1924 and Lehrman 1953) is too often a rhetorical ploy to get rid of the innate and still keep on with the learning. In spite of protestations, Lehrman's (1953) alternative interpretations of instinctive behaviors almost all ultimately relied on hypothesized conditioning, and many have proved erroneous.

Gottlieb's (1973) classification of determinative, facilitative, and maintenance embryological precursors was a major conceptual advance to which Johnston, surprisingly, does not refer. I used it as the main framework for a treatment of ontogeny in communication (Burghardt 1977) that addresses every major issue brought forth by Johnston at this late date. So what is going on here?

Attempts to deny behavior the same status in biology as other phenotypic characteristics are comparable to the criticisms of evolution by creationists. Whereas biologists have a lot of data that is most consistent with an evolutionary interpretation, the creationists scour the literature for inconsistencies, lapses of logic, overenthusiastic claims, and, most tellingly from their point of view, slippery moral and ethical slopes that will be greased if the evolutionary approach is allowed to continue unchallenged.

Many attacking the acceptance of specific genetic or innate factors in animal behavior have the sincere conviction that such acceptance will foster racism, sexism, capitalism, and fascism in our own species (e.g., Lewontin et al. 1984). Lehrman's (1953) famous critique of classical ethological theory made many salient points and clarified important issues. But it is well known that there was a political agenda behind the attack and that the concept of genetic factors in behavior was itself suspect in the post-World War II thinking of Lehrman and others. This was shown near the end of Lehrman's (1953) analysis when he could not resist bringing in Lorenz's speculations on human racial differences and domestication.

More subtly, Johnston's careful analysis also seems to be motivated by similar ideological concerns. Why else does the last paragraph voice his displeasure that "many students of song development are keeping alive an invidious distinction that should have been laid to rest decades ago"? Invidious how? A mistaken approach to studying birdsong may be foolish but hardly invidious (except perhaps to all those deafened birds). If one feels that those who entertain the concept of genetic control of behavior are unwitting dupes or fellow travelers on a slippery slope, one should say so explicitly. Otherwise, one must get on with the task of studying song development in order to demonstrate the empirical power of his point of view. Fortunately, unlike during the Lysenko and Pavlovian eras in the Soviet Union, the accusation of being "theoretically suspect" has less ominous implications today.

Just as developmental studies of molecular biology have progressed well beyond the simple one-gene/one-enzyme idea, so have behavioral studies, and they will increasingly approach the interactionist stance advocated by Johnston. However, there is much that we need to know, even at the "crude" level, before we can effectively address the more subtle, the nonobvious. Bateson (1985), in commenting on the SchneirlaLehrman approach, stated that "a model should simplify and point to particular problems that are amenable to analysis. This one primarily seems to tell us that life is complicated" (p. 9). We may finally begin to appreciate a most profound statement on scientific methodology by one of the founders of classical ethology:

An unbroken description of reality would be simultaneously the truest and most useless thing in the world, and it certainly would not be science. If we want to make reality and therefore truth useful to science, we must do violence to reality. We must introduce the distinction, which does not exist in nature, between essential and inessential. By seeking out relationships that seem essential to us, we order the material in a surveyable way at the same time. Then we are doing science. (von Uexküll 1909/1985, p. 227) 


\section{Selectionist mechanisms: A framework for interactionism}

\author{
Stanislas Dehaene and Jean-Pierre Changeux \\ Departement des Biotechnologies, Neurobiologie Moleculaire, Institut \\ Pasteur, 75015 Paris, France
}

The nature/nurture dichotomy has been commonly used as a paradigm for the experimental study of the complex interactions between an organism and its environment. That it turned out to be an oversimplification is no surprise, but it does not entail returning to such extreme interactionism as Johnston suggests. The contention that there is "a host of potential contributors to the development of the organism" can hardly be denied. Being neutral with respect to the nature of the interaction between these contributors, interactionism appears too powerful to suffer refutation by experiment.

Selectionist (or Darwinist) theories of learning (Changeux et al. 1984; Changeux \& Dehaene, in press; Edelman 1978; 1987; see also Jerne 1967) offer a third way between the oversimplification of the nature/nurture approach and the excessive generality of interactionism. Selectionist theories belong to the interactionist framework since they attribute adult behavior to an interaction of genetic potentials and environmental pressures. However, the rules of this interaction are clearly defined. In their full generality, selectionist theories apply to any two successive levels of study of a biological system (Changeux \& Dehaene, in press). It assumed that lower levels function as generators of a diversity of transient forms, produced by a combinatorial rule, which are later selectively stabilized or eliminated at a higher level according to their fitness (or resonance) with environmental or internal cues. For example, in the development of the neuromuscular junction in vertebrates, multiple innervation governed by molecular mechanisms of "blind" growth precedes a pruning of functional nerve endings by neuronal activity, which ultimately leaves one axon terminal per muscle fiber.

Another example at a higher level is the initially wide "genetic envelope" (Changeux \& Danchin 1976) that human neonates possess for discriminating linguistic sounds (Eimas 1975), which gets reduced as the baby loses the capacity to discriminate sounds that do not belong to his maternal language (Werker \& Tees 1984). These examples do not imply that selection is always a two-stage process: In general, there may be several hierarchically organized phases of diversification followed by selective stabilization, each taking place within the structures laid down by the preceding one (see Nottebohm, 1981, for a suggestion that seasonal dendritic growth underlies periodic relearning in the canary). [ See also Ebbesson: "Evolution and Ontogeny of Neural Circuits" BBS 7(3) 1984. ]

Applying selectionist theories to birdsong acquisition, although not mentioned by Johnston, is not recent (see Marler \& Peters 1982b). Plastic song initially contains a wide diversity of syllables, most of which will not be retained in adult song. The well-documented process of syllabic attrition (Marler \& Peters 1982b) has been interpreted as a selection by matching of early productions with syllables memorized in the first weeks of life (Marler \& Peters 1981). The selectivity of learning to conspecific material observed in birds like Melospiza georgiana (Marler \& Peters 1977) may result from constraints in the initial "genetic envelope": The set of "pre-representations" produced at the early stages of song development should not in general provide the potential to learn any song.

We have recently proposed a formal neuronal model of birdsong acquisition (Dehaene et al. 1987). The model applies to song memorization (sensory learning), which is supposed to be as selective as the later sensory-motor or imitation phase. Three biologically plausible properties are simulated: (1) "synaptic triads," which model the possibility that the efficacy of a synapse is modulated by a neighboring synapse of the same postsynaptic neuron via allosteric modifications of receptor conformations, (2) self-excitatory clusters of neurons which can maintain a sustained activity and are organized into superimposed layers termed sensory, input, and internal, and (3) a Hebbian modification rule which stabilizes connections when their presynaptic activation matches the postsynaptic activity of their target cell. In the simulated network, some clusters act as sequence detectors of the input song. These detectors respond initially to diverse transitions and progressively acquire more selectivity to the particular song which is learned. The initial connectivity provides the network with the capacity of internally producing a diversity of songs. The learning rule progressively prunes this repertoire according to its resonance with the song heard.

Our model, and selectionist theories of birdsong acquisition in general, suggest a number of experimental tests that are not considered by Johnston. Johnston is basically right in proposing to stop the isolation rearing paradigm. But rather than studying more closely the social aspects and functional outcomes of birdsong, which is likely to add more complexity but little understanding to the acquisition process, we propose to explore further the learning mechanism itself. Very little is known about how song is memorized in the first weeks of life. Our model proposes that the sensory phase is governed by the same principles of selection as the later imitation phase. Initial responding to a global repertoire, followed by subsequent narrowing and tuning of sensory capacities is predicted. At the neural level, single-cell recordings in the HVc,nucleus of the whitecrowned sparrow (Konishi 1985; Margoliash 1983) have led to the identification of sequence-specific neurons. Similar recordings at different ages in the course of learning should reveal a progressive tuning of sequence-detecting neurons to more and more restricted portions of the song. At the behavioral level, it should be possible to selectively maintain song elements that are normally eliminated by exposing the bird early to synthetic songs containing those elements. Supporting this prediction, Kreutzer (1987) describes a population of cirl bundings (Emberiza cirlus) whose repertoire contains an atypical, normally eliminated song which resembles the productions of isolation-reared birds.

To conclude, selectionist theories of learning adhere to the interactionist view that adult behavior results from an interaction between internal potential and external constraints, but with definite limits on this interaction. The notion of "learning by instinct" (Gould \& Marler 1987) emphasizes a similar idea. Recently, we have suggested (Changeux $\&$ Dehaene, in press) that similar selectionist mechanisms may extend to the higher level of human reasoning. At short time scales, "mental models" and rules of behavior would be selected according to their congruence with the current goal of the organism. The prefrontal cortex would generate a diversity of "models" and rules available for later selection. If such a theory of "mental Darwinism" is correct, and if selection is indeed the key to brain function, song learning in birds might be a useful animal model for the study of its neural bases.

\section{Nature/nurture and other dichotomies}

\author{
Eugene S. Gollin \\ Department of Psychology, University of Colorado at Boulder, Boulder, \\ Colo. 80309
}

Johnston's target article is a clear and valuable exposition of the so-called interactionist position that is descended intellectually from the work of Anastasi (1958), Carmichael (1925), Kuo (1967), Lehrman (1953), and Schneirla (1957). Among its main points are the emphasis on the impact of nonspecific experience upon 
development (nonspecific experience refers to a wide range of activities not typically thought of as formal learning) and the conceptual difficulties that inhere in the retention, even implicitly, of the nature/nurture dichotomy. In addition, Lehrman's (1953) well-conceived critique of isolation-deprivation experiments is reaffirmed.

Elsewhere, Johnston (1987) has conducted an extensive critique of the use of dichotomies in the study of behavioral development. It is therefore surprising that he persists in retaining two dichotomies in the present paper: The first inheres in any interactionist position, whether it is rendered in terms of heredity and environment as has been the traditional usage, or in Johnston's (via Lehrman 1953) preferred organism and environment formulation. The second dichotomy that is retained is the treatment of function and structure as separate entities, a theoretical stance and research strategy that pervades theory and research in developmental biology and psychology (Collin et al. 1988).

With respect to an interactionist position, Hebb (1963) has pointed out that, "For the present, at least, we may note that the interactions of experience with the genetic and nutritive factors have become really inextricable. It is no longer possible to distinguish sharply between constitutional and experiential factors in the development of behavior" (pp. 22-23). Freedman (1974) put it even more succinctly, holding that the relationships between organisms and environments are not interactionist, as interaction implies that organism and environment are separate entities that come together at an interface. Organism and environment constitute a single life process (Gollin 1984). This view has been asserted by Johnston himself (1985), who held that, "Evolution forged the organism and its environment into a single integrated system, and it is the properties of the ecosystem, rather than those of the organism alone, that hold the key to a successful analysis" (pp. 92-93).

Silvern (1984) has put the issue in the following terms in dealing with emotional-behavioral disorders:

The concept of open systems suggests that organismic and environmental characteristics do not interact so much as they are interdefined. Insofar as description is to be relevant to life, health, or pathology, the organism must be described in terms of the process of exchange with the field; the field must be defined by the structure of the organism that allows only certain aspects of the "objective environment to enter into the organism-environment system." (p. 118) It follows from the rejection of the interactionist position that no aspect of the environment is intelligible in itself but is so only in relation to the focus or needs of some organism (Goodman 1984). In von Uexkiill's (1926) terms, what becomes a feature of the Umwelt does so at least partially because of the structure, focus, and developmental status of the organism.

With respect to the function-structure dichotomy, it is important to recognize that what is taken as a structure is a function of the salience of an organization from some point of view. All structures may be regarded as dynamic configurations, that is, as patterns of functional relationships, and in complementary fashion functions are to be regarded as the activities of structures. These ideas have been expressed neatly by Toulmin (1967):

A physical system, or mechanism, is now characterized by a waveequation that characterizes in one step both the material constitution of the system and its mode of operation. There is no procedure for specifying the one independently of the other, and to speak of either in isolation is a mere abstraction. (p. 828)

The persistence of dichotomies in developmental biology and psychology is amply demonstrated in Johnston's target article, whose main thrust is to demonstrate the conceptual inadequacies and research fallacies that are the consequences of dichotomous formulations in science. It will not be an easy task to adopt perspectives that shed these often implicitly held commitments. Their pervasiveness is amply illustrated in this otherwise commendable work.

\section{"Template theory" is heuristic in disentangling organism-environment interactions}

\author{
Hans-Rudolf Güttinger \\ FB Biologie der Universität, D-6750 Kaiserslautern, Federal Republic of \\ Germany
}

Comparing the two template concepts formulated by Marler in 1963 and 1984 illustrates a great step forward in the way we think about behavioral development, from the innate-learned dichotomy to a highly interactionist approach (1984). However, in his critique, Johnston has completely overlooked this. In 1963, the template was characterized as follows: "The two most obvious ways in which such control could operate are either by an inherited pattern of motor input to the sound producing organs, or by an inherited auditory 'template' to which the animal would match the sounds produced as a result of hearing its own voice." This template requires no specific auditory stimulation in order to begin influencing song development. In the deprivation experiment song structures the birds produced were categorized as either normal (innate) or aberrant (learned).

There is no doubt that this categorization has been strongly influenced by the nature/nurture dichotomy. Marler's postulation of latent auditory templates in 1984 brings a highly interactive framework to the song differentiation process. He suggests that these endogenous templates require specific triggering from the environment: "Lacking species-specific auditory stimulation, some templates remain latent and uninvolved in song development, hence the abnormality of song reared in isolation. When activated, the templates provide the basis for memorizing learned songs and converting them into motor patterns by auditory feedback" (p. 289). Looking for latent templates provides a way to disentangle the set of interactions in the organism-environment system, as postulated by Johnston. Latent templates cannot be assessed by the classical rearing experiments using soundproof boxes. Instead, we must do selective rearing experiments by manipulating, specified aspects of the environment that may activate the latent template for guiding the developmental process.

In addition to the frequently discussed adherence to theoretical viewpoints, we should take into account the fact that the song-learning data are highly channeled by the technical design of the apparatus used for converting acoustical events into a visual display from which the songs can be analyzed. The sonograph shows songs not according to the bird's own sensory processing but according to a scale defined by human engineers for the special purpose of speech analysis. If sonograms of songs from different individuals of the same species are compared with what is heard by the human listener one receives two contrasting impressions: Individual differences in the microstructure of single notes are emphasized by sonograms, but species-universal temporal rules for note delivery, one of the dominant features for our ears, is less easy to decipher from sonograms. Individual differences in the structure of notes are impressively documented sonographically. In contrast, species-typical characteristics such as tonal quality and the temporal rules for uttering single notes within songs are hard to detect, whereas changes in pitch frequencies are extremely well documented. As a consequence, the analysis of the individual frequency pattern of the notes dominates studies of birdsong development. Since it is these patterns that are most subject to sensory experience, the contribution of learning tends to be overemphasized.

In the focus on note morphology the more general notion of song as a "melody pattern" has been overlooked. The melody pattern is determined by the rhythmic arrangements of single tones in sequences. To assess this more general aspect of songs, we studied the temporal (rhythmic) rules for producing single notes within song units in several Cardueline finches (e.g., 
Guttinger 1978; Guttinger et al. 1978). In contrast to the microstructure of the single notes, the rules for producing the vocalizations do not vary from song to song during singing bouts or between the songs of different individuals. Thus, we can study organizational rules independently of the individually shaped repertoire.

The songs of greenfinches (Chloris chloris) and those of canaries (Serinus canaria) show large differences in their organizational rules. Unlike greenfinches, canaries sing in strophes, with two major temporal groupings: highly predictable short intervals between subunits within the strophe and highly variable pauses separating consecutive strophes. In greenfinches there are no preferred groupings and the duration of pauses is independent of the duration of the preceding "trill," whereas in canaries there are statistically preferred and avoided combinations of durations of vocalizations and pauses.

These regularities are also shown by extremely deprived animals (deafened as nestlings or raised by foster parents without hearing conspecifics). We varied both the environment and the genotypes (contra Johnston, section IV): We studied three morphologically different species of greenfinches (Guttinger

1978) and various breeds of domesticated canaries as well as wild canaries (Guttinger 1985). The greenfinches showed variable pauses whereas the canaries showed very similar bimodal frequency distributions resembling those observed in acoustically deprived canaries. I accordingly conclude that these organizational rules are genetically determined to a high degree.

Having demonstrated high constancy in the temporal pattern within one species, we went on to inquire into the extent to which these constraints can be overcome by intensive tutoring of an aberrant pattern. Juvenile canaries were isolated as eggs from singing conspecifics and were tutored with playbacks of six strophes of the whinchat songs (Saxicola rubetra). The canaries copied the individual notes with high accuracy and embedded the entire, heterospecific strophe into their song. However, whinchat strophes are much shorter $(2 \mathrm{sec})$ than canary strophes $(10-60 \mathrm{sec})$ and the canaries who had been tutored with tapes of whinchat strophes integrated them into their songs as subunits. Each heterospecific strophe was followed by vocalizations typical of their own species. These embedding trills, which highly resembled the note categories of normal canaries, had been developed without any specific acoustic models.

These results suggest that the overall pattern of the speciesspecific note morphology can be internally guided (Schwager \& Guttinger, in prep.). Analyzing variation ranges of various song parameters in nature and under selective rearing conditions can reveal "relative differences" in the degree of genetic influence. We are aware that even "innate" parameters can be shaped by subtle epigenetic interactions between genetically formed neural mechanisms and sensory experience.

\section{Behavior-genetic analysis versus ontogenetic imperialism}

\author{
Jerry Hirsch \\ Departments of Psychology and of Ecology, Ethology, and Evolution, \\ University of Illinois at Urbana-Champaign, Champaign, IIl. 61820
}

At one time (the 1950s \& early 1960s) most of us would have accepted Johnston's characterization: "in behavioral genetics ... the aim is to assess the contributions of genetic variation to behavioral variation" or to make "estimates of heritability" (see Hirsch \& Boudreau 1958). In those days it took us time to appreciate its inadequacy. That realization stimulated our advance to the - behavior-genetic analysis" conceptualization (Hirsch 1967a; 1967b; 1986), which describes more accurately the approach to the study of organisms and their behavior that combines the concepts and methods of behavioral analysis from psychology and ethology, based on knowledge or control of experience, with those of genetic analysis, based on knowledge or control of ancestry. The object of a behavior-genetic analysis is a species and its objectives are twofold, one for each of its two methodologies. The objective of the behavioral analysis is the description and analysis of one or more of the behaviors in the species repertoire, as well as of the components into which each behavior can be resolved. The objective of the genetic analysis is the discovery of chromosome and gene correlates of behavior and of its components. (Hirsch 1986, p. 130, emphasis added; also see p. 132)

Individual, population, and species differences are the raw materials for the behavior-genetic analysis of one species or several, because it is such reliably measured differences in behavior-trait expression that are the phenotypes providing access to the genetic system through the breeding studies that constitute genetic analysis. There is neither a "mean genotype" nor a genetics of behavior.

During courtship the males of many Drosophila species emit a species-specific song, analogous to birdsong but produced by the flies' wing displays. It serves two functions: (1) It induces sexual receptivity in females and (2) its species-specificity serves to maintain sexual isolation between species. Experimenting with backcrosses and $\mathrm{F}_{1}$ hybrids between the sibling species Drosophila persimilis and D. pseudoobscura, Arthur Ewing found independently inherited X-chromosome gene correlates of two parameters of the songs which differ between the species both quantitatively and qualitatively (Hirsch \& McGuire 1982, pp. 277, 290-95).

It is important to distinguish methodological from substantive issues; genetical, developmental, and behavioral questions are each studied by methods developed in response to the nature of the three quite different properties of organisms as our understanding of such properties improved. In part, dissatisfaction with - instinct-innate" rests on the misconception that, unlike behavior, learned behavior has been, or can be, described with conceptual clarity. Hebb's 1953 critique claimed: "Instinctive behaviour is what is not learned, or not determined by the environment, and so on. There must be great doubt about the unity of the factors that are identified only by exclusion" (Ricker et al. 1986, p. 163). Hebb believed that unlike learning, instinct lacked validity as a singular concept because it is inferred from negative evidence.

Nevertheless, in Drosophila research, geotaxis, phototaxis, and other "tropisms" have certainly not been recognized as instinctive on the basis of negative evidence from deprivation experiments. When we began working with them (Hirsch \& Tryon 1956), these readily observable events had been universally accepted as innate since well before Jacques Loeb's classic 1888 articles (Hirsch 1973, p. x). In our studies of the "evolution of an instinct" in D. melanogaster, we recognized opposite expressions of geotaxis in two divergently selected populations to be instinctive (i.e., what was formerly species-typical had evolved in response to selection to become population-typical [Hirsch \& Erlenmeyer-Kimling 1961]) and questions were raised about correlations with reproductive fitness in laboratory habitat(s) that have resulted in further research into the adaptiveness of the behavior (Ricker $\&$ Hirsch 1985; 1988a; 1988b). The approach has afforded a unique opportunity to study evolution experimentally in the laboratory.

Negative evidence is used, however, to infer learned association. The control experiments in conditioning and learning studies are the analogue of the deprivation experiment criticized by both Hebb and Johnston in the study of instinct. Unlike tropisms, one does not observe associative learning directly, but only infers its presence when controls have excluded substantial effects of nonassociative (innate) factors. So one might also question its validity as a singular concept. For example, unconditioned excitatory states are aroused by our 
procedures, which have proved so successful for conditioning identifiable individual flies (Holliday \& Hirsch 1986; Ricker et al. 1986). It must hence be demonstrated that such unconditioned states (innate reactions) cannot account for all responses to the conditioned stimulus (CS). More generally, association is inferred from the portion of the increment in responses to CS that remains after one has controlled for (i.e., subtracted away) effects due to sensitization, pseudoconditioning, habituation, excitation, and so forth, some or all of which do occur. There is a heretofore unappreciated historical parallel between the study of instinct and the study of learning that is paradoxical because these usually have been considered polar opposites: Instinctive behavior is unlearned and learned behavior is not merely (i.e., is something more than) instinctive.

Unlike the Cheshire cat's grin in the tale, neither song nor any other trait develops or endures by itself. What develops is a genotypically specific individual. When the ontogeny (embryology, etc.) of that individual is studied we describe the development of the expression of specific phenotypic traits - anatomical, physiological, behavioral, and so on. Just as there literally are no "genes for" specific trait expressions, I neither can there be "developmental events for" specific traits. Individuals develop, and at a certain stage in their ontogeny we can record the expression(s) of certain trait(s); for example, at a certain age a male canid ceases the female squat and lifts one hind leg to urinate, an event that can be advanced to an earlier age by hormone administration. But the timing and topography may vary over genotypically disparate individuals, breeds, and species, and perhaps over ecological conditions.

The very nature of experimental analysis imposes dichotomous or multichotomous thinking: to the extent possible we hold heredity (or environment) constant and manipulate environment (or heredity) to identify environmental (or genetic) influences. In no other metazoan is there a better chance for studying the role of specific genes in ontogeny and exploring the "technical limitations" Johnston invokes. But even in $D$. melanogaster the task is daunting, as witnessed in the line of research from Benzer (1967) or Hirsch (1959) through Johnston's Quinn and Greenspan (1984) reference (p. 13) ${ }^{2}$ and more recent publications; thus my plea for an eclectic behavior-genetic analysis versus any imperialism: genetic, environmentalist, or developmentalist.

\section{NOTES}

1. About 1910 T. H. Morgan did call a Drosophila X-chromosome locus "white eye," and likewise many other early investigators labelled loci by the phenotypic trait expression through which they were first discovered. But subsequently maybe 50 loci have been discovered, alleles of which may "cause" white eye. That is why now we speak of "gene correlates."

2. The widely cited Rothenbuhler (1967) reference on hygienic bee behavior ("caused" by two genes) that I published remains without corroboration since 1958. The Brown and van Scoy bee colonies were never shared with interested colleagues; I understand the colonies have since been lost.

\section{Selective breeding-selective rearing interactions and the ontogeny of aggressive behavior}

\section{Kathryn E. Hood}

Individual and Family Studies, College of Health and Human Development, Pennsylvania State University, University Park, Pa. 16802

If "the interactionist approach replaces the mysterious, but somehow reassuring, power of the genes with a series of unanswered questions," (Johnston, 1987, p. 175), then it falls to the interactionist theorist to specify the appropriate and most useful questions to ask about the origins of form and change. In this insightful review and critique, Johnston frames several promising approaches to the study of song development in birds, including an emphasis on the functionally significant, socially effective features of song. One recommendation is to implement behavioral studies with "systematic and precise manipulation of genetic structure and activity, for example by the careful use of single-gene mutants and genetic chimeras. "

There is a complementary approach to genetic-developmental analysis that is based on functional units of behavior that are more readily interpretable than the behaviors induced by single-gene mutation. Robert Cairns and his colleagues have shown that aggressive behavior is rapidly responsive to selective breeding, and that selective breeding effects may occur as alterations of developmental timing, or heterochrony (Cairns et al. 1983). The effects of selective rearing are equally powerful: When male mice are reared in tactile and visual isolation, aggressiveness is enhanced in an age-dependent function (Cairns et al. 1985). Applied to the selectively bred lines, selective-rearing differentials are sufficient to eclipse selectivebreeding effects through repeated exposure to the social setting of the test situation (Cairns 1983) or through continuous social differentials (Cairns \& Hood 1983; Hood \& Cairns, submitted). Furthermore, disentangling the relative contributions of selective rearing and selective breeding reveals the cross-sex inheritance of aggressive behavior (Hood \& Cairns 1988).

The behavioral mediation of selective breeding effects on fighting has been investigated (Gariepy et al., in press). The mediating behavioral system that changes under selection pressure is one component of the configuration of ontogentic changes produced by selective rearing (Cairns et al. 1985): it is correlated with attacks, but also with other forms of social behavior. For example, not only are low-aggressive-line males less likely to fight other males, they are also less likely to copulate in 10-minute tests with estrus females (Hood \& Cairns, unpublished data). Future neurobiological and molecular genetic analyses using these lines could provide results that are interpretable as aspects of evolutionarily meaningful social patterns and as biological and contextual factors fused in social ontogeny (Cairns et al. 1988; Cairns \& Gariépy 1988).

There is an implicit loss of precision in moving from singlegene effects to the multiple yet unidentified epigenetic complexes that may be altered by selective breeding and the different sets of genetic alterations that, in separate studies, might produce identical patterns of behavior change. While awaiting the techniques to "induce single-gene mutations that affect song development," as Johnston suggests, it yet might be useful to test the hypothesis that the functional components of song are responsive to two experimental operations that are available now: selective breeding and selective rearing.

Lehrman (1970) notes that genetic differences may consist of differences in responsiveness to "the same" environment. "Natural selection can select for specific ways of being sensitive to experience, or for phenotypic structures that make experience possible, just as readily as it can for any other characteristics" (p. 37). This underscores the need for measures of the environment that are independent of measures of organismic response to the environment (experience).

I was enormously cheered by Johnston's dispelling of the mystical properties that adhere to the term "information" (see especially Johnston 1987). The first pre-Mendelian use cited in the Oxford English Dictionary as meaning "the action of giving form to matter" ("in-forming") was in 1646: "There was a seminality and contracted Adam in the rib, which by the information of a soule, was individuated into Eve." Divine information, transmuted into DNA, may yet be understood as development. Johnston's continuing discussions of these issues and those of other scientists (Oyama 1988b; Plomin 1988a; Schneirla 1966) are the means to that end. 


\section{The polythetic perspective}

Donald D. Jensen

Department of Psychology, University of Nebraska-Lincoln, Lincoln, Nebr. 68588-0308

Johnston's central thesis is that innate and experiential factors are neither exhaustive nor exclusive and that terms such as "innate" and "learned" apply to differences in behavior, not to behaviors or behavioral components. That thesis was stated in an early article (Jensen 1961), was criticized (Lorenz 1965), and has been revised and extended (Jensen 1970; 1987). The revised viewpoint is broader in focus than the interactionism of Johnston and Lehrman, emphasizes covariation rather than differences in behavior, and supports additional criticisms of recent work on birdsong. This methodological perspective is that of "polythetic operational biological behaviorism," an eclectic approach to the study of behavior whose major features are expressed by the terms combined in its name.

Operationism is the principle that the scientific meaning of a concept is the observations and investigative procedures which measure or justify the use of that concept. Operationism demands observations and clearly stated procedures for arguing from observations to more theoretical constructs. Biological behaviorism involves observing, describing, and measuring variation in behavioral content, and then investigating covariation of behavioral content with other biological events or variables (causes, correlates, and consequences at ecological, organismic, and intraorganismic levels). Polytheticism is the principle that biological concepts are not effectively defined by monothetic definitions specifying a few key characteristics which are logically necessary and sufficient to identify an exemplar. Instead, biological concepts are effectively defined by polythetic definitions which indicate the many characteristics typical of an exemplar, but no one or small set of these characteristics is necessary or sufficient to give the meaning of a biological concept (Sokal \& Sneath 1963). A polythetically defined behavior is a temporary state of an organism which is to be classified and understood, not just by its behavioral content or by some key character, such as dependence upon genotype or particular experiences, but by its content and by the many causes, correlates, and consequences of that behavior at all biological levels - by all the events or states which constitute or covary with that behavior. The polythetic behaviorist holds that $a$ behavior is understood to the extent that its variation is well described and its major covariances have been identified (Jensen 1987).

How would taking this point of view change the criticisms offered of the work on birdsong? It would not change the useful and thoughtful suggestions made by Johnston to manipulate nonobvious experiential factors and to study functional outcomes of song development (consequences). It would demand from template theorists a clearer operationalization of their ideas in terms of observable covariances. It would argue that specification of "sources of information" as genetic or experiential may be operationally and scientifically impossible, and, even if possible, that it would be trivial, since it would be a monothetic rather than a polythetic conceptualization of behavior.

Scientific investigation of behavior can achieve the measurement of variance in behavior and covariation with other biological variables. There is simply no operational justification available from the study of variation and covariation for terming behaviors or components of behaviors "learned" or "innate." As long as investigators seek evidence to justify the classification of songs, components, or templates as innate, rather than systematically studying variance and covariances, their investigations will be misguided and their theories muddle-headed.

Much of the work on birdsong is very satisfying to a polythetic behaviorist, since birdsong is a polythetically definable behavior class. In contrast, the view that birdsong is an especially good model for the understanding of human oral language and communication is untenable from the polythetic perspective, since the structures producing signals (larynx and syrinx) are not homologous, the covariances of birdsong and of human speech with many biological variables are strikingly different, and the organisms involved are not closely related. To the polythetic behaviorist a better model would be a primate oral communication system (i.e., squirrel monkey calls or gibbon song) which would appear to be simpler than but homologous to human speech, rather than only analogous, as appears to be the case with birdsong.

The study of birdsong is important in its own right, but the investigation of syrinx-produced sounds of descendants of dinosaurs cannot be expected to be especially useful for understanding human vocal and linguistic communication. Birdsong, when studied for its own sake, should be studied polythetically, with attention to all events which constitute and covary with the song of the sparrow, the cooing of the dove, and the melody of the nightingale.

\section{Ab ovo with song?}

\section{S. N. Khayutin and L. I. Alexandrov}

Laboratory of Ontogenesis of Brain Functions, Institute of Higher Nervous Activity and Neurophysiology, U.S.S.R. Academy of Sciences, Moscow, U.S.S.R.

The polemical article of Johnston is very timely. The author vigorously upholds an obviously fruitful view of behavioral development, one that considers development as a product of the interaction of an intricate complex of both endogenous and exogenous factors.

Although most investigators nowadays are declaring their break with the traditional understanding of a behavior as a complex of innate and acquired components, the fact that only minor conceptual progress has been achieved in this field is due to the use of traditional terms and to the tempting clarity of both the experimental design and the interpretation of the results. The unfruitfulness of the traditional approach to behavioral development in terms of a dichotomous paradigm became so obvious long ago that it has even been formulated in aphoristic form. The question of the extent to which certain behavior depends on genetic versus environmental factors was said to have no more meaning than the question of the primary determinant of area - length or width (Hebb 1953). Shepherd (1983) wrote that considering the influence of genetic and environmental factors separately is as senseless as discussing the problem of the sound of one hand clapping. However, such declarations are mostly found in articles' introductions, whereas discussions usually reveal the tacit sympathies (ecological or genetic) of the author. Thus the occasional publication of conceptual manuscripts like Johnston's is very helpful.

Johnston's target article possesses great polemical potential in its negative section, criticizing the dichotomous approach; unfortunately, its constructive part is less convincing. This might be due to the fact that the methodology of the interactionist approach has not yet achieved either its final form or a sufficient number of consistent adherents. Even in the current article, in order to substantiate his position, Johnston must make use of data obtained with the "untenable" dichotomous approach.

Johnston's ideas expressed in terms of a "developmental ecosystem" are very hard to develop consistently in experiments because it is almost impossible to monitor simultaneously numerous parameters of this ecosystem. Some of the parameters must be fixed in order to reveal experimentally the developmental contribution of the others. A logical realization of Johnston's ideas may lead, for instance, to no more than replacing the two-dimensional graph (Fig. 2) based on the dichot- 
omous paradigm by a multidimensional graph that would include "nonobvious" developmental factors. The difference between these would be quantitative rather than qualitative. Nevertheless, again drawing attention to this alternative to the dichotomous viewpoint may, we think, contribute to the development of the favorable intellectual climate that is a necessary premise of the real (rather than merely declared) acceptance of an interactionist approach more adequately reflecting the multifactorial nature of behavioral development.

We agree with Johnston that the role of nonobvious factors in behavioral development must be taken into consideration. We hope that our own experimental material can shed some light on the role of nonobvious song experience as well as the effects of social contacts on the process of song formation.

Konishi (1985) singled out the following functions of song as a social signal: It supplies the female with information about the closeness of a potential partner - its species and its individual identity - and about territory and breeding conditions; song also has territorial functions. However, the studies of the organization of nest behavior in pied flycatcher (Ficedula hypoleuca) nestlings in the wild have revealed (Khayutin et al. 1978) that during the first half of the nest period males sing near the nestbox several hundred times a day. This suggests that the male's song could affect not only adult birds but also nestlings, whose behavior during this period depends only on acoustical stimuli. It is worth noting here that, according to behavioral and electrophysiological criteria, the maturation of nestlings' acoustic sensitivity is practically complete by the end of the first half of nest life (Khayutin \& Dmitrieva 1987). Species song has been shown not only to be a security signal for the young (its action being antagonistic to that of alarm call), but also to affect greatly their emotional state. Electrocardiographic recordings showed that nestling heartbeat frequency increased during alarm calls and immediately returned to normal when the alarm calls were abruptly replaced by species song. Without song presentation, the recovery of normal heart rhythm after alarm calls took several minutes (Khayutin et al. 1978). The creation and maintenance of the comfort state by the species song may be an important factor in initial song fixation for future reproduction. On the other hand, this adequacy of the song to the situation may be one of the mechanisms underlying the differential efficacy of live tutors and tape tutors, the problem often stressed by Johnston.

Another problem we would like to consider is that of "nonobvious factors of experience." We think that the choice of experiential factors and their categorization as obvious and nonobvious will depend on the initial position of the investigator. For example, the auditory thresholds of a cuckoo nestling reared by redstarts were shown to differ from the very beginning from those of the foster parents' own chick living in the same nest (Khayutin 1985). Both nestlings lived in the same environment in terms of physical parameters, but they probably perceived it differently because of the differences in the physiological organization of their acoustic systems. This difference cannot fail to contribute to the formation of species-typical vocalization in these species, but, unfortunately, this notion can only bring us a little closer to understanding the entire system of factors that interact in the process of birdsong development.

\section{Ducks don't sing}

Andrew P. Kinga and Meredith J. Westb

'Department of Psychology, Duke University, Durham, N.C. 27706 and 'Department of Psychology, University of North Carolina, Chapel Hill, N.C. 27514

Johnston's target article evokes mixed reactions. We could not agree more about the need to consider the study of song ontogeny with respect to more progressive developmental prin- ciples or about the need to use a more enlightened set of methodologies. But the sense of ideological camaraderie cannot overcome our sense of discomfort over Johnston's advice about what birdsong researchers ought to be doing. We feel the way one does when being given advice about the rearing of one's children from someone who does not have to cope with those same children day in and day out. We suspect that Johnston might change the tone, if not the substance, of many of his remarks, if he considers the actual problem involved in implementing his proposed developmental designs at this point in time.

What is at issue for us is not the status of the template. The latter is one of those constructs (like linguistic capacities in other animals) that scientists either love to love or love to hate. But for that very reason, it has ultimately fueled the formulation of better theories of song learning (Petrinovich 1988), theories Johnston does not address. And until someone comes along with some new words to help us describe how and why acoustically naive songbirds can produce species-recognizable signals (and even functionally effective subsong, see West \& King 1988), template-like concepts, with all their limitations, will persist. And if they provoke argument, all the better. Arguments ignite new initiatives. "A theory which cannot be mortally endangered cannot be alive," warned Rushton (in Platt 1964, p. 349). The template deserves credit because, as Konishi was attempting to say, it invites the testing of hypotheses.

But the greater source of our frustration comes from Johnston's call that more use should be made of the interactionist perspective espoused by Lehrman and that more attention should be paid to nonobvious sources of experiential influence. $\mathrm{He}$ is right that only the more obvious sources of stimulation have been studied in detail, but he is wrong about the reasons. It is not theoretical naivete, inertia, or intractability that has precluded such experiments: It is time and its interaction with the ontogenetic cycles of songbirds and the funding cycles of institutions. Scholarly works on nature and nurture rarely discuss time or money. The omission is unfortunate, because the synergy between these commodities has much to do with the canalization of research objectives.

Consider that the study of song ontogeny is only beginning its fourth decade. In that period, researchers have had to learn how to raise songbirds reliably from a young age or ideally from the egg (still not practical for most species); they have had to learn how to care for them in the laboratory for multiyear periods; they have had to find out, through trial and error, which species thrive in the laboratory (sparrows do, mockingbirds do not); they have had to develop new acoustic skills to analyze the thousands of sounds each young bird utters even before he produces his first real "song"; they have had to work out experimental regimes based on their best guesses about possible sources of stimulation; and then they have had to accommodate their research schedules to the seasonal cycles of songbirds. Is it any wonder that extensive longitudinal data even on structural variation in exclusively captive settings are available for only several of the thousands of species assumed to learn their songs? (Marley \& Peters 1982a; 1982b; King \& West 1988).

Johnston also calls for more functional assessments of developmental outcome. In that we have championed bioassays in words and action, we speak with authority and empathy (West \& King 1987a). It took three years to learn to breed cowbirds in captivity; it took another four to learn to rear the young; it took another six to master the rudiments of their song system well enough to know what functional metrics to use. Several more years were devoted to testing different populations and to assimilating the within-species variability encountered. And all of these steps had to be taken before we could do what we wanted to do in the first place, that is, to study the roles of social and acoustic experience during song ontogeny, an endeavor now in its eighth year and still in progress.

Consider the effects of time from another perspective. The 
average life span of a cowbird in the wild is 18 months; in the laboratory, it is 5 to 7 years. But what is the lifespan of the average research grant? Never as long as the 15 -year program we have just described. The asynchrony of research cycles, funding cycles, and songbird cycles is a major impediment to implementation of some of Johnston's ideas. Moreover, asking for funds to study nonobvious sources of experience for which there is as yet little field data is risky business (especially at a time when molecules are the coin of the realm).

Finally, we question the utility of comparing the paradigms of imprinting and song learning. If songbirds could be ordered from a supplier, or even raised in sufficient numbers in incubators, or studied and tested before their postnatal care and feeding even became an issue, Johnston would have answers to many of his questions. It is only quite recently that students of imprinting have seriously explored the question of social influences - and with intriguing results (Lickliter \& Gottlieb 1985). Why has it taken so long? Johnston would do us a service by providing an answer, especially given his part in effecting the ecological about-face (Johnston \& Gottlieb 1981a).

In sum, we agree that all scientists need to take care when choosing the words to describe their findings. But Johnston must realize that his words are not falling on deaf ears but on ears tuned by pragmatics to problems that may seem nonobvious to nonpractitioners. But if Johnston is right, the more song researchers learn, the more they will hesitate to adopt the provocative dialect of nature/nurture-ese.

\section{When is developmental biology not developmental biology?}

\section{Ronald Konopka}

Department of Biology, Clarkson University, Potsdam, N.Y. 13676

I would agree with Johnston's contention that "comparing the songs of [birds] reared under identical conditions . . . cannot reveal any of the detail that we need in order to understand how genes contribute to development." However, he then states: "Only by systematic and precise manipulation of genetic structure and activity ... can any useful substance be added. Techniques such as these, of course, belong in the province of geneticists and developmental biologists, not of ethologists and other students of animal behavior."

I believe the day is past when a behavioral scientist refuses to draw upon the techniques of other disciplines. If he wishes to study development, he must become, at least in part, a developmental biologist willing to combine genetics, developmental neurophysiology, and ethology. One of the most important issues in birdsong development concerns the role of genes and environment in the generation and maintenance of neural plasticity. The regulation of plasticity in the brain involves a genetic component, which may specify a general "template" (Konishi 1985), as well as auditory feedback and other neurological and hormonal mechanisms. These mechanisms must be studied with the appropriate physiological techniques.

Johnston's view resembles that of the early behaviorists, who were concerned with input-output relations, not with the physiological mechanisms underlying the observed behaviors. The recommendation that "nonobvious experiential contributions to behavioral development" be studied misses the mark. The suggested experiments do not remove the problem of separating genetic variation from environmental variation; variation is inherent in "normal" or "functional" song. The understanding of the developmental mechanisms that contribute to the formation of adult song necessarily involves an interdisciplinary approach to neural circuitry. A good example of the results of such an approach is provided by the discovery of 1 seasonal replacement of neurons in the adult canary (Not- tebohm 1985). The modern ethologist must be a geneticist, a developmental biologist, and a physiologist in order to properly investigate an organism's behavior.

\section{Behavioral ontogeny research: No pain, no gain?}

\section{Donald E. Kroodsma}

Department of Zoology, University of Massachusetts, Amherst, Mass. 01003-0027

To me Johnston's target article emphasizes, first and foremost, that the vocabulary used in developmental studies misleads, misinforms, and even angers. One could argue that the $i$-word (starts with "i," ends with "e," double "n," etc.) and its close relatives are merely "linguistic conveniences," but on one important level the outcome of any such debate would be largely irrelevant. Continued use of such terminology will serve only to alienate those in diverse disciplines who should be communicating in a constructive way with each other about the intricacies of behavioral development. I have used these terms in the past, but the passion evident in Johnston's article has convinced me that there is no excuse, other than stubbornness (which his article might actually promote), for continued use of any vocabulary that has such "invidious" effects among those who should be talking to each other.

Johnston encourages additional research in two areas that have proven exciting and fruitful: the role of nonsong experience in song development and the use of bioassays to test functional outcomes of the developmental process. I can't imagine anyone disagreeing. Johnston also rehashes the Lorenz-Lehrman controversy, and again I don't disagree with the essentials of the arguments. The environment of a developing organism contains many factors, a few of which are excluded in "isolation rearing," many of which are not.

To state, however, that those who rear birds in soundproof boxes in so-called deprivation experiments are attempting to "eliminate all [emphasis mine] environmental contributions to development" is an exaggeration. Konishi and Marler, for example, favorite targets of Johnston, recognized and studied the importance of auditory feedback (Konishi 1965a; 1965b; Marler \& Sherman 1983). Neither has my use of the "i-word" and its close relatives prevented me from asking additional questions at lower levels, such as how "obvious" or "nonobvious" (depending on one's viewpoint) changes in the environment (e.g., rearing in groups, with males, with females, by cross-fostering at egg stage, without auditory feedback, etc.) influence song development. Throughout his article it seems to me that Johnston establishes a nonconstructive polarity of viewpoints; he passionately argues how one is right and the other wrong, how only one gives useful knowledge of the world, and how only one allows a glimpse of the "obvious" avenues for research.

Although much of the developmental literature is unfortunately discussed in "invidiously" absolute terms (e.g., behavior "x" is "bleep"), the implicit value of most developmental work is in its relative, or comparative, nature. Someone interested in the ecology or evolution of developmental differences among populations or species or other taxonomic groups is not necessarily obsessed with "the only question," the question that seeks to determine, in absolute terms, exactly how "genes contribute to the process of development." For many studies Johnston would restrict our conclusions to the "unhelpful platitude that 'genes affect behavior'," and perhaps appropriately so if one confines his world view to how genes produce behaviors. I wouldn't argue that such studies aren't important; I would merely point out that they address different questions, at different levels from those usually asked. And, contrary to Johnston's forceful message, they aren't the only questions begging for 
study. For my studies of song development among flycatchers and songbirds (representatives of the 2 suborders of the Passeriformes), I am less interested in how the genes produce behaviors than in the evolutionary and phylogenetic implications of drastic developmental differences between the two groups.

Overall, I applaud Johnston for encouraging rigor in our vocabulary and quality in our experiments. I am not convinced, however, that different uses of terminology by "them" and "us" and that different viewpoints by Lorenz and Lehrman have led to bad and good science, respectively.

\section{Song development and sexual imprinting: Toward an interactionist approach}

\section{Jaap P. Kruijt and Carel ten Cate \\ Zoological Laboratory, University of Groningen, 9750 AA Haren, the Netherlands}

Johnston's vigorous attack on the conceptual framework of much research on song development will no doubt arouse a lot of heat. One reason for this may be the way in which Johnston phrases his criticisms. He seems to overstate his case when he argues that the study of song development "has only served to perpetuate the confusion" to which the distinction between learned and innate behavior gave rise. It is true that examples of innatelearned dichotomies are not difficult to find in this field. Despite this, these studies have contributed a great deal of insight into the factors involved in the development of song, and Johnston at times illustrates the interactionist approach by quoting results from this field. Also, although Johnston is nowhere stating this explicitly, we sometimes got the impression that he rejects the concept of templates entirely or fails to appreciate its potential merits. If this is correct we wish to reply that the concept of templates will probably remain useful in developmental research if stripped of its connotations of genetic determination. Finally, Johnston's statement in section VII, that using the template metaphor hampers the analysis of "functional development," fails to convince us. Studying the functional outcomes of development is of course important. However, we do not see why studying structural outcomes should make one blind to functional ones, if only because much of the quoted functional research was done by the same people Johnston criticizes with regard to their structural research.

However, these objections should not distract from Johnston's main message: He rightly points out that the Lorenzian way of thinking about development is still very much alive despite lip service to the contrary. We agree that the use of an untenable dichotomy, however cleverly disguised, hampers rather than illuminates insight in behavioral development. The interactionist approach treats development as a complex process resulting from the interaction of many factors impinging from inside and outside on the developing organism. Therefore, the absence of an environmental influence cannot reveal the direct operation of a genetic program, let alone how genetic factors have contributed to the end product. The fallacy of this "exclusion argument" was already put forward by Lehrman (1953) and has been ably recounted by Johnston.

We are familiar with the exclusion argument from studies on "sexual imprinting," showing that mate preferences in birds can be influenced by their early rearing environment. If reared with foster parents of a different species or morph, individuals often prefer to mate with individuals of that other species or morph later on. However, in other cases cross-fostering with another species may reveal tendencies to respond to, or to prefer, conspecifics, even in the absence of any previous contact with them. In a striking parallel to the examples on song develop- ment quoted by Johnston, here too the conclusion derived from such experiments has often been that the preference is "innate" (Schutz 1965), "genetically determined" (Sonnemann \& Sjolander 1977), "genetically preorganized" (Bischof 1979), or expresses "genetical predispositions and constraints" (Immelmann 1979). In this view the final mate preference is seen as a superposition of innate and learned components similar to the intercalation of both proposed by Lorenz (e.g., Bischof 1979).

The same objections formulated by Johnston can be raised against the false dichotomy concerning the development of mate preferences, and it has been possible to get further insight into the development of these preferences by abandoning this dichotomy (e.g., Kruijt et al. 1982; Kruijt 1985; ten Cate \& Mug 1984 ; ten Cate 1985a; 1988). This example serves to illustrate that the dichotomous approach criticized by Johnston is also prominent in a related area of ontogenetic research. Therefore, and in view of the perennial nature of the problems with innatelearned dichotomies (Beach 1955), we believe that it is useful that researchers are reminded from time to time of the pitfalls in this approach, and we welcome that Johnston has once more outlined the flaws of the dichotomy under consideration.

In section VI Johnston outlines the specific contribution that the interactionist approach may make to developmental problems. We would like to suggest that the interactionist approach not only draws attention to the identification of nonobvious experiential contributions, but may also require us to rethink the value of an outcome demonstrating the effect of experiential factors. As pointed out by Johnston, finding that some factor does not influence the development of some trait leaves the question of the developmental process unanswered. But suppose that an influence of some environmental factor does occur, for example, suppose contact with a live tutor causes a young bird to learn the tutor's song. Such a result should not lead us to conclude that we understand the developmental process. The interactionist approach raises further questions, not only about which other factors are involved, but also, and perhaps in particular, about the process by which the external factor achieved its impact. To identify an influence of "social context" on song learning, as is the case for zebrafinches (Immelmann 1969) and white-crowned sparrows (Baptista \& Petrinovich 1984), should immediately raise the questions of how the influence is brought about and of what the underlying mechanism might be (cf. ten Cate 1988). Abandoning the dichotomy thus not only makes "innate" traits a subject for further investigation, it may do the same for "learned" traits.

\section{Birdsong development: Real or imagined results?}

\section{R. E. Lemon}

Biology Department, McGill University, Montreal, Quebec, Canada H3A $1 B 1$

Johnston is right in saying that studies of birdsong development have not clarified the innate-learned argument as much as we would have liked. But I think he is wrong in asserting that there is no point to such an argument. In a sense, this is exactly what geneticists do when trying to determine the importance of genotypic and phenotypic effects.

The "inheritance" of birdsong has been demonstrated to occur in two distinct ways: One way, mainly phenotypic, is through cultural means in which one individual copies another; the second is through "innate" means, as is demonstrated by the fact that the song of an experimental subject is predictably equivalent to a model song, even though that model was not available to the subject when he might have copied it. Johnston may complain about the failure to control for this and that 
variable, but to me the argument and evidence seems clear in its essentials.

Birdsong researchers are not alone in thinking that certain acoustic behaviors are learned or innate, as exemplified by those studying acoustic behavior in other animals, including man. In man, one recognizes that persons of different races and languages have no trouble in acquiring the languages of others, provided that the acquisition occurs in a particular social context and within certain age limits. Yet it is equally clear that major differences occur between Homo sapiens and his closest allies, differences which prevent the latter from ever acquiring speech (Lieberman 1984); even Neanderthal man probably did not speak, judging from the estimated position of the larynx. In this sense, therefore, researchers have claimed "innate" differences between man and the other primate species. Perhaps the beststudied examples of innate acoustic behavior are those in crickets (Teleogryllus) where partial localization of genes has been achieved (Bentley 1971; Bentley \& Hoy 1972).

Yet, the studies on song development have shown serious problems. One has been the confusion of levels of similarity. If one were to say that the song of a species is innate, one might expect to be able to match to a high degree the frequency modulation patterns of models' and isolates' songs, as one does in confirming or denying that copying has occurred. This has not always been the case (see Discussion in Lemon 1975); the details of the song that matched were sometimes more general features of organization rather than the precise and detailed sequence of the sounds.

This failure to distinguish the levels of detailed description has carried over to conceptual levels. There has been a tendency to reify the unspecified processes into an organizing "speciesspecific" template. Again, at a descriptive level such a concept fails to distinguish which parts of the song are considered innate or species-specific - the component sounds, the ways they are organized, or both. The emphasis on differences separating species also fails to consider the similarities, for often the best predictor of the detail and organization of a song in one species is the song of a close relative, as in New World warblers, thrushes, and so on. Does this mean there are generic or family-specific templates as well?

Another problem is what exactly the term "innate" implies. The implication would seem to be that there are genes somehow determining the neural control of the song and still others producing the vocal structures on which these patterns are expressed. This genetic control could extend to details of the motor patterns themselves, as in crickets, or it could be more limited to feature detectors on the sensory side. What we need to identify in birdsong are genes and their alleles, and to my knowledge we have not yet attained that state of the art in birds, although it is much closer in crickets. Indeed, we are unlikely to have this information available in many studies because of the difficulties of breeding birds quickly, as Johnston has noted. A likely success would be small finches.

The two problems of "what is innateness" and "what levels of organization is one addressing" are evident in studies of cardinals (now Cardinalis cardinals) (Dittus \& Lemon 1969; 1970). I believe we neither said nor intend to say that the sounds eventually developed by the birds isolated from nestling stage were in themselves innate in the sense of having precise neural programming. What we concluded, however, was that the sounds that such birds produced were predictable in certain parameters, although for the most part different in precise detail from those of their parents. In other species such as flycatchers (Tyrannidae) (Kroodsma 1984), it would seem equally reasonable that the actual motor pattern of the song components is neurally controlled in an "innate" manner.

In conclusion, birdsong is probably not the best vehicle for studying innate-learned interactions, as Johnston argues. Yet the problem is a valid one that cannot be avoided in such studies. Birdsong research also has the attraction of illustrating a number of features similar to acoustic behavior in other animals and man.

\section{Beyond interactionism: A transactional approach to behavioral development}

\section{David B. Miller}

Department of Psychology and Center for the Ecological Study of Perception and Action, University of Connecticut, Storrs, Conn. 06268

I applaud Johnston's effort in pointing out that the nature/nurture issue is not only alive but has found a happy (but unfortunate) home in the birdsong literature. I agree that the "interactionist" position of Lehrman and others affords a more realistic view of behavioral development. However, most contemporary scientists would probably refer to themselves as "interactionists," including both those who think that some behaviors are innate and some learned and those who attempt to assess how much of a given behavior is genetic and how much is influenced by experience. Interactionism, by its very name, invites dichotomous thinking (i.e., one interactant acting upon another).

An appreciation of the overwhelming complexity of behavioral development necessitates adopting a world-view or metatheory that transcends a relatively simplistic exchange between two interacting components. Specifically, as I (and others) have advocated elsewhere (Miller 1988), development can be better characterized as a transaction. A transactional approach dictates that the organism and its internal (neuroanatomical, physiological, genetic) and external (physical and social contexts) environments form a functional unit. Transactions refer to a continuous exchange of influences among these components. Thus, at all points along the developmental trajectory, the organism is a "new" organism, and the internal and external environments are "new" environments as a function of the transactions occurring throughout development. Since the functional unit of analysis is the "organism-internal environment-external environment," one can neither parcel out individual components as being exclusively responsible for the development of a particular behavior nor assess what percentage of a behavior is influenced by each component (see Hebb, 1953, for a particularly cogent critique of this latter point). Unfortunately, this point of view has not been popular among investigators who have taken an experimental approach to the study of species-typical behavior. As Johnston points out, the birdsong literature remains a hotbed of genetic-deterministic as well as environmental-deterministic thinking.

Rather than being an alternative to Lehrman's $(1953 ; 1970)$ interactionism, this transactional approach is, instead, a metatheoretical shift in emphasis or extension of his views. If one views the organism and its environments (internal and external) as a cohesive action system, the only changes that can occur throughout development are to the system as a whole rather than to isolated constituent elements. In such a system, some components may change more than others at any point in time, but there is a gradient governing the system such that any change in one component, however minute or large, influences other components, thereby altering the system as a whole. Moreover, the system is always in a state of flux, thereby rendering development a continuous process. Thus, as the environment changes, so does the organism, which in turn causes the environment to change again (often in ways too minute for us to assess), as does the organism, and so on.

As Johnston aptly points out, subtle or nonobvious environmental changes can greatly affect the developmental trajectory (see also Gottlieb 1981). Accordingly, the development and 
expression of species-typical behavior (e.g., birdsong) can be influenced by factors not often considered important by experimenters. One such influence, which Johnston mentions, is the influence of context on behavior. Although Kuo (1967) included environmental context as one of five major determining factors of every behavioral act, it is a feature that is often neglected or assumed to be relatively unimportant (particularly in the laboratory study of behavior, where the animal's context is far from species-typical). However, if one were to adopt a transactional approach to the study of species-typical behavior, context becomes a major factor, as it is inseparably related to the developing organism. There are, in fact, at least two contexts that an experimenter or observer needs to be concerned with - developmental context and assessment context. (We sometimes refer to the latter as the testing context or the behavioral context.) Birdsong experiments that use varying degrees of isolation rearing followed by recording songs (or assessing responsiveness to songs) in laboratory enclosures implicitly assume that context is not very important. (The same criticism holds for most laboratory studies of animal learning as well as behavioral development in general.) Yet, in the relatively few studies where investigators have attempted to assess contextual effects (usually social versus asocial rearing or enclosure type), dramatic differences have been found in the development and expression of instinctive behavior (e.g., Blaich \& Miller 1986; Brookhart \& Hock 1976; Hofer \& Shair 1987; McClintock 1987; Smotherman \& Robinson 1986; Vestal \& Schnell 1986; Wallen 1982; Whitney 1986). Only after many years of research on the development of birdsong did investigators realize that social tutoring affects the developmental trajectory of song acquisition differently from the commonly used, convenient method of tape tutoring (as discussed by Johnston). These tutoring experiments illustrate the importance of social context in behavioral development. Little attention has been directed toward assessing the effects of asocial contextual factors on birdsong learning or perception. Such factors encompass those features of the natural habitat of the species under study that are typically missing from laboratory (and sometimes seminatural) settings.

What also remains to be investigated is the interaction between developmental and assessment contexts. For example, the common laboratory practice of moving an animal from a particular developmental context (e. g., rearing or home cage) to a different type of testing context (e. g., open field, Skinner box, preference-testing apparatus, etc.) might greatly affect the expression of species-typical behavior patterns. We have recently found this to be the case with respect to the development of the "freezing" response that mallard ducklings exhibit upon initial exposure to the maternal alarm call (Blaich et al., in press).

In conclusion, Johnston has raised some important red flags regarding the tradition of studying the development of a particular species-typical behavior (which can, in fact, be extended to developmental studies in general). It is hoped that the transactional approach I have outlined, along with a heightened consideration of the importance of context, will stimulate some investigators to reconsider the kinds of developmental questions they are asking and the means by which they are seeking answers.

\section{"Innate": Outdated and inadequate or linguistic convenience?}

\section{Eugene S. Morton}

Department of Zoological Research, National Zoological Park, Smithsonian Institution, Washington, D.C. 20008

Johnston offers constructive criticism of isolation experiments and their interpretation as research pertinent to the development of behavior. But is development the entire focus of the experiments he criticizes? I think not. The general question of how the end product functions, quite apart from a developmental scientist's interest in determining the details of control over the end product's ontogeny, is also important. These details are significant and interesting to learn, but, if focused solely on questions about how birdsong develops, they may or may not be relevant to questions about why the end product is as it is. Indeed, that focus might miss important aspects of ontogeny.

This is because birdsong development may be due to factors not immediately connected with its function or its contribution to individual fitness. This is not unique to birdsong. For example, Lack (1949) refers to habitat selection in an invertebrate, which in nature is found only in fresh waters between certain temperature limits, as follows:

It might be shown, first, that the animal selects its habitat through a direct response to temperature, and second that, under laboratory conditions, it readily survives in temperatures outside these limits. In this case, though temperature is the proximate factor controlling habitat selection, the ultimate factor determining survival is different, perhaps competition for food with another species. A temperature response has evolved because the animal is thereby brought into the habitat where it can survive. (pp. 299-300)

Two things are important: Detailed developmental research may not provide answers to ultimate questions in evolutionary biology and these answers must involve knowledge of function derived from studies of the animals in nature. For these reasons, the concept of "innate" as a linguistic convenience is useful: Research into birdsong function is showing that relative canalization of song development has important evolutionary causes and consequences. Furthermore, the innate versus learned dichotomy, as a linguistic convenience reflecting that canalization, seems to describe what occurs in birds in nature better than does a model that emphasizes gradation. That its use may have caused mischief in studies of development, or has sometimes led to relegating development to a "black box," does not mean that it has no heuristic value in evolutionary biology.

In nature, only a few avian taxonomic groups are described as having learned songs (Nottebohm 1975). Normal song structure is lacking without auditory experience of the adult song in the oscine passerines, whereas in other passerines, such as flycatchers (Kroodsma 1984; 1985) and antbirds (Morton, personal observation), normal song structures develop without such experience. It would be valuable, in the manner that Johnston suggests in sections VI and VII, to study the development of song in more representatives of all passerine families from a variety of climatic, ecological, and social environments. The study of song function is crucial to understanding ultimate causation.

Most earlier studies of song function have concentrated on species-specific coding in oscines (e. g. , Becker 1982). A positive response to a song playback is taken as proof that species-specific information is present. Recent work is showing that variation in response levels is even more informative about the function of song as a long distance signal. It is also more closely allied with modern evolutionary biology, since response variation is discussed at the individual level, at or nearer where natural selection operates, rather than at the species level (Williams 1966).

In developing a hypothesis (the Ranging Hypothesis, Morton 1982) to incorporate variation in responses to song with song function, I stated:

It differs from many recent hypotheses on the significance of bird song and its evolution by incorporating the fact that these signals travel some distance through environments and evolve in populations differing in demographic profile. An analysis of bird song spectrograms cannot incorporate these elements because the data are largely lost in spectrograms. Hypotheses of bird song function and evolution must incorporate all of the natural characteristics of bird songs, including the effects of distance on their physical structure and 
other elements of the acoustic environment in which they function. (Morton 1986, p. 66)

By this I meant that singing is only a part of the analysis of song function because the results of song development have consequences for the same individual as a perceiver of the songs of conspecifics. If the individual has a song stored in memory, it is able to assess acoustic degradation in the incoming signal by matching it with the same song stored in memory. This provides it with an estimate of its distance to the singing conspecific (range). The ability to expend energy efficiently is closely tied to the ability to range in those birds with small body size. These species have a low energy storage capacity relative to their daily energy need: They can starve overnight. It is this class of birds that is said to "learn" long distance signals. I suggested that ranging ability is directly related to the evolution of song learning as exhibited by small oscines and hummingbirds (Morton 1986). It follows that large species of oscines, such as crows, do not use their phylogenetic ability for vocal learning to develop signals with which to defend territories.

This is to say that function is important in birdsong research but it is not without its own pitfalls as a guide to generating hypotheses. Whenever proximate causation is not directly tied to ultimate causation, it might be best to encourage many approaches to research before we relegate some to the outdated and inadequate category.

\section{Conceptual errors, different perspectives, and genetic analysis of song ontogeny}

\author{
Paul C. Mundinger \\ Department of Biology, Queens College, City University of New York, \\ Flushing, N.Y. 11367
}

The "conceptual errors" Johnston assigns to ethology appear to be the outcome of a misalignment of psychological and ethological perspectives. Ethologists are biologists. The gene and evolution are of central interest, as are ultimate as well as proximate questions about behavior and a focus on detailed behavioral description. Interactionists are primarily trained as psychologists for whom the gene and evolution are not as central and who tend primarily to ask proximate, mechanistic questions. Now consider the ethological "error" of focusing on structural analyses and overlooking functional ones. Ethologists do focus on structural analysis. Careful description is a basic component of ethological training. But structural analyses are basic and logical first steps to subsequent comparative or functional analyses. And they do not limit asking functional questions; for example, Johnston cites several functional analyses performed by ethologists (sect. VII.2). So there is no "conceptual error" here; this seems to be a fiction, primarily apparent and of concern to someone who, like Johnston, has a strong functional bias in assessing the structural emphasis of a different scientific tradition.

A more important "error" is Johnston's claim that modern ethology still dichotomizes behavior into innate (=gene determined) and acquired categories. This "error" may not be real either. The two different perspectives may have produced misunderstandings once again, in this instance facilitated by the dual meaning of "innate." The first meaning (11) is used when behavioral differences are attributable to genetic differences. Essentially "innate" then means "genetically determined" (Brown 1975; Lehrman 1970). Comparative behaviorists (interactionists) prefer this meaning (Lehrman 1970), which is best applied to differences appearing in genetic experiments.

The second meaning (I2) is applied to behavior that develops independently of learning from other individuals, such as to the songs of birds raised in isolation experiments. I cannot speak for all ethologists, but it is 12 that I apply to isolate behavior, and I believe it is the one most ethologists use. Johnston, following interactionist tradition, seems to prefer II. He gives 12 only passing reference (sect. II. C.3), while devoting sections II and III to citing many ethologists in ways that make it appear they intended "innate" to mean "genetically determined. "

If this were really so then the charge that modern ethologists categorize behavior as either acquired or genetically determined might hold. But that is not how I interpret their work. Many of the studies cited refer to the innate (I2) songs of acoustic isolates. Then, when considering or discussing the causal factors associated with those innate patterns, ethologists, being biologists, will generally focus on ultimate questions and on genes as a causal factor of special interest, instead of, say, nonobvious factors. By linking 12 to genes in his discussion, an ethologist might seem to equate innate with gene-determined and thereby appear to be supporting the dichotomy. So ethology's "conceptual error" of dichotomizing behavior into innate (gene determined) and acquired also seems to be a fiction arising from the failure of two scientific traditions to fully understand the other's point of view. Lehrman (1970) brought some of this to our attention a generation ago.

Johnston is quite partisan in his presentation of the interactionist agenda. I noted a number of strongly worded statements and predictions very critical of the ethological position while supporting an interactionist one. For example,

(1) Johnston predicts that the ethological approach will prove inadequate for the genetic analysis of song development (see Abstract; also sect. IV, last para.).

(2) He states "Until [we] induce single-gene mutations that affect song development ... our knowledge of genetic contributions to song development must remain virtually nil."

(3) He is almost dogmatic in the contention that the innateness concept is not useful in analyzing behavior development. For example, he says "Lehrman (1953) argued the learned-innate dichotomy was entirely inadequate to the task of analyzing the development of behavior" and later he criticizes Marler and Sherman (1985) for suggesting that finding innate differences in behavior (11) has developmental relevance. I contend that these statements reflect conceptual errors by Johnston, and perhaps of the interactionist school as a whole. Not yet published evidence falsifying these statements, thereby exposing them as errors, comes from a recent genetic analysis of canary song learning (Mundinger, in preparation).

Genetic analysis of canary song learning. This breeding experiment focused on song-learning predispositions, but other developmentally relevant data were collected. The canary was chosen because inbred strains exist; some (e. g., the roller strain) have been selected for their song patterns for perhaps 200 years. Other strains (border canaries) have not been selected for song. The experimental design, based on the isolation experiment, was similar to the hypothetical one in Johnston's Figure 2. There were four genetic treatments: pure roller (RR), pure border (BB), and the two reciprocal cross hybrids (RB \& BR). There were two environmental treatments: untutored isolates and tutored (providing equal exposure to a roller and a border song pattern). The results reveal clear, statistically significant behavioral differences among the genetic lines. All four tutored borders learned only from the border tutor; all three tutored rollers learned only from the roller tutor; all four BR and RB hybrids learned from both tutors. Figure $1 B_{\text {- }}$ D provides some examples of this differential imitation. The conclusion reached was that differences in song-learning predispositions are due to genetic differences between the strains. In the language used here and in the article, differences in roller and border songlearning predispositions are I1, or "genetically determined."

This experiment was based on the standard ethological isolation experiment and no single-gene mutations were identified. Yet the experiment represents a useful first step in the genetic 


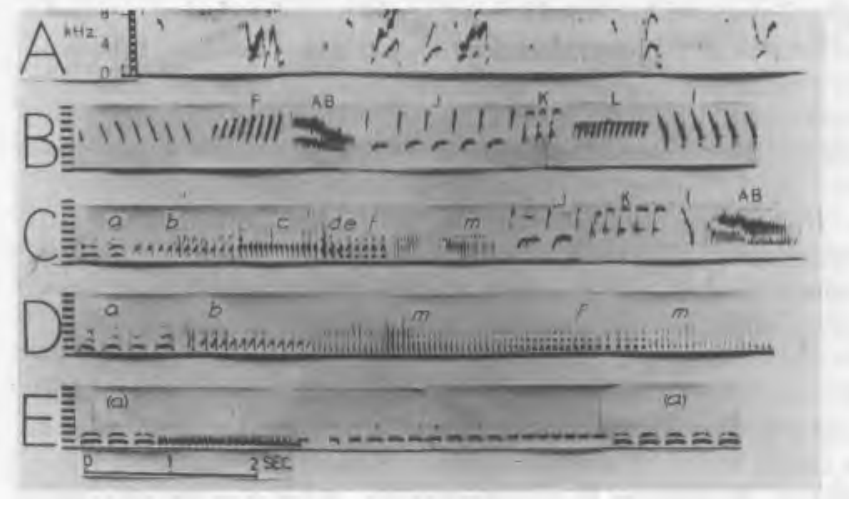

Figure 1 (Mundinger). Representative songs of different canary strains. A, untutored border; B, tutored border; C, tutored roller X border hybrid; D, tutored roller; E, untutored roller. Upper-case letters refer to border tutor imitations; lower-case letters refer to roller tutor imitations; letter (a) in parentheses refers to a roller-tutor-like tour that developed independent of tutoring.

analysis of song development. For the first time in the analysis of song development, ethology went from the isolation experiment to one embedded in a genetic experiment. Furthermore, the project uncovered detailed strain differences involving the motor side of song development (e.g., rollers go through song ontogeny much faster than borders, with hybrids intermediate). So the first two of Johnston's predictions and statements are falsified.

Now I turn to innate behavioral patterns, to an innateacquired classification, and to whether or not they have any relevance to the analysis of behavior development. Figure IA and $1 \mathrm{E}$ are the $\mathrm{I} 1$ song patterns of an untutored border and roller, respectively. They are representative and reveal that the innate songs of borders are structurally abnormal. These isolate songs are not organized into tours, and they do not sound like canary songs. A comparison between the songs of tutored and untutored borders shows clearly that border canaries require tutor experience to develop normal song organization. In contrast, the 12 songs of the isolate rollers were, like those of the tutored rollers, organized into tours (Fig. 1D\&E) and sounded somewhat normal. But the tours were generally not composed of syllables resembling those in the roller tutor, with an occasional exception such as syllable type (a) in Figure 1E. Tour (a) is flute-like in quality and roller breeders have, for over a century, bred for long, tour-dominated songs that include such flute-like tours.

Thus it seems that modern roller canaries have a genetic constitution that results in long, tour-dominated, 12 song patterns, and on occasion, some individual rollers will develop flute-like tours independent of tutoring. These genetic breeding results show that roller and border developmental programs differ and that differences in their song development programs are II. These innate differences involve differences in songlearning predispositions, differences in rate and timing of motor development, differences in their respective subsong stages, differences in tour organization, and differences in the structure of 12 syllable patterns. These are all developmentally relevant findings.

Therefore statement 3 (above) is incorrect as both 12 and acquired categories (used when comparing song patterns of tutored and untutored birds), and the concept of innate differences in behavior (used in examining strain differences in 12 song structure) were needed to discover some of those developmentally relevant results. Furthermore, the discovery of I1 differences in canary song structure and in song development programs may in the future be used to search for those proposed single-gene mutations affecting song development.

This commentary is not a criticism of the interactionist perspective, which is an important one. To understand birdsong development we benefit by having the subject studied by scientists trained in different traditions, with differing intellectual perspectives, different questions posed, and different experimental techniques employed. But we also need mutual understanding and a clear channel of communication. Johnston's target article is beneficial in that he has articulated the interactionist perspective clearly, and perhaps it will stimulate ethologists to choose their words more carefully and to expand their research horizons. Where he seems to have erred is in being too partisan and in not fully appreciating and understanding the ethological perspective.

\section{How do you transmit a template?}

\section{Susan Oyama}

Department of Psychology, John Jay College, City University of New York, New York, N.Y. 10019

Johnston's analysis clearly demonstrates the ways in which the nature/nurture opposition, frequently declared to be obsolete, continues to inform basic assumptions, methods, and interpretations in a highly influential field. Work in this area has reflected its major figures' insistence on distinguishing, in some way or other, between innate and acquired components of phenotypes. The target article shows forcefully the consequences of formulating a research question in terms of the nature/nurture dichotomy; it reveals the intimate links between theoretical framework, design, and explanation. Indeed, it helps us understand why, in the face of constant disclaimers, methodological clarifications, and cautionary notes, the nature/nurture dichotomy (or continuum, as its liberal proponents would have it) lives on.

If Johnston's message is taken to heart, it will be a good thing, not only for students of birdsong, but for all those others who look to birdsong studies for models and kinds of explanations. I remember very well how salient the imprinting and birdsong literatures were for students of language in the 1960s and 1970s. Anyone who had been the least bit impressed by Chomsky's (1959) critique of Skinner's (1957) Verbal behavior was on the lookout for a "biological perspective" on language. Penfield and Roberts's volume had appeared the same year (1959), and later, Lenneberg's book, Biological foundations of language (1967), was seen as giving definitive biological support to the claim that language was innate. Lenneberg's thinking on "biological bases" became progressively more subtle as time went by, and ultimately he grew quite unhappy with the way the notion of critical periods was being used by students of language development (Oyama 1978). But templates and imprinting were irresistible. Images of experience being trimmed to fit genetically ordained outlines or of shutters opening and snapping shut on the sensory world were too attractive to pass up. To be an courant was to be a nativist, and the ethologists and other biologists were showing us how.

A look at some papers from a relatively recent volume on human language acquisition (Wanner \& Gleitman 1982) shows the continuing pervasiveness of these ideas. There is a strong presumption of innateness in the collection. Goldin-Meadow (1982, p. 51) cites (among others) Lenneberg on critical periods, Marler on birdsong, and Mayr on open and closed programs, arguing for "resilient" ("prepared" or "closed") properties of language. Shatz (1982) adopts the increasingly popular language of internal constraints (though she also speaks of programs); the primary problem in acquisition studies, she says, is the assign- 
ing of "the primary burden of development" to internal or external control. Although she believes both are involved, "the issue is still how and how much each contributes" (p. 108).

The birdsong literature is obviously not responsible for the nature/nurture dichotomy in studies of human language. Both draw on a very old tradition of thought. Two things are noteworthy, though. One is the similarity of the intellectual strategies used in both research traditions (infer innateness from deprivation cases, pit insides against outsides, quantify causal contributions of genes and environment to the phenotype, and, conversely, partition phenotypes according to the kind of cause that supposedly formed them). The other is psychologists' and linguists' use of biologists' accounts to justify nativist arguments. The authority of biology is used to legitimate just the dichotomous views that need criticism. Like the reverberating circuit between theory and evidence, this sort of cross-reference among fields helps shaky concepts to transcend their weaknesses and become deeply entrenched through sheer reiteration.

Running through all nature/nurture literature is the metaphor of transmission. Transmission by genetic means is contrasted with cultural transmission; maturation and learning are the alternative "mechanisms." The induction favored by psycholinguists accords the young human a greater role than the imitation and conditioning that exhaust many conceptions of learning, but both maturation and learning, however misguided their conventional meanings, are developmental processes, and development is just what the transmission metaphor denies (Oyama 1988c; in press). The language acquisition field's focus on cognitively active children is a kind of antidote to the old child-as-sponge view, but it does not succeed in overcoming the weaknesses of the dual-transmission framework. [ See also Lightfoot: "The Child's Trigger Experience" $B B S$, forthcoming.]

Leaving aside the question of just what a template could be, we may wonder how such a thing (or a grammar, or a language acquisition device, or any other feature) can be transmitted in the genes. Or, alternatively, how can it be transmitted socially? How can it be transmitted at all, if by transmission one means the conveyance or delivery of an object or message, rather than its ontogenetic construction? And, if we are less literal-minded and use the word to refer only to the reliable outcomes of development, we are assuming the formative processes, not identifying or explaining them. Nor is it possible to distinguish two kinds of process, one in which the genes are more important and one in which they are less important. Finally, if "transmission" is reserved for variation attributable to genetic or environmental variation, it is properly applied to populations, not phenotypes. We find ourselves in just the muddle over differences and characters that Johnston describes in his section IV.

Bever's chapter in the Wanner and Gleitman (1982) volume points out that both nativists and empiricists claim that the other side's mechanism cannot possibly explain language; one's own position is declared valid by default. "We must rely either on as yet inconceivably complex genetic mechanisms of behavioral

I transmission or on an inconceivably delicate and sensitive inductive system of learning" (p. 432). Following Katz, he suggests a retreat from the perplexities of the phenotype - away from language acquisition and use, to a view of language as uncaused Platonic reality.

I think Bever is right to scrutinize some of the assumptions underlying nativist and empiricist views of language. My own preference would be to take another look at development before turning my eyes to the realm of uncaused forms. The interactionist perspective described by Johnston offers us a way of taking that look without having to fit what we see to the dualtransmission model.

\section{Nature/nurture reflux}

\section{Irene M. Pepperberg}

Department of Anthropology, Northwestern University, Evanston, III. 60208

Johnston's target article brought to mind the chemical reflux experiments of undergraduate days when we would endlessly boil and reboil the voluminous products of a synthesis. We would eventually distill a few mls of pure sample, the "experimental essence." This endproduct, a well-known material, could also be obtained in large quantity from lab supplies, and repetition of the distillation process, once it had been mastered, did little to further our education.

Johnston's paper boils down to two admonitions: that careless use of nature/nurture terminology can lead to careless interpretation of results and that research merely for the purpose of attributing behaviors to "a particular cause (genes or environment)" may obscure more fruitful lines of investigation. These admonitions are already well known (see Bateson 1984; Schleidt 1985; West \& King 1985a). I agree with Johnston's aim of stimulating further research on developmental questions, particularly with respect to the stage of development at which such investigations should begin. I do not agree that yet another discussion of the nature/nurture dichotomy is necessary to effect significant changes in experimental design, nor that labeling a behavior "innate" has specifically prevented important further research from taking place.

Johnston targets areas in the study of birdsong that he feels have been ignored or performed poorly because of adherence to the innate versus learned dichotomy. He believes, rightly, that much can be learned by examining different or more basic developmental stages. But one need not first discredit the concept of innate versus learned in order to suggest that what is "innate" might be more basic than was originally thought - e. g. , an innate blueprint for neurons that respond only to a specific call rate, rather than to a species-specific call. And although birdsong researchers do indeed use terms such as "innate" when they should instead state that the role of learning in one system is relatively small compared with that in another, I doubt that anyone studying song would refuse to do the experiments Johnston suggests because a behavior has already been labeled "innate."

It wasn't the acceptance of an innate template, for example, that prevented studies on the effects of social interaction on song acquisition prior to the recent work cited by Johnston. The effects of social interaction were ignored because many researchers, not yet understanding either what young birds actually experienced in the field or the effects of a sterile environment on an animal's behavior, blithely adopted (rather than adapted) the conditions of the psychology lab in an attempt to establish experimental rigor (see discussions in Kroodsma 1985a; Pepperberg 1988; West \& King 1985b). Even so, some researchers did perform finer-grained examinations of behaviors that had already been designated "innate." For example, despite the (then) generally accepted idea that song sparrows (Melospiza melodia) produced "basically normal" songs without experience (i.e., had an innate program for conspecific song; Konishi \& Nottebohm 1969; Mulligan 1966), Kroodsma (1977) cross-fostered song sparrows with canaries and found that the juvenile sparrows produced abnormal conspecific songs and replicated some song characteristics of their foster parents. Similarly, Waser and Marler (1977) examined the effects of social interaction on song learning in another bird thought to have an "innate template," the roller canary.

The point of the above examples is that careful researchers recognize that the problems Johnston (mis)attributes to a desire to partition behavior into innate and learned components are instead caused by (1) premature conclusions drawn from experi- 
ments that misapply techniques from other fields (both in design and scope) and (2) our continuing ignorance of the complex interactions that actually occur between birds (young-old, female-female, male-male, male-female) in nature. Many experiments have not yet been done because researchers recognize these pitfalls and cannot yet see how they can be avoided. Johnston does recognize the technical difficulties that prevent certain experiments from being performed: for example, that genetic manipulation cannot yet contribute to the study of birdsong. Unfortunately, our ability to perform the other experiments he proposes is also limited, because they require careful adaptation of procedures from other fields as well as assays solidly based on the detailed behavioral ecology of the subject (note Kamil 1984).

I am sensitive to the issues Johnston raises: I have proposed (although not in print) some of the same experiments that Johnston suggests. My colleagues have patiently explained why such experiments haven't yet been done or they have described their attempts to design or perform these experiments. Thus, although there is agreement that the effects of prenatal hearing should be part of a comparative study on song development, few labs are equipped for such an undertaking. To perform these experiments correctly, one must raise birds from eggs both in total isolation and with many forms of auditory stimulation; for example, one must not only play tapes of allospecific calls and songs but also find a different species capable of cross-fostering to examine the effects of allospecific social interaction as well as vocalization. Controls must be run using devocalized conspecific and allospecific parents to examine effects of nonvocal interaction. Experiments must also be performed with birds that are deafened both pre- and postnatally to examine the effects of self-stimulation. But passerines, unlike mallards, are not easily raised in the laboratory from eggs, and I doubt that prenatal deafening of these birds is yet a viable technique. Many of these experiments might elicit objections from animal care committees. Nevertheless, these are important experiments if we are to understand all the environmental aspects that influence vocal development. In a similar vein, Johnston proposes examining the functional normality of songs and singing behavior of tape-tutored males. Such experiments require appropriate male and female assays of potency of male song - but the quality of current assays and the conditions under which they are valid are still not clear (e.g., Rothstein et al. 1988; Searcy \& Marler 1981; West et al. 1981b).

A new (or resurrected) paradigm is not necessary to energize research into developmental issues. Important discoveries will be made by those who carefully adapt techniques from other fields and design exacting experiments, not by those who argue over the definition of "innate." Bateson (1984), for example, already defined the difference between "unlearned," "genetically inherited," and "phylogenetically adapted" behaviors; he also stressed that behavior patterns that were first expressed without learning could be modified by later learning. Ethologists like Tinbergen succeeded because they were committed to discovering the most basic, underlying reasons for a behavior. By exhaustively examining and describing a behavior in nature, continuously questioning the reasons for its existence, and designing new techniques to answer these questions, they made the kinds of discoveries that Johnston desires. And this form of science is still in existence: At a recent ornithological meeting (American Ornithologists' Union, August 1987), many of the topics that Johnston proposes for study were indeed the subjects of the papers presented.

Had Johnston's theme simply been that birdsong researchers ought to improve their techniques (e.g., Kroodsma 1987) and learn to integrate their field experiences with detailed knowledge of endocrinology, neurophysiology, neuroanatomy, social psychology, nonverbal linguistics, and so on, I would have unhesitantly cheered. I do believe that that was the essence of his paper - but I regretted having to perform the distillation.

\section{ACKNOWLEDGMENTS}

Preparation of this commentary was supported by NSF grant BNS 86-16955. I am indebted to Roger Milkman for the title.

\section{In defense of innateness and of its critics}

\author{
Jonathan Schull \\ Department of Psychology, Haverford College, Haverford, Pa. 19041
}

Although Johnston's intention is to show that the concept of innateness is incoherent, his Figure 2 only demonstrates (with considerable elegance) that "innate" does not mean "heritable." There are many other things "innate" does not mean, and Johnston demonstrates that the concept continues to cause confusion and to occlude worthwhile research questions. But he does not get at the source of the trouble: We need a concept that means "not learned" (approximately; see below) yet we also need to (1) dissociate it from other attributes which do not necessarily go along with innateness ("heritable," "evolved," "developmentally fixed," "present at birth," etc.) and (2) discard other connotations which are now bankrupt and incoherent if compellingly seductive ("in the genes," "independent of experience," etc.).

"Innate" does not mean "due to genotypic differences." Everyone agrees that when two genotypes give rise to phenotypic differences these are validly attributed to the genotypic differences. Unfortunately, the concept of innateness has been yoked to this formulation by commentators as diverse as Lehrman (1970) and Johnston on the one hand, and Mader and Sherman (1985) on the other. Thus, Johnston allows that "we may describe the behavioral differences as innate," whereas Marler and Sherman even assert that the "crucial point for ethologists to appreciate ... is that . . . the appropriate application of the term [. . . innate is not to characteristics of organisms but to .. .] differences between organisms" (p. 57; italic in original).

Although all these writers seem to hold that "innate" is a synonym for "due to genotypic differences," we usually bring an entirely different kind of evidence to bear upon the conclusion that a trait (or a difference) is innate: The trait (or difference) must arise in an environment in which it could not have been learned. So, for example, Marler and Sherman write that "the most striking result of this experiment [comparing song sparrows with swamp sparrows] is the large number of song differences that persist in birds of the two species when they are reared in isolation from adult conspecific song. We conclude that many of the differences between normal swamp and song sparrow songs are innate, developing as a consequence of genotypic differences between the two species" (p. 68). The validity of this conclusion stems not from the fact that it is applied to differences, but that it is applied to animals reared in isolation from all plausible models.

Showing that behavioral differences are due to genetic differences is neither sufficient nor necessary to demonstrate that the behavioral differences are innate. Suppose individuals of species $\mathrm{X}$ and of species $\mathrm{Y}$ are exposed to $\mathrm{Y}$ 's normal song. $\mathrm{Y}$ individuals learn their normal song, whereas $X$ individuals learn nothing and acquire only a crude song. The "behavioral-differences-due-to-genotypic-differences" formulation would have us conclude that the difference between normal and crude song is innate, even though it is clear that the difference is due to learning and that the normal song is learned. Similarly, suppose neither species is exposed to normal song, and both species 
develop identical, crude songs. Since there is no difference, the "differences-are-innate" formulation must fail to draw the right conclusion - that the crude song (or the pattern-generating process which gives rise to it; see below) is innate in both species.

This is not to deny the value of demonstrating that behavioral differences are due to genetic differences. Such a demonstration indicates that the behavioral differences are heritable and could have been, or could be, naturally selected. But those (I urge) are different questions. Conversely, although the demonstration that a behavior pattern can develop in the absence of an environmental model may establish the innateness of the pattern, the example demonstrates that this need not mean "developmentally fixed," "present from birth," and so on. These too, are different and eminently investigatable questions. Thus, if we dissociate "innateness" from other characteristics which may or may not be associated with it, the conclusion that a behavioral pattern is innate should open (rather than foreclose) further investigation. Indeed, I suggest below that a whole other type of investigation and explanation is mandated for innate behavioral patterns. Learned patterns are copied. "Innate" patterns, ultimately, are generated.

Explanations of complex patterns are of two distinct (but not incompatible) types. The first type of explanation shows how a complex pattern arises through the interaction of processes which do not themselves contain the pattern. For example, it has been suggested that relatively simple processes of reactiondiffusion could give rise to complex patterns of pigmentation in animal fur (Murray 1988). This may explain how zebras get their stripes. The second type of explanation shows how a complex pattern is derived from a preexisting isomorphic pattern that has been "captured" by some kind of a copying mechanism. For example, my skin could be sunburned in stripes if I fell asleep in the shadow of a venetian blind. Applying this distinction to birdsong, Johnston's "nonobvious experiential contributions to song development" inform explanations of the pattern-generating type; learning processes by which behaviors acquire the patterning of environmental patterns (such as conspecific songs or contingencies of reinforcement) inform explanations of the copying type.

This distinction allows a refinement of the definition of "innate": Behavioral patterns are innate if they are not copied from the environment (thus, neither learned patterns nor unlearnedbut-copied patterns like striped suntans are innate). More important, the failure to recognize the distinction is arguably responsible for much of the confusion and controversy regarding innate characteristics.

For one thing, the demonstration that a behavior pattern is innate often leads to the spurious conclusion that the environment does not contribute to the pattern. This is necessarily false because the environment interacts with the organism to produce every organismic trait, innate or acquired; in the case of innate behaviors, however, the environment does this via pattern-generation processes. Another source of confusion is that our facility with pattern-copying accounts can lead to spurious explanations of innate patterns. Consider the case in which species-typical song characteristics develop in an environment which provides no opportunity for learning - either (1) the pattern was created rather than copied or (2) the pattern was copied from a pattern elsewhere within the organism (e.g., a sensory template). Contrary to Johnston, I see nothing wrong with this hypothesis, which is supported by the observation that deafening prevents the development of normal innate song (putatively by preventing the bird from learning how to sing songs which fit the sensory template).

However, researchers will inevitably be led astray if they think that copying-type explanations can be extended "all the way down" to the genome, since genes do not in any meaningful sense contain, represent, or encode the innate behavioral patterns they make possible. Genes encode sequences of amino acids. Sequences of amino acids make sequences of behavior possible, but the latter are in no sense copies of the former, not even copies many times removed. Rather, genes somehow enable an organism to interact with its environment to generate an innate pattern. Behavioral scientists haven't a prayer of discovering how this occurs unless they recognize that explanations of the noncopying-type must be sought and that all explanations are bankrupt which presume that patterns of behavior, aspects of behavior, or even differences in behavior are represented "in the genes," or in a genetic "blueprint." If they do recognize the need for the pattern-generation type of explanation they will be better prepared to manipulate genetic, physiological, and environmental variables in order to identify critical organism-environment interactions.

This then is the significance of innateness. To the extent that an organismic pattern is innate it is (a) not explicable in terms of a copying process from the environment and therefore (b) must ultimately be explained in terms of pattern-generation rather than pattern-copying. To the extent that an organismic pattern is learned, (a) its provenance is to be found in the environment and (b) explanation in pattern-generation terms may or may not be necessary. (Even if a pattern was learned from an environmental model, we will often want to know how the pattern is regenerated by the nervous system during - playback.") In either case, however, the pattern is inevitably due to interactions of a developing organism with an environment, and these interactions are made possible by the organism's genome. Investigating these interactions is a good thing but does not require that we abandon the notion of innateness.

\section{AKNOWLEDGMENTS}

I thank Sidney I. Perloe, David Smith, Beatrice Wood, and the students of my animal behavior class for their discussion and criticism of the ideas which went into, or out of, this commentary.

\section{Song development from evolutionary and ecological perspectives}

William A. Searcy

Department of Biological Sciences and Pymatuning Laboratory of Ecology, University of Pittsburgh, Pittsburgh, Pa. 15260

Johnston's criticisms of work on song development in birds can be divided into two categories: He suggests, first, that this work has relied on an outmoded theoretical formulation, the innate versus learned dichotomy, and second, that researchers in this area have used uninteresting and unproductive research designs while ignoring better ones. Without conceding the first criticism, I will concentrate on the second, which I regard as more fundamental.

It should hardly be necessary to point out that judgments about what is and is not interesting may vary between scientific disciplines. Most workers on song development come from the discipline of ethology, which has traditionally placed great emphasis on the evolution of behavior, especially in terms of elucidating the selective costs and benefits of behavior in ecological settings (Hinde 1982; Tinbergen 1951). Thus, although workers in song development must necessarily have some interest in proximate mechanisms of development, their interests are likely to go beyond this to include ultimate questions about the evolution of song and song development. It is in this context that we need to evaluate the form taken by song development studies.

Among research designs that have been used commonly, 
Johnston is most critical of isolation experiments, in which young birds are reared in conditions that prevent them from hearing songs during their critical learning period and the songs developed by these isolates are compared with songs of control birds reared with exposure to song from recordings or live tutors. Johnston complains that this design "offers only a rather crude analysis of the contribution of experience to song development and provides no information at all about genetic contributions to development." However, from an evolutionary perspective, this experiment does seem a logical first step in analysis, since its results will indicate the extent to which observed variations in song are the product of imitation. Features incorporated due to imitation of conspecifics may be classified as cultural traits; in fact, it would be terminologically more correct (if less euphonious) to refer to a nonculturalcultural dichotomy in place of the "innate-learned" dichotomy. This noncultural-cultural dichotomy is of special importance from an evolutionary perspective in that the forces that cause culture to evolve, although they are not well understood, are certainly different from those causing genetic evolution (CavalliSforza \& Feldman 1981). Another positive feature of the isolation experiments is that, because this one type of experiment has been repeated many times with different species (though the methods are not as standardized as one would like), phylogenetic trends of great interest are starting to emerge concerning the relative importance of imitation in different taxa (Kroodsma 1982).

Johnston also criticizes studies of differences between songs developed by individuals of different genotypes raised in identical environments. He states that "comparing the songs of, say, swamp and song sparrows reared under identical conditions (Marler \& Sherman 1983; 1985) cannot reveal any of the detail that we need in order to understand how genes contribute to development." Perhaps, but again this design does give us information of evolutionary interest: It tells us which differences between the two species' songs are not due to imitation and must therefore be attributed to genetic rather than cultural evolution.

The areas that Johnston claims have been neglected because of a failure to adopt an interactionist viewpoint include fine-level genetic differences, nonobvious experiential contributions, and functional outcomes. The absence of studies of fine-level genetic differences can be ascribed to the unavailability of the necessary tools (such as single gene mutations affecting song), as Johnston admits. However, I would add that such studies would strike many ethologists as uninteresting anyway; if we know that a feature is under genetic control, then it will almost certainly evolve due to natural selection, no matter how the genetic control is realized.

Among factors that might make nonobvious experiential contributions, Johnston lists social context; calls produced by parents, siblings, or the subjects themselves; nonvocal stimulation; and song heard prenatally or in early postnatal life. Johnston admits that the first of these has been extensively studied. The reason that ethologists have focused on effects of social context is that this bears on a number of important evolutionary and ecological questions. For example, the question of whether social stimulation affects the length of the critical learning period is tightly tied to the problem of the origin and significance of dialects (Baker \& Cunningham 1985; Baptista \& Petrinovich 1984; Marler \& Tamura 1962). In addition, the effect of social relationships on choice of song models by the male has major implications for how the song can be used in mate choice by the female (e.g., McGregor \& Krebs 1982; Millington \& Price 1985). The other factors listed by Johnston have certainly been relatively, though not entirely, neglected, undoubtedly because they do not have such obvious evolutionary implications. Further work on any of these factors should certainly be encouraged.
The final area that Johnston claims has been neglected in song development concerns functional outcomes: the question of how experimentally induced alterations in song development affect the function of song in communication. To me, this question seems to flow more logically from the evolutionary and ecological interests of the ethologists than from an interactionist viewpoint. A recent comprehensive review of song learning called for just this type of study (Kroodsma 1982), and systematic experiments along these lines antedate this call (King \& West 1977; West et al. 1981a) and have continued to be performed (Searcy et al. 1985; Searcy \& Marler 1987, Spitler-Nabors \& Baker 1987). Much more work certainly remains to be done in this area, but its importance has already been realized.

Progress in any scientific discipline can hardly be expected to be optimal, depending as it does on decisions made by many researchers working independently, each with an agenda. Nevertheless, I believe the overall trend of research in birdsong development can be fully justified; given the interests of the workers involved, the most productive research designs have been used, and no better ones have been neglected.

\section{The nature and nurture of birdsong}

\section{P. J. B. Slater}

Department of Biology \& Preclinical Medicine, University of St. Andrews, Fife KY16 9TS, United Kingdom

Johnston's target article is a timely one, although his case is somewhat overstated. There is hardly the widespread reversion to thinking in terms of a learning/instinct dichotomy amongst those working on song development that he claims. However, Peter Marler, who is justifiably regarded as the leading figure in this field, together with some of his co-workers and students, certainly does use some of the terminology of that earlier era (e.g. Marler \& Sherman 1985). It is to his group that most of Johnston's quotes are attributable. Most others who study song development at least claim to espouse a more interactionist viewpoint, though their wording may suffer from the occasional lapse and some of their experiments may ask inappropriate questions.

I agree totally with Johnston's distaste for such expressions as "preordained," "blueprinted," or "genetically controlled." It is hard to imagine anyone imprinted on the writings of Danny Lehrman during the sensitive phase of their early ethological upbringing who would think otherwise. There is nothing new in Johnston's argument here. What is new, and surprising, is that it should be necessary to reiterate it so soon after the nature/nurture controversy seemed dead and buried. The oddest sign of this is the fact that the word "innate," having all but disappeared from the ethological dictionary during the 1970s, is making something of a comeback. Its problem is rather different from that of the other expressions referred to above, for the very word is ambiguous and unclear in meaning. Is it implied that the behaviour is "genetically determined," or is it simply "present in the newborn animal," as a more literal interpretation might imply? Is it totally "unaffected by environmental influences" or just "unlearnt" or, more precisely still, is it "developed without copying from others"? Perhaps innate behavior is that which "appears in its typical adapted form the first time an animal of suitable age is faced with the correct situation" as Ewer (1971) would have had us agree. The word innate simply has too many possible meanings to be other than confusing, especially when different authors use it, without definition, in different ways. Amongst those studying song development I doubt if many of its adherents wish to imply genetic determination. Most who use the word probably mean that the song develops without copying from others: for example, this certainly seems to be its meaning 
in Kroodsma's (1984) title. But it would have been better had he said just that and avoided both the ambiguities and the possible accusation of genetic determinism altogether.

Yet, even here, we must be cautious. Although it is impressive that the flycatchers Kroodsma raised sang their own species-specific songs despite hearing only that of another species while in his care, the young birds were 7-10 days old when taken from the nest. There is no evidence to date that songbirds (oscines) can learn as nestlings, but these Tyrannid flycatchers are suboscines and may well differ in this respect. The fact that the young birds produced songs which were recognizably those of their own species as early as 15 days of age certainly shows that its development is exceptionally rapid: Experience of the species-specific song in the first few days of life (or even earlier) could well be crucial. It is thus a strong claim to call their song innate, even if all this is meant to imply is that it is not copied from others.

Whether, as Johnston argues, these problems over phrasing reflect outdated thinking which has closed the eyes of those studying song development to worthwhile questions I find it hard to judge. As the target article makes clear, Marler himself has done some very impressive and interesting studies in recent years, and work is already in progress in his laboratory and elsewhere along several of the lines that Johnston recommends. In particular, the growing literature on social influences on song learning and on the timing of sensitive phases (e.g., King \& West 1983; Petrinovich \& Baptista 1987; Slater et al. 1988) has an impeccably interactionist pedigree. By contrast, only a small minority of the papers on song development currently being published profess the aim of investigating the extent to which it is under genetic or environmental control.

\section{The nature/nurture debate: Same old wolf in new sheep's clothing?}

\section{Horst D. Steklis}

Department of Anthropology, Rutgers University, New Brunswick, N.J. 08903

There are compelling reasons in addition to those addressed in Johnston's target article for a renewed broadscale attack on the nature/nurture problem (see especially Oyama 1985). Many have declared that debate "dead," settling for a comfortable "interactionism" that seems to threaten neither innatist nor environmentalist, with neither camp emerging the winner or the loser of the classic debate. As a result, we have a new vocabulary to describe the interplay of innate and learned components of behavior, one that appears to satisfy both biologist and social scientist. Examples of this new interactionist language abound. Consider the following terms: "prepotent," "predisposition," and "potential." These are frequently used to +describe behaviors whose expression is codetermined by significant biological factors (implicitly genes) as well as early experience (such as postnatal learning in mammals). In their choice of popular book titles, some wax more metaphorical but speak the same interactionist language: The whisperings within (Barash, 1979); The tangled wing (Konner 1982). Although it allays deep fears of "determinism" and "reductionism" (two "no's" in the current behavioral science community), the new vocabulary rarely elucidates mechanisms of behavior. The terminology and metaphors are poor substitutes for specifying the genetic, hormonal, neural, and experiential factors that govern the development and expression of behavior. More often than not, the language betrays our ignorance of these factors.

I am unconvinced, however, that the less simplistic kind of interactionism proposed by Johnston (cf. Lehrman 1970) is sufficient to lay to rest the nature/nurture dichotomy. Even at its very best, as in Johnston's analysis of birdsong development, an interactionist position may validate the very dichotomy it tries to avoid. According to Johnston, the interactionist position considers "all behavior to arise in development from interactions within and between the organism and its environment." This sounds prima facie reasonable, but it quickly raises questions as to the identity of the interacting factors. Most (perhaps all) of these factors (such as "the organism" at a point in time) are merely endstates reached as a consequence of previous interactions among endstates (e.g., the onset of endocrine functioning, axonal sprouting), and so on. It is not clear what is gained from interactionism, since all life processes can be reduced to a (seemingly infinite) series of interactions of structure-function units. To avoid this problem of infinite regress, we may select particular endstates (or factors) for experiment and discussion, for example, genes and the cellular-organismic environment or the "organism and its environment." When we now proceed to unravel the relative contribution of any such set of dichotomous factors to some further structural-functional endstate, we may (because of the dichotomy imposed by interactionism) commit the same analytical errors inherent in the original nature/nurture dichotomy.

In speaking of the contribution of genes to behavior, Johnston suggests "modern developmental genetics . . . provides no support for the alternative view that some elements of behavior can be described as 'genetically determined,' that is, specified by the genes alone." Strictly speaking, the idea that genes (or any other part of the organism) cannot act alone is a mere truism. When used in this narrow sense, "determinism" loses all meaning. However, "determine" also means "cause" or "induce," and in this sense genes may well determine at least some aspects or types of behavior. This is particularly the case where the linkage between gene activity and neurobehavioral function is a close one.

The egg laying behavior of the marine snail Aplysia (Scheller et al. 1983) is a good example. This behavior pattern consists of an elaborate but stereotypical set of coordinated muscular contractions, glandular secretions, and other autonomic changes. These are reducible to the neural and systemic effects of several peptides transcribed from three genes. It is hard to see why in this case the genes cannot be said to "cause" the behavioral pattern. Such deterministic influences on behavior should not be ruled out in principle in more complex organisms either. We accept that possibility in cases of pathology, such as Huntington's disease. Why not also for the regulation of (at least aspects of normal behavior patterns, such as reproduction (e.g., Pfaff 1980), where genetic-hormonal-neural links are being established? It is only strict adherence to an interactionist position that, on the basis of principle, robs genes (or other factors) of deterministic qualities.

A final example further illustrates the potential pitfalls of interactionism. Johnston asserts that persistent differences in behavior between groups of animals reared in identical environments "allows one to say only that the behavioral differences can be attributed to genetic differences between the groups." This conclusion seems no better than one reached from a deprivation experiment by a good Lorenzian. I am sure Johnston will agree that many factors other than genetic ones (e.g., prenatal nutrition, hormones, sensory stimulation) can account for persistent differences between animals reared in identical environments.

My point here is not so much to show where I disagree with Johnston, for I agree with most of what he says, but rather to advocate a more extreme position than does Johnston in favor of identifying mechanisms of behavior. As I have tried to indicate, there is a weak kind of interactionism that does no more than pay lip service to the contribution of so-called innate and environmental factors to behavior. A stronger type, one that addresses mechanisms of behavior and its development, for all its merit, seems nonetheless potentially hamstrung by its strict adherence 
to interactionist philosophy. My own sense is that the most gains could be made in understanding the origins of behavior if we simply focused on mechanisms (e.g., genetic, biochemical, physiological, ecological) at appropriate levels of analysis (e.g., organismic, interorganismic). If in this scheme we read "interactions" among factors to be "influences," then determinism, as in embryonic induction, for example, is a type of influence. Other types of influences on neurobehavioral development are described by Gottlieb (1976). We should be able to forge ahead unconcerned about the "sins" of "isms" (reductionism, determinism) that are of great social and moral, but little scientific, significance.

\section{Interactionism is good, but not good enough}

\section{Esther Thelen}

Department of Psychology, Indiana University, Bloomington, Ind. 47405

The Lehrman-Johnston program of empirical interactionism goes a long way toward broadening the scope of inquiry into developmental processes. Their position eschews the simple learned-innate dichotomy and underscores the multidetermined and functional aspects of ontogeny. Johnston calls for a developmental analysis "to determine which elements interact in what ways to give rise to particular aspects of the phenotype."

We need to know the developmental story, as Johnston suggests, species by species, function by function, and trait by trait. But that is not enough. The essence of development is the appearance of new morphological and behavioral forms from precursors which do not contain those forms. We also need a principled basis for epigenesis, for understanding across levels and species what pushes the developmental process along to create complexity where none existed before. Nothing in the interactionist program alone points toward an integrated theory or offers guidance about which elements and which processes may have developmental significance.

Promising candidates for more general ontogenetic principles entirely consistent with the interactionist program may be derived from contemporary work in nonlinear dynamical systems theory, a branch of mathematics dealing with pattern formation in complex systems. Questions about the origins of order and complexity are being asked about a wide variety of physical, chemical, and biological systems (see, for example, Kelso et al. 1988; Yates 1986). Insights gained from other physical and biological systems may be fruitfully extended to developmental analysis.

Systems composed of many microscopic elements that exist in thermodynamic nonequilibrium can exhibit self-organizing properties. That is, these systems may generate patterns with complex temporal and spatial organization without a prior plan specifying those patterns. It is the cooperation of the elements and the peculiar exchange of energy between the system and its surrounds that determines the pattern. Such systems are highly nonlinear; they remain stable within certain boundary conditions, but when those conditions are exceeded, the system may reorganize into a qualitatively different mode. Changes in only one or a few of the elements can disrupt the stability of this system. Small changes can thus reverberate and have systemwide consequences (Haken 1977; Nicolis \& Prigogine 1977; Yates 1986)

When we characterize developing organisms as part of a more general class of complex, self-organizing systems, we can provide a more principled basis for the interactionist program, explain many persistent and puzzling features of behavioral ontogeny, and indeed, generate a set of powerful predictions not derivable from interactionism alone (Fogel \& Thelen 1987;
Kugler et al. 1982; Thelen et al. 1987; Thelen, in press a; in press b). The basic assumption is that, as in other systems that openly exchange energy with their surrounds, behavior emerges as a function of the cooperative interaction of all the participating elements strictly within a task context. No prescription or code for the particular configuration of behavioral form exists in symbolic or iconic form beforehand, either in the genes, in a cognitive code, or in the structure of the environment. Rather, the behavior is fluidly assembled as a function of the maturational status of the animal, its task context, and general environment constraints. Some behavioral configurations are thermodynamically more stable than others and are preferred outcomes in particular contexts, but they are not predetermined. Under even slightly different conditions, the components may reassemble into other preferred configurations. Examples of such exquisite context-sensitivity during development abound, and it is not uncommon to shift young animals into seemingly more mature or more retarded performance by experimentally manipulating the task context (Fogel $\&$ Thelen 1987; Thelen 1986).

Interactionism itself is not enough because complex dynamic systems are nonlinear. As performance is determined by the coherent whole, a small scalar change in only one or a few critical parameters may have systemwide consequences. No element alone is causal, but the asynchronous and asymmetrical growth of the components means that at different times in ontogeny, different elements may act as these critical agents of change. The elements contributing to new ontogenetic forms may be, as Johnston points out, entirely nonobvious. Most important, there is no logical distinction between the within-the-organism agents for change, such as anatomical growth or neural differentiation, and those outside the organism, such as social systems or other expected environmental opportunities and constraints. The innate-acquired dichotomy is meaningless. Behavior emerges as more or less stable or fluid assemblies of components, which themselves shift in dominance and influence as the organism develops and as its ontogenetic niche changes as well.

Dynamical systems theory suggests that we exploit the instabilities at transitions to uncover the processes which move the systems forward. At transitions, systems exhibit more variability. We often characterize developing animals as playing with or exploring new ensembles, some of which are lost and some of which are retained. At such times, systems are also more vulnerable to perturbations. By selectively removing or facilitating environmental supports, we can isolate the component agents of change. Because these agents of change are themselves nonstationary, isolation or selective rearing over a long developmental span is too nonspecific to tease out these fluctuating and interactive processes. At each transition, the underlying dynamics can -be different.

An interactionist, constructivist, and dynamical view of development signals the demise of any single-cause or deterministic model, be it genetic, neurological, cognitive, or environmental. However, the principles must be useful to explain developmental phenomena at many levels from morphology to cognition and across many time scales as well. The neuronal group selection theory of Edelman (1987), for example, promises an integration of epigenetic mechanisms across levels consistent with a truly dynamical perspective. 


\section{Author's Response}

\section{Challenges to an interactionist approach to the study of song development}

\author{
Timothy D. Johnston \\ Department of Psychology, University of North Carolina at Greensboro, \\ Greensboro, N.C. 27412-5001
}

The commentators have raised a number of interesting and provocative issues. The tone of many of them is rather critical of my arguments, but overall there seems to be some consensus that the issues $\mathbf{I}$ raised are important ones - although there is less agreement on whether my proposed resolutions are successful. The diversity of the commentaries has made it a challenging task to compose an integrated response. Several readings have suggested the (perhaps somewhat artificial) classification of commentaries in Table 1. I have tried to respond to all of the commentaries as thoroughly as possible, but paid most attention to the most critical ones. I am largely in agreement with the points made by Hood, Jensen, Miller, Oyama, and Thelen; their supportive remarks receive less attention than they deserve.

As should have been clear from the target article (and as several commentators also pointed out), the interactionist position that forms the basis of my criticisms is not an original one, but is part of a long tradition of which Kuo,

Table 1. Commentators grouped by topics

1. Innateness and templates: Defenders and detractors Guttinger; King \& West; Kroodsma; Kruijt \& ten Cate; Mundinger; Oyama; Pepperberg; Slater

2. The many different meanings of the word "innate" Alcock; Burghardt; Gttinger; Hirsch; Jensen; Lemon; Morton; Mundinger; Pepperberg; Schull; Slater

3. Learning is as obscure as instinct

Burghardt; Dehaene \& Changeux; Hirsch; Hood; Khayutin \& Alexandrov, Kruijt \& ten Cate; Oyama; Schull

4. What is the logical status of interactionism? Alcock; Bekoff; Dehaene \& Changeux; Gollin; Khayutin \& Alexandrov; Kruijt \& ten Cate; Oyama

5. Developing an interactionist theory of development Bekoff; Dehaene \& Changeux; Gollin; Hirsch; Jensen Khayutin \& Alexandrov; Miller; Steklis; Thelen

6. Genetic contributions to development Hirsch; Hood; Konopka: Lemon; Mundinger; Searcy; Steklis

7. The origin of traits and the origin of differences Hirsch. Schull; Steklis

4 8. The evolutionary interests of ethologists Alcock; Gollin; Konopka; Kroodsma; Morton; Mundinger; Searcy

9. Technical issues in the study of birdsong Güttinger; Khayutin \& Alexandrov; King \& West; Kruijt \& ten Cate; Pepperberg
Schneirla, and Lehrman have been perhaps the most prominent architects. Given the frequent repetition of arguments against dichotomous thinking in development, and the equal frequency of attempts to rebut them, I was pleased that very few commentators took the position that this is a stale issue, tiresomely familiar to everyone, and not worth a rehearing. The issue may well be familiar, but as several commentators (including Khayutin \& Alexandrov, Oyama, Slater, and Steklis) pointed out, it is extraordinarily persistent. One reason for its persistence, as Khayutin \& Alexandrov note, is that it offers an attractive simplification of an enormously complex problem: that of explaining how the phenotype develops. Simplification, of course, is no bad thing: As Burghardt points out, one of the main tasks of theory in science is to simplify, to draw our attention to important aspects of the phenomena we want to explain and to let the less important details recede into the background. Simplification alone, however, is no guarantee of theoretical cogency; the trick is to simplify appropriately, and the interactionist position is that the dichotomous approach to development is the wrong kind of simplification.

\section{Innateness and templates: Defenders and detractors.}

The target article argued, first, that there is a widespread tendency in the song development literature to approach development from a dichotomous perspective and, second, that the dichotomous perspective is an inadequate one. Clearly, not all research on song development has adopted such a perspective, although I would dissent from Slater's view that this approach characterizes only a "small minority of the papers" in the field. Indeed, Slater himself admits that the concept of innateness has risen to greater prominence in recent years, indicating an increased willingness to adopt the dichotomous view of development that I criticized. Several commentators who acknowledge that innateness and its cognates are widely used to discuss the results of experimental studies on song development argue that this really doesn't matter. Pepperberg and Kroodsma both argue that there is nothing in the use of the word "innate" that precludes valuable and productive research. I agree that the terminology does not make it impossible to do good experiments; obviously much of the research that has been carried out under the auspices of the innate-learned dichotomy has contributed a great deal to our understanding of how birdsong develops. But I think all this misses the point. We should surely attempt to use the best conceptual tools available to guide our analysis of song development rather than relying on an inadequate perspective simply because it doesn't absolutely preclude getting useful results. Dichotomous thinking has obviously produced a lot of data about development; I do not think, as Mundinger proposes, that the innate-acquired distinction is not developmentally relevant. I argued that it is conceptually inadequate and that interactionism is to be preferred on theoretical grounds as a basis for developmental research. The point of worrying about problems like this is not simply to do good experiments (although that is one important outcome of the debate), but to build good 
theories. If dichotomous thinking is bad theory then it should be replaced by something better, not defended because it doesn't preclude doing the right experiments. Indeed, Khayutin \& Alexandrov remark that it is partly because of the tempting clarity of the experimental approach dictated by the dichotomous view that conceptual progress in the study of development has been so slow.

Because the concept of a sensory template is so important in research on song development, many of my criticisms against the concept of innateness were directed more specifically against the concept of innate templates. This led Kruijt \& ten Cate to wonder whether I mean to reject the template concept altogether; together with King \& West, they suggest that this would be a mistake because it has been and will remain a useful concept in the field. I intended my criticisms of the template concept to address only the idea that some determinant of song (such as a template) can be said to be innate, or genetically determined. To the extent that the template is used to explain the development of singing during the young bird's first season (through an auditory feedback mechanism of the kind illustrated in Figure 1 of the target article), I tend to agree with Kruijt \& ten Cate that it is a useful concept. For example, it provides a compelling account of the effects of deafening at different times during the acquisition of song (Konishi 1965a). Oyama has less sympathy for the template than I do, and the concept is certainly not without its problems. My primary concern, however, was with the nondevelopmental connotations of an innate template, with the idea that templates can be said to be genetically determined; I fully endorse Oyama's elaboration of the problems inherent in such formulations. The concept of "latent templates," discussed by Guttinger, seems just as vulnerable to Oyama's criticisms.

\section{The many different meanings of the word "innate."} Several commentators pointed out that "innate" can be used in a variety of ways, not all of them open to the criticisms I raised. There is ample reason for believing that the implication of genetic specification is very tightly linked to the use of "innate" in the minds of many (Johnston 1987), but in any case, pointing to the multiple meanings of a term in scientific discussion is a strange defense of its use. Jensen points out the necessity of precise and operationalized terminology, and the commentators themselves illustrate just how little precision is accomplished by the use of "innate" in discussions of development. The word is used by these commentators to mean at least the following: developing in the absence of exposure to a song model (Alcock, Lemon, Mundinger); developmentally buffered or canalized (Alcock, Morton); latent, but requiring specific triggering by the environment (Guttinger); resulting from nonassociative factors (Hirsch); different because of genetic differences (Mundinger); and, grounded in precise neural programming (Lemon).

As pointed out by Burghardt, Pepperberg, Schull, and Slater, the use of "innate" to mean so many different things underscores the need for a different and more sophisticated terminology for talking about development (see Arnold 1981; Bateson 1984). The confusion that results from this multitude of meanings can be seen in
Lemon's commentary. He first uses "innate" to refer to song that develops normally without exposure to a song model; he then illustrates the use of this concept in other fields by citing evidence on presumed innate differences between man and other primates in regard to speech acquisition. The imprecision engendered by such diverse usage is a good argument for abandoning the term; it can hardly be advanced as an argument in its defense.

Mundinger bases a critique of my argument on a detailed analysis of two meanings of "innate" in ethological writing (in the second paragraph of his commentary). I found it very difficult to follow this analysis, partly because Mundinger seems to use "genetically determined" to refer both to differences and to traits (see sect. 7, below).

Is all of this just a debate over semantics? Pepperberg and Kroodsma seem to feel that it is (although Kroodsma does acknowledge the importance of terminological rigor in science). As mentioned above (sect. 1), several commentators pointed out that those who discuss song development in terms of learned and innate contributions have nonetheless made important empirical discoveries. The collective message of those commentators seems to be that this is all simply a debate over words, an editorial rather than a scientific issue. But the problem cannot be dismissed so easily. What is really at stake in this discussion are the ideas that provide the foundation for theories of behavioral development, and the connection between semantic and theoretical precision is very close; indeed, I would suggest that we can hardly expect precise theories if we do not demand precise terminology. It may be argued that the conceptual distinctions I sought to draw in my target article are not important, but if they are, then so are the words we use to draw them. The fact that Lemon and Guttinger both seem content to use the word "innate" to refer to the genetic determination of certain characters illustrates the persistence of that concept.

3. Learning is as obscure as instinct. As Lehrman (1953; 1970) pointed out in his criticisms of the concept of instinct, the temptation to attribute some behavior to the genes is strongly reinforced by a narrow interpretation of what is meant by "learning." It does not seem to be true that, as Burghardt suggests, interactionists seek to attribute behavior entirely (or mostly) to learning, although this remains as persistent a misinterpretation today as it was when Eibl-Eibesfeldt (1961) first offered it in response to Lehrman's criticism of ethological instinct theory (see Lehrman 1970; Johnston 1987). Although Kuo (1929) did deny the utility of learning as an explanation for development, later interactionists (such as Gottlieb 1976; Lehrman 1953; Schneirla 1966) addressed their criticisms to the narrow interpretation given to learning, and to the view that learning and instinct are alternative (and exhaustive) sources of behavior. The reason interactionist criticisms have tended to focus more on instinct (or innateness) than on learning is that theories of learning do offer an account, no matter how narrow, of how behavior might develop, whereas theories of instinct avoid the developmental question by proposing that behavior originates in the genes. One thrust of the interactionist argument has been that we must expand our concept of learning to accommodate a broader range of mechanisms 
by which experience can influence the development of behavior. Khayutin \& Alexandrov, Kruijt \& ten Cate, and Dehaene \& Changeux all emphasize the importance of specifying such mechanisms; the last of these authors even offer a specific suggestion which is discussed below.

I agree with Hirsch and with Schull that current concepts of learning are hardly adequate to the requirements of a theory of behavioral development (see Johnston 1981; 1982; 1985). Hirsch makes this point by suggesting that the critics of dichotomous thinking have held the mistaken belief that learning is a unitary, easily defined concept. That hardly seems a fair characterization, since interactionists from Kuo to Gottlieb have argued that traditional concepts of learning are as inadequate for the analysis of development as are traditional concepts of instinct. The term "learning" can be defined quite narrowly (for example, as synonymous with conditioning) or more broadly, to include all effects of experience on behavior. The disadvantage of the narrow definition has been pointed out above, although Hirsch seems willing to accept both the definition and its disadvantage when he uses "innate" to refer not just to unlearned behavior but to any nonassociative factor in learning as well. That seems to stake out a larger territory for innate behavior than even Lorenz was willing to accept.

Providing a detailed account of learning that is compatible with the interactionist perspective would be impossible within the confines of this response (see Johnston 1981; 1982). Schull suggests a formulation that would continue to distinguish between learned and innate beas follows: "Learned patterns are copied [from the environment]. 'Innate' patterns, ultimately, are generated." This seems to be just a reformulation of Lorenz's (1965) sources-of-information metaphor for distinguish, ing learned and innate behavior (see Johnston 1987). The only difference is that Lorenz attributed innate behavior to genetic information, whereas Schull attributes it to unspecified "pattern-generating processes." I don't see the difference between such processes and Lorenz's process of maturation, by which genetic information unfolds to produce the innate components of the phenotype. The copying mechanism in Schull's formulation is left unspecified, just as the mechanisms for the transmission of innate patterns of behavior are left unspecified in instinct theory. Oyama's commentary cautions against the use of such unspecified mechanisms of transmission, and elsewhere (Oyama 1985) she has spelled out the problems of transmission metaphors in some detail. Curiously, Schull realizes the inadequacy of copying metaphors when they attribute the source of information to the genes, but not when the source is in the environment. As Hood emphasizes at the end of her commentary, information has been given almost mystical powers in discussions of development. Dispelling the mystery is just as important when the information is presumed to originate in the environment as when it is presumed to originate in the genes. Kruijt \& ten Cate make a similar point when they urge more careful consideration of the processes of development as well as its outcomes.

Dehaene $\boldsymbol{\&}$ Changeux recommend that more attention be given to the process by which song learning occurs; they offer their selectionist model of learning as an exam, ple of how that process might occur. Selectionist accounts of learning are not new (Campbell 1960; 1974; Skinner 1981) but recent proposals by Changeux and his colleagues and by Edelman (1987) are important additions to this theoretical lineage. As Dehaene \& Changeux point out, Marler and Peters's (1982b) demonstration of attrition of syllables in the development of song in the swamp sparrow suggests that the late phase of song learning (when song production begins) may be especially amenable to a selectionist account. Khayutin \& Alexandrov describe some experiments showing that hearing song has a powerful influence on nestlings' state of arousal, suggesting that this effect may partly underlie the early learning of song. Investigations of this kind will provide the evidence that is needed to construct theories of how song learning occurs.

4. What is the logical status of interactionism? The logical status of interactionism, and its relation to the dichotomous view of development, seems to have been misunderstood by some commentators. Interactionism is a theoretical framework (or paradigm, following Kuhn 1961) that legitimates certain kinds of experiments and offers interpretations of their results. The dichotomous view is a different framework, legitimating different experiments and interpretations. The test of interactionism lies in whether it generates productive experiments, provides a compelling account of their results, and ultimately leads to a clearer understanding of development than its competitor. Neither view is an empirical hypothesis, capable of being tested by an experiment.

Dehaene \& Changeux complain that interactionism is incapable of being refuted by experiment, thus giving it the logical status of a hypothesis. Bekoff sees interactionism as a theory, suggesting that while it may account for some instances or types of development, an alternative theory might account for others. By proposing that there might be an (unspecified) "middle ground" between dichotomous and interactionist theories of development, he implies that each position is too extreme, laying claim to more territory than is plausible. "Middleground" solutions are appropriate when the disputants occupy opposite ends of some continuum. For example, when one school claims that human behavior is infinitely malleable and another that it is rigidly constrained, one might reasonably suggest that the truth lies somewhere in between. But dichotomous and interactionist views of development do not stand in that kind of relation to one another. Rather, they offer competing and qualitatively different accounts of the way in which behavioral development should be understood.

Alcock suggests that there have been few productive research applications of interactionism, and asks why. It is true that the interactionist view has not been widely assimilated into the study of behavior, as I argued in the introduction to my target article, but I think it has proven its value in many applications. The study of cowbird song development by West and King (1985a; see especially King \& West 1987) is thoroughly interactionist, as is much of the research on zebra finches cited by Slater in his commentary. Outside the song-development literature, Gottlieb's (1981) and Miller's (1988) studies of auditory development in ducklings, Emlen's (1972a) research on navigation in indigo buntings, and Held and 
Hein's (1963) work on visuomotor development in kittens all illuminate the interactionist nature of behavioral development. Not all of these authors were (so far as I know) specifically influenced by theorists such as Lehrman and Schneirla, whose contributions I discussed, but all of them demonstrate that an interactionist perspective can generate productive research programs. Why, then, has the interactionist approach not been more widely adopted in the light of both its conceptual cogency and its apparent productivity? Alcock asks whether this is simply the result of a slavish adherence to dichotomous thinking; his question is rhetorical, but in part I believe he is right. The dichotomous view of development has very deep historical roots, and as Gollin, Khayutin \& Alexandrov, Kruijt \& ten Cate, and Oyama point out in their commentaries, it manifests itself implicitly as well as explicitly throughout the study of development (see also Johnston 1987). As already noted, it provides a compellingly straightforward account of behavioral development, with a deceptive simplicity that is lacking in the interactionist alternative.

\section{Developing an interactionist theory of development.}

The interactionist approach to development is not itself a theory, as suggested above, but it does provide a basis for theory construction. Gottlieb's (1976; 1981; see Aslin 1981) theoretical writings offer one example of the kind of theory that might be built along interactionist lines. Gottlieb proposes three roles for experience in the development of behavior: maintenance, in which experience is necessary to preserve an already existing behavioral ability; facilitation, in which experience ensures the appearance of behavior at the normal time in development; and induction, in which a behavior will not appear at all without the experience. The selectionist model of song development outlined by Dehaene \& Changeux is another example of an interactionist theory of development. Their model implies that a fourth role of experience might be added to Gottlieb's account: attrition, in which some experience is necessary for the normal loss of a behavior from an animal's repertoire (see also Marler \& Peters 1982; King \& West 1983; 1987).

Several commentators offered criticisms of interactionism that will need to be taken into account as interactionist theories are developed. (One general criticism, that interactionism is too vague to be a useful theory of development, has already been addressed, under sect. 4, above.) Bekoff questions whether the view that development results from an organism-environment, rather than a gene-environment, interaction is correct. He links this question to that of defining the unit of selection in evolutionary theory, but I confess that I do not see the relation between the two questions. [ See also Ghiselin: "Categories, Life and Thinking" BBS 4(2) 1981.] I will argue below (sect. 8) that evolutionary and developmental inquiries should be more closely linked than some commentators implied, but the units-of-selection issue does not seem to link them in the way Bekoff suggests. The question whether genes can be said to interact with the environment is nonetheless an important one. When development is described as a "gene-environment" interaction, it is usually the organism's (not the genes') environment that is being referred to, and that is why the formulation is usually rejected as inaccurate. Of course, genes do interact with an environment, but that environment is the biochemical milieu within the cell, not the environment outside the organism. Another reason for rejecting the "gene-environment interaction" formulation is that it invites confusion with the statistical use of the term "interaction" in population genetics (see Section IV of the target article). Despite these important cautions, there is mounting evidence that events in the organism's environment may influence genetic activity, although this influence is always exerted through complex intermediate pathways of physiological and biochemical interactions. For example, Grouse et al. (1978) have shown that environmental enrichment results in an increase in genetic activity in rats' brains (but not in other body tisses) and experiments reviewed by Moses and Chua (1988) reveal that light influences plant growth in part by controlling genetic activity. The conventional proscription against speaking of gene-environment interactions may need to be relaxed, but it is important to remember that even in these cases, the link between genes and environment is only relatively direct. The biochemical and physiological intermediaries are part of the phenotype, which provides the direct interface with the external world.

Gollin suggests that interactionism, while criticizing the dichotomy between learned and innate behavior, introduces other dichotomies of its own that may be just as problematic. The distinction between organism and environment is one of these, and I agree with both Gollin and Miller that it is necessary to formulate developmental theories that respect the integrity of the organism-environment system (ecosystem). This is a point I should have made more clearly in the target article (although I have developed it extensively elsewhere: Johnston 1982; 1985; Johnston \& Turvey 1980). The transactional approach described by Miller (see also Johnston \& Turvey 1980) preserves that integrity and emphasizes the necessity of an ecological approach to developmental analysis. The emphasis in my article on nonobvious sources of experience and on the development of functional attributes of song both derive from an ecological perspective of that kind. As Miller points out, the transactional approach is entirely compatible with more conventional interactionist principles, and indeed is implicit in Lehrman's original formulation (see quotation from Lehrman [1953, p. 345] in Section V of the target article). But all such approaches require, eventually, the identification of elements whose influences on one another cause the changes that we identify as development; identifying those elements requires their experimental manipulation to see whether they have the hypothesized effects. As Hirsch and Khayutin \& Alexandrov both point out, any experimental approach requires that we isolate certain factors for manipulation and measurement, implicitly fractionating the organism-environment system in the process. However, this does not seem to resurrect the problems of the nature/nurture dichotomy, as Steklis suggests, because identifying a contributory factor in the developmental interaction is not the same as attributing elements of behavior to separate causes (environmental and genetic). Demonstrating that a particular pattern of genetic activity contributes to the development of a 
behavior is not the same as claiming that the behavior is genetically determined (see also sect. 6, below).

Hirsch and Miller both emphasize that development involves change in the whole organism (and its environment), not in isolated behavioral traits; again, however, we are constrained to focus on particular elements of behavior in order to make the problem of analysis tractable. The challenge is to do this in a way that maintains the integrity of the system (Johnston 1981; 1985). The application of nonlinear dynamical systems theory (Kugler et al. 1982; Schoner \& Kelso 1988), described by Thelen, is one promising approach. As Thelen points out, this theory eliminates the linear causal approach to development typified by the acquired/innate distinction, which Jensen also identifies as one of its underlying problems.

6. Genetic contributions to development. Interactionists are often accused of being uninterested in the role of genes in behavioral development; some have even claimed that interactionists deny any significant genetic contribution at all (e.g., Eibl-Eibesfeldt 1961; see Burghardt's commentary). It is true that we have generally had less to say about genetic influences on development than about environmental ones, but there is nothing in the interactionist perspective that either minimizes the genetic contribution to development or prevents a specification of how that contribution might be made. The problem is, at least in the case of birdsong, that there are few data available to support any account of the genetic contribution to development. Konopka is right that the study of behavioral development must draw on a variety of fields, including some (like developmental molecular genetics) that are very far removed from traditional areas of ethological concern and expertise. Konopka apparently read my remarks on that point as a suggestion that ethologists should not trespass on the territory of other disciplines, which is not at all what I meant. I was merely pointing out that the conventional techniques of ethological analysis (such as isolation rearing) will not illuminate genetic contributions to development, which will require tools borrowed from other disciplines. I think Konopka and I are in closer agreement on this issue than his commentary would suggest.

Steklis raises an interesting point concerning what we mean when we speak of genes as "causing" a behavior. He cites research on egg-laying in Aplysia that has shown genetic regulation of the behavior through the production of different peptides at appropriate stages of the egglaying cycle and suggests that it is entirely appropriate to speak of this behavior as caused by the genes; Scheller 1 and Axel (1984) describe the behavior as "innate." These experiments show that the activity of certain genes is necessary for the appearance of egg-laying behavior (although on a somewhat shorter time-scale than that typically involved in developmental studies; see Johnston \& Turvey 1980). Scheller and Axel call the products of these genes "control elements"; they function as biochemical switches, activating existing neuromuscular systems. But the genes do not cause the development of the systems that they activate. Those systems are the result of prior developmental processes that involved interactions among numerous elements (including other genes) of the organism and its environment. The sense of "cause" in which genes may be said to cause the activation of egglaying behavior is quite different from the sense in which genes are (erroneously) said to cause the development of that behavior.

The artificial selection described by Hood is one way in which small genetic modifications affecting behavior can be produced without identifying single-gene mutations. Experiments of this kind with songbirds would be very valuable, but I think their interpretation in developmental terms is limited by our inability to specify precisely what genetic modification has been produced. I take it that this is the kind of work Hirsch refers to as "an eclectic behavior-genetic analysis," and (if so) I certainly support his call for further efforts along these lines. Of course, songbirds are a lot harder to breed for studies in selection than are either rats or Drosophila, but Lemon suggests that small finches might be appropriate. Mundinger argues that his research with canaries demonstrates that information about genetic contributions to the development of song can be made using standard ethological methods (such as deprivation rearing), contrary to my claims in the target article. His work shows that different canary strains show differences in song, in song-learning, and in the effects of isolation rearing. I don't see the conceptual distinction between this study and those of Marler and Sherman $(1983 ; 1985)$. Mundinger has used different strains of a single species rather than different species, which means that the genetic differences involved are likely to be smaller. Sufficiently small differences would in fact approximate the effect of a singlegene mutation. If the genetic differences between roller and border canary strains can be precisely characterized, then Mundinger's work could provide the basis for a more tractable analysis of genetic contributions to song development. As they stand, however, these experiments show only that the development of song differs in genetically different strains.

7. The origin of traits and the origin of differences. Section IV of the target article distinguished the analysis of behavioral differences between individuals from the analysis of the origin of the behavioral traits in which the differences are measured. Both are important tasks in the study of behavior, although it is the latter that is of direct relevance to the understanding of development. Hirsch points out that the analysis of behavioral differences is not the only thing that behavior geneticists are interested in these days, but it is certainly part of the subject matter of the field and the source of many misinterpretations (Oyama 1988b; Plomin 1988a).

Steklis questions whether attributing behavioral differences between animals reared in identical environments to genetic differences is correct. He suggests that these differences might arise from differences in prenatal nutrition, hormones, or sensory stimulation. The first and last of these factors are themselves environmental and so do not seem to help in making Steklis's point. The capacity to produce hormones develops as a result of interactions between the animal and its environment; the capacity itself is not genetic, but differences in hormonal capacity (given identical environments) would seem to be. It is true, however, that attributing behavioral differences to genetic differences is an incomplete analysis 
Johnston: Birdsong Development of the situation - one would also want to know how the different genetic makeups of the organisms in question bring about the observed behavioral differences, and I think that is the real point of Steklis's argument. I think the same point underlies Schull's thought experiment in which two species of birds ( $\mathrm{X}$ and $\mathrm{Y}$ ) are given exposure to $Y$ 's normal song; $Y$ learns the song and $X$ learns nothing. Since the environments are identical, we would attribute the differences in song to genetic differences, but it appears that in fact they are due to differences in learning (i.e. , Y learns the song and X learns nothing). But then again, the differences in learning are due to differences in neurophysiological organization, which are due to differences in the patterns of development in the nervous system, which are due to differences in the molecular recognition systems that form nerve circuits, . . . which are due to differences in genes. The view that differences in song between $\mathrm{X}$ and $\mathrm{Y}$ in Schull's thought experiment are due to genetic differences is not so much incorrect as it is incomplete.*

8. The evolutionary interests of ethologists. Not everyone who studies behavior is interested primarily in its development, nor should they be. Morton and Searcy point out that the interests of many ethologists lie primarily in the evolution of song, not in its development; they both argue that the dichotomous approach is appropriate to those interests. Setting aside (for a moment) the question of whether a dichotomous view is indeed appropriate for the evolutionary study of behavior, it is clear that many ethological studies (including virtually all of those discussed in my article) do concern the development of song, not its evolution. If my criticisms of those experiments is well-founded from a developmental perspective (as these commentators seem to agree) then they cannot be dismissed on the grounds that the experiments may yet provide us with information about the evolution of song. The conclusion that our understanding of development is not being advanced as advertised still stands.

But is it in fact the case that evolutionary analysis is well served by the acquired-innate distinction? I think a strong argument can be made that dichotomous thinking is as unhelpful in evolutionary theory as in developmental theory. Part of the argument is that evolutionary theory must account for change in phenotypes, and phenotypes are brought into being by development. If, as interactionism maintains, the acquired-innate dichotomy is conceptually inadequate for understanding the development of phenotypes, then it must surely transport those inadequacies into any account of how phenotypes change in the course of evolutionary time. (Of course, if it is denied that evolutionary theory seeks to explain change

\footnotetext{
*Editorial Note

Without any vested interests in the dichotomist/interactionist dispute, one finds this reasoning rather strained. "Semantics" may not be the right word for it, but some sort of farfetched view of the chain of causation seems to have been adopted here that simply deprives the dichotomy at issue of any real content. One may as well declare oneself a cosmologist rather than an interactionist! On this reasoning it would seem that every question about the causes of behavior - even "Why did the chicken cross the road?" - can have only one satisfactory answer: because of the Big Bang and all of its complex ramifications. Ed. [T. D. Johnston's reply to this editorial note appears at the end of this Author's Response.
}

in phenotypes, being concerned only with change in genotypes, this argument fails. However, when we speak of the evolution of birdsong, we are clearly referring to change in a phenotype.) As modern evolutionary biology deals more and more directly with the relation between evolutionary and developmental mechanisms (see Bateson 1984; Ho \& Saunders 1979; Jamieson 1986; Johnston 1984; Rosen \& Buth 1980), any problems with the conceptual fit between evolutionary and developmental theory become more and more acute. A developmentally based evolutionary biology must examine the adequacy of the developmental theory on which it builds (see Johnston \& Gottlieb 1982; in preparation).

The distinction between evolutionary and developmental analysis is sometimes expressed as a distinction between ultimate and proximate causes of behavior, which has a venerable history in biology. Alcock chides me for not making this distinction when I suggested that the study of song development has focused extensively on the form rather than the function of song. I certainly do not believe that the study of form precludes the study of function (or vice versa) as Alcock implies - indeed, one of my arguments in the target article was precisely that both kinds of study are necessary for understanding song development. But my primary concern in this issue was not the question "What function does this signal have?" (an inquiry into its ultimate causation) but rather a related (and more proximate) question "How does the song acquire its functional characteristics (whatever those may be) in the course of development?" The former question must, of course, be answered before the latter can be asked at all, and there is a large literature on the functions of adult song in a number of species. These, I think, are the studies to which Lemon refers in the last sentence of his commentary, but this literature does not address the issue of song development, except for the few papers I cited in the target article.

Whereas Alcock objects that I did not make the structure-function distinction correctly, Gollin chides me for making the distinction at all. He recommends a style of analysis that captures the structural and functional aspects of a system in a single description, making it unnecessary, and indeed impossible, to separate them. Since the function of any structure can only be defined in relation to some ecological context, Gollin's point reinforces his other argument (discussed under sect. 5, above) against strict separation of animal and environment, an argument with which I am in complete agreement. A similar point surfaces in Morton's commentary, when he points out that behavioral development may depend on factors that are unrelated to the function of the behavior in question. The idea of nonobvious contributions to development (Gottlieb 1976) addresses that issue - the lack of a relation between developmentally and functionally relevant factors usually provides the motivation for calling the developmental factors nonobvious. A formal account of such relationships is provided by Sommerhoff's (1950) concept of a coenetic variable, which is discussed in detail elsewhere (Johnston 1982; Johnston \& Turvey 1980).

9. Technical issues in the study of birdsong. The technical problems of studying birdsong are formidable, as 
Pepperberg and King \& West both point out. King $\&$ West's commentary eloquently describes the difficulties (both intrinsic and extrinsic) that they faced in their own, highly interactionist research program on song development in the cowbird. I do not intend to minimize those difficulties by suggesting that the conceptual issues that were the main concern of my article are both prior to and partly independent of problems of technique. No experiment, whether straightforward or demanding, is likely to be conducted unless there is a theoretical justification for supposing that it will give valuable results. The more demanding the experiment, the more compelling the theoretical justification must be; King \& West point out that experiments of the kind I propose would be very demanding, so they will require a particularly compelling theoretical justification. That is what my article sought to provide; it was not, contrary to Pepperberg's evaluation, simply a call for the use of different techniques to study song development. But even if such techniques are impracticable at present, that is no reason to abandon attempts to sort out the theory we use to motivate technically feasible experiments and to explain their results. We can design such experiments to test interactionist hypotheses, and we can articulate theories of song development that offer interactionist explanations rather than dichotomous ones.

The inertia imposed by entrenched conceptual frameworks, even where technical obstacles are not especially great, is illustrated in another field of behavioral development, namely the study of imprinting. Kruijt \& ten Cate point out that work on sexual imprinting has been largely guided by dichotomous thinking until very recently. Only with the abandonment of that perspective, they argue, has further insight into the process of sexual imprinting been possible. This suggests an answer to the question that King \& West raise, namely, why certain questions (such as the role of social influences) went unasked for so long in the study of filial imprinting (the process whereby young precocial birds learn to recognize the visual characteristics of their mother). The conceptual framework in this field was based on work by Lorenz (1935) and Hess (1959) that viewed imprinting as a process whereby learned information (the mother's visual features) was intercalated with an innate tendency to approach a moving, calling object. That framework ignored the context in which imprinting takes place, overlooking possible contributions by the maternal call (Johnston $\&$ Gottlieb 1981b) and the presence of siblings (Johnston \& Gottlieb 1985; Lickliter \& Gottlieb 1985). No radically new techniques were required to investigate these contributions; the old framework simply failed to recognize them as possibilities and offered an appealingly simple, but largely incomplete, solution to the problem of filial imprinting. As Khayutin \& Alexandrov suggest, the appealing simplicity of apparent solutions to the problem of development that are offered by a dichotomous approach may be one reason why it has engaged the attention of the field for so long. [ See also Ewert: "Neuroethology of Releasing Mechanisms" BBS 10(3) 1987.]

The interplay between technical and conceptual issues in scientific research is complex. Students of song development have already produced an impressive battery of techniques that allow them to answer questions raised within a particular conceptual framework. Sometimes the available techniques may have partly determined the direction of research in the field: Guttinger points out that the use of the sound spectograph encouraged researchers to focus on the microstructure of notes and syllables in the song rather than on more global patterns of song organization, although his own research suggests that the latter may be more important in some species. Pepperberg believes that it was the importation of psychological techniques into the study of birdsong that resulted in social factors being overlooked for so long, although I find this connection less convincing. The study of song development derives from ethology, not psychology, and the influence of the classical deprivation experiment seems quite clear.

10. Conclusion. It is clear that the dichotomy between learned and innate behavior, so often pronounced dead and buried, is in fact alive and well. That is shown not only by the papers reviewed in the target article but also by many of the commentaries. Those who, like myself, believe that it is an obstacle to theoretical progress in the study of development will need to articulate more compelling arguments against its use and (most important) must continue to construct alternatives that can eventually supersede it. Several commentators indicated ways this might be done. No doubt the problem of how best to explain the development of behavior will continue to be debated and the study of birdsong will continue to provide fertile ground for those debates. The resolution of this important problem is unlikely to come quickly or easily; searching for it, however, will remain an exciting challenge.

\section{Response to Editorial Note}

Rather than trying to discuss all of the philosophical issues raised by the editor's comment, let me simply clarify the point I was making in this passage. If we design an experiment to manipulate one independent variable (genetic constitution in the example discussed) and hold all others constant, then any differences between the experimental groups can be attributed to the change in the independent variable. Of course, the differences that are measured in the experiment may depend on the independent variable through a number of intermediate variables; a complete understanding of the situation would require that we specify all of those interconnections in addition to the endpoints. For example, if I grow tomatoes in soils with low and high nitrogen content, with all other variables held constant, I may find that one group of plants produces a higher yield than the other. If so, I can attribute the difference in yield to the difference in nitrogen. Of course, the plants will differ in a number of other characteristics having to do with the role of nitrogen in the physiology and development of tomatoes, which elaborates but does not contradict my original conclusion. However, if I want to explain the origin of tomatoes (rather than the origin of differences between groups of tomatoes), then I must include these physiological and developmental factors in the explanation; it would be incorrect, not merely incomplete, to say that tomatoes are produced by nitrogen. 


\section{References}

Anastasi, A. (1958) Heredity, environment, and the question "How?" Psychological Review 65:197-208.

Arnold, S. J. (1981) The microevolution of feeding behavior. In: Foraging behavior: Ecological, ethological, and psychological approaches, ed. A. C. Kamil \& T. D. Sargent. Garland STPM.

Aslin, R. N. (1981) Experiential influences and sensitive periods in perceptual development: A unified model. In: Development of perception, vol. 1, ed. R. N. Aslin, J. R. Alberts \& M. R. Petersen. Academic Press.

Baker, M. C. \& Cunningham, M. A. (1985) The biology of birdsong dialects. Behavioral and Brain Sciences 8:85-133.

Baptista, L. F. \& Petrinovich, L. (1984) Social interaction, sensitive phases and the song template hypothesis in the white-crowned sparrow. Animal Behaviour 32:172-81.

(1986) Song development in the white-crowned sparrow: Social factors and sex differences. Animal Behaviour 34:1359-71.

Barash, D. (1979) The whisperings within. Harper \& Row.

Bateson, P. P. G. (1978) How does behavior develop? Perspectives in Ethology 3:55-66.

(1984) Sudden changes in ontogeny and phylogeny. In: Behavioral evolution and integrative levels, ed. G. Greenberg \& E. Tobach. Erlbaum.

(1985) Problems and possibilities in fusing developmental and evolutionary thought. In: Evolution and developmental psychology, ed. G. Butterworth, J. Rutkowska \& M. Scaife. St. Martin's Press.

(1987) Biological approaches to the study of behavioural development. International Journal of Behavioral Development 10:1-22.

Beach, F. A. (1955) The descent of instinct. Psychological Reviews 62:401-10

Becker, P. (1982) The coding of species-specific characteristics in bird sounds. In: Acoustic communication in birds, vol. 1, ed. D. E. Kroodsma \& E H. Miller. Academic Press.

Beer, C. G. (1970) Individual recognition by voice in the social behavior of birds. Advances in the Study of Behavior 3:27-74.

Bekoff, M. (1981) Mammalian sibling interactions. Genes, facilitative environments, and the coefficient of familiarity. In: Parental care in mammals, ed. D. J. Gubernick \& P. H. Klopfer. Plenum Press.

(1988) Behavioral development in terrestrial carnivores. In: Carnivore behavior, ecology and evolution, ed. J. L. Gittleman (in press). Cornell University Press.

Bentley, D. R. (1971) Genetic control of an insect neuronal network. Science 174:1139-40.

(1975) Single gene cricket mutations: Effects on behavior; sensilla, sensory neurons and identified interneurons. Science 187:760-64.

Bentley, D. R. \& Hoy, R. R. (1972) Genetic control of the neuronal network generating cricket (Teleogryllus gryllus) song patterns. Animal Behaviour 20:478-92.

Benzer, S. (1967) Behavioral mutants of Drosophila isolated by countercurrent distribution. Proceedings of the National Academy of Sciences, USA. 58:1112-19.

Bever, T. G. (1982) The nonspecific bases of language. In: Language acquisition: The state of the art, ed. E. Wanner \& L. R. Gleitman. Cambridge University Press.

Bischof, H.-J. (1979) A model of imprinting evolved from neurophysiological concepts. Zeitschrift fur Tierpsychologie 51:126-39.

Blaich, C. F. \& Miller, D. B. (1986) Alarm call responsivity of mallard ducklings (Anas platyrhynchos): IV. Effects of social experience. Journal of Comparative Psychology 100:401-5.

Blaich, C. F., Miller, D. B. \& Hicinbothom, G. (in press) Alarm call responsivity of mallard ducklings: 8 . Interaction between developmental history and behavioral context. Developmental Psychobiology.

Bottjer, S. W. \& Arnold, A. P. (1986) The ontogeny of vocal learning in songbirds. In: Handbook of behavioral neurobiology. Vol. 8: Developmental psychobiology and developmental neurobiology, ed. E. M. Blass. Plenum Press.

Brandon, R. (1982) The levels of selection. In: Proceedings of the Philosophy of Science Association Meetings, ed. P. Asquith \& T. Nickles. Philosophy of Science Association.

Brookhart, J. \& Hock, E. (1976) The effects of experimental context and experiential background on infants' behavior toward their mothers and a stranger. Child Development 47:333-40.

Brown, J. L. (1975) The evolution of behavior. W. W. Norton.

Burghardt, G. M. (1973) Instinct and innate behavior: Toward an ethological psychology. In: The study of behavior: Learning, motivation, emotion, and instinct, ed. J. A. Nevin \& G. S. Reynolds. Scott, Foresman.
(1977) Ontogeny of communication. In: How animals communicate, ed. T. A. Sebeok. Indiana University Press.

(1988) Precocity, play, and the ectotherm-endotherm transition: Profound reorganization or superficial adaptation? In: Handbook of behavioral neurobiology, vol. 9, ed. E. M. Blass. Plenum.

Byers, J. A. \& Bekoff, M. (1986) What does "kin recognition" mean? Ethology $72: 342-45$.

Cairns, R. B. \& Gariépy, J-L. (1988) The ontogeny and phylogeny of social interactions: Ten years later. In: Genes, development and behavior, ed. M. Hahn, K. Hewitt, N. D. Henderson \& R. Benno. Oxford University Press.

Cairns, R. B., Gariépy, J-L, \& Hood, K. E. (1988) Dual genesis and the puzzle of aggressive mediation. In: The evolution of social behavior, ed. S. Parmigiani, P. T. Brain \& D. Mainardi.

Cairns, R. B. \& Hood, K. E. (1983) Continuity in social development: A comparative perspective on individual difference prediction. In: Life-span developmental psychology, ed. P. B. Baltes \& 0. G. Brim, Jr. Academic Press.

Cairns, R. B., Hood, K. E. \& Midlam, F. (1985) On fighting in mice: Is there a sensitive period for isolation effects? Animal Behaviour 33:166-80.

Cairns, R. B., MacCombie, D. J. \& Hood, K. E. (1983) A developmentalgenetic analysis of aggressive behavior in mice: I. Behavioral outcomes. Journal of Comparative Psychology 97:69-89.

Campbell, D. T. (1960) Blind variation and selective retention in creative thought as in other knowledge processes. Psychological Review 67:380400 .

(1974) Evolutionary epistemology. In: The philosophy of Karl Popper, vol. 1, ed. P. A. Schlipp. Open Court Press.

Carmichael, L. (1925) Heredity and environment: Are they antithetical? Journal of Abnormal Psychology 20:245-60.

Castro, C. A. \& Rudy, J. W. (1987) Early-life malnutrition selectively retards the development of distal- but not proximal-cue navigation. Developmental Psychobiology 20:521-37.

Cavalli-Sforza, L. L. \& Feldman, M. W. (1981) Cultural transmission and evolution. Princeton University Press.

Changeux, J. P. \& Danchin, A. (1976) Selective stabilization of developing synapses as a mechanism for the specification of neuronal networks. Nature 264:705-12.

Changeux, J. P. \& Dehaene, S. (in press) Neuronal models of cognitive functions. Cognition.

Changeux, J. P., Heidmann, T. \& Patte, P. (1984) Learning by selection. In: The biology of learning, ed. P. Marler Sr H. Terrace. Springer-Verlag.

Chomsky, N. (1959) A review of Skinner's Verbal Behavior. Language 35:2658.

DeCasper, A. J. \& Fifer, W. P. (1980) Of human bonding: Newborns prefer their mothers' voices. Science 208:1174-76.

DeCasper, A. J. \& Spence, M. J. (1986) Prenatal maternal speech influences newborns' perception of speech sounds. Infant Behavior and Development 9:133-50.

Dehaene, S., Changeux, J. P. \& Nadal, J. P. (1987) Neural networks that learn temporal sequences by selection. Proceedings of the National Academy of Sciences of the United States of America 87:2727-31.

Dittus, W. P. J. \& Lemon, R. E. (1969) Effects of song tutoring and acoustic isolation on the song repertoires of cardinals. Animal Behaviour 17:52333.

(1970) Auditory feedback in the singing of cardinals. Ibis 112:544-48.

Dooling, R. \& Searcy, M. (1980) Early perceptual selectivity in the swamp sparrow. Developmental Psychobiology 13:499-506.

Edelman, G. M. (1978) The mindful brain. Cortical organization and the group-selective theory of higher brain function. MIT Press.

(1987) Neural Darwinism: The theory of neuronal group selection. Basic Books.

Eibl-Eibesfeldt, I. (1961) The interactions of unlearned behavior patterns and learning in mammals. In: Brain mechanisms and learning, ed. J. Delafresnaye. Blackwell.

Eimas, P. (1975) Speech perception in early infancy. In: Infant perception: From sensation to cognition, ed. L. B. Cohen \& P. Salapatek. Academic Press.

Emlen, S. T. (1972) An experimental analysis of the parameters of bird song eliciting species recognition. Behaviour 41:130-71.

(1972a) The ontogenetic development of orientation capabilities. In: Animal orientation and navigation, ed. S. R. Caller, K. Schmidt-Koenig, G. J. Jacobs \& R. F. Belleville. National Aeronautics and Space Administration.

Ewer, R. F. (1971) Review of Animal behaviour: A synthesis of ethology and comparative psychology, by R. A. Hinde. Animal Behaviour 19:802-7. 
Fogel, A. \& Thelen, E. (1987) The development of expressive and communicative action in the first year: Reinterpreting the evidence from a dynamic systems perspective. Developmental Psychobiology 23:747-61.

Fox, M. W. (1970) Neurobehavioral development and the genotypeenvironment interaction. Quarterly Review of Biology 45:131-47.

Freedman, D. G. (1974) Human infancy: An evolutionary perspective. Erlbaum (distributed by John Wiley).

Gariépy, J-L., Hood, K. E. \& Cairns, R. B. (in press) A developmentalgenetic analysis of aggressive behavior in mice: III. Behavioral mediation by heightened reactivity or immobility? Journal of Comparative Psychology.

Gish, S. L. \& Morton, E. S. (1981) Structural adaptations to local habitat acoustics in Carolina wren song. Zeitschrift fur Tierpsychologie 56:74-84

Goldin-Meadow, S. (1982) The resilience of recursion. In: Language acquisition: The state of the art, ed. E. Wanner \& L. R. Gleitman. Cambridge University Press.

Collin, E. S. (1984) Developmental malfunctions: Issues and problems. In: Malformations of development: Biological and psychological sources and consequences, ed. E. S. Gollin. Academic Press.

Collin, E. S., Stahl, G. H. \& Morgan, E. (1988) On the uses of the concept of normality in developmental biology and psychology. In: Advances in child development and behavior, ed. H. W. Reese. Academic Press.

Goodman, N. (1984) Of mind and other matters. Harvard University Press.

Gottlieb, G. (1971) Development of species identification in birds. University of Chicago Press.

(1973) Introduction to behavioral embryology. In: Behavioral embryology, vol. 1, ed. G. Gottlieb. Academic Press.

(1976) The roles of experience in the development of behavior and the nervous system. In: Studies on the development of behavior and the nervous system. Vol. 3: Neural and behavioral specificity, ed. G. Gottlieb. Academic Press.

(1980a) Development of species identification in ducklings: VI. Specific embryonic experience required to maintain species-typical perception in Peking ducklings. Journal of Comparative and Physiological Psychology 94:579-87.

(1980b) Development of species identification in ducklings: VII. Highly specific early experience fosters species-specific perception in wood ducklings. Journal of Comparative and Physiological Psychology 94:1019 27.

(1981) Roles of early experience in species-specific perceptual development. In: Development of perception, vol. 1, ed. R. N. Aslin, J. R. Alberts \& M. R. Petersen. Academic Press.

(1983) The psychobiological approach to developmental issues. In Handbook of child psychology. Vol. 2: Infancy and developmental psychobiology, ed. P. H. Mussen. Wiley.

(1984) Development of species identification in ducklings: XII. Ineffectiveness of auditory self-stimulation in wood ducklings (Aix sponsa). Journal of Comparative and Physiological Psychology 98:137-41.

Gould, J. L. \& Marler, P. (1987) Learning by instinct. Scientific American 256:62-73.

Gould, S. J. (1988) Pussycats and owls. New York Review of Books 35:7-10.

Grouse, F. B., Schrier, B. K., Bennett, E. L., Rosenzweig, M. R. \& Nelson, P. G. (1978) Sequence diversity studies of rat brain RNA: Effects of environmental complexity on rat brain RNA diversity. Journal of Neurochemistry 30:191-203.

i.

Stieglitz (Carduelis carduelis) und Grunlingsverwandten (Chlorin spec.). Journal of Ornithology 119:172-90.

(1979) The integration of learnt and genetically programmed behaviour: A study of hierarchical organization in songs of canaries, greenfinches and their hybrids. Zeitschrift fur Tierpsychologie 49:285-303.

(1981) Self-differentiation of song organization rules by deaf canaries. Zeitschrift fur Tierpsychologie 56:323-40.

(1985) Consequences of domestication on the song structures in the canary. Behaviour 94:254-78.

Guttinger, H. R., Wolffgramm, J. \& Thinn, F. (1978) The relationship between species-specific song programs and individual learning in songbirds: A study of individual variation in songs of canaries, greenfinches and hybrids between the two species. Behaviour 65:241-62

Hacking, I. (1965) Logic of statistical inference. Cambridge University Press. Haken, H. (1977) Synergetics. Springer-Verlag.

Hebb, D. 0. (1953) Heredity and environment in mammalian behavior. British Journal of Animal Behavior 1:43-47.

(1963) The semiautonomous process: Its nature and nurture. American Journal of Psychology 18:16-27.

Held, R. \& Hein, A. (1963) Movement-produced stimulation in the development of visually guided behavior. Journal of Comparative and Physiological Psychology 56:872-76.

Hess, E. (1959) The relationship between motivation and imprinting. In: Nebraska Symposium on Motivation, ed. M. R. Jones. University of Nebraska Press.

Hinde, R. A. (1982) Ethology: Its nature and relations with other sciences. Oxford University Press.

Hirsch, J. (1959) Studies in experimental behavior genetics: II. Individual differences in geotaxis as a function of chromosome variations in synthesized Drosophila populations. Journal of Comparative and Physiological Psychology 52:304-8.

(1967a) Behavior-genetic, or "experimental," analysis: The challenge of science versus the lure of technology. American Psychologist 22:11830 .

(1967b) Epilog: Behavior-genetic analysis. In: Behavior-genetic analysis, ed. J. Hirsch. McGraw-Hill.

(1973) Introduction to J. Loeb (1918) Forced movements, tropisms, and animal conduct. Reprinted by Dover Publications.

(1986) Behavior-genetic analysis. In: Readings from the 19th International Ethological Conference: Genetic approaches to behaviour, ed. J. Medioni $\&$ G. Vaysse. Toulouse, France: Privat.

Hirsch, J. \& Boudreau, J. C. (1958) Studies in experimental behavior genetics: I. The heritability of phototaxis in a population of Drosophila melanogaster. Journal of Comparative and Physiological Psychology 51:647-51.

Hirsch, J. \& Erlenmeyer-Kimling, L. (1961) Sign of taxis as a property of genotype. Science 134:835-36.

Hirsch, J. \& McGuire, T. R., eds. (1982) Behavior-genetic analysis. Hutchinson Ross.

Hirsch, J. \& Tryon, R. C. (1956) Mass screening and reliable individual measurement in the experimental behavior genetics of lower organisms. Psychological Bulletin 53:402-10.

Ho, M. W. \& Saunders, P. T. (1979) Beyond neo-Darwinism - an epigenetic approach to evolution. Journal of Theoretical Biology 78:573-91.

Hofer, M. A. \& Shair, H. N. (1987) Isolation distress in two-week-old rats: Influence of home cage, social companions, and prior experience with littermates. Developmental Psychobiology 20:465-76.

Holliday, M. \& Hirsch, J. (1986) Excitatory conditioning of individual Drosophila melanogaster. Journal of Experimental Psychology: Animal Behavior Processes 12:131-42.

Hood, K. E. \& Cairns, R. B. (1988) A developmental-genetic analysis of aggressive behavior in mice. II. Cross-sex inheritance. Behavior Genetics 18:5.

(submitted) A developmental-genetic analysis of aggressive behavior in mice: IV. Genotype-environment interaction.

Howes-Jones, D. (1984) The vocal behaviour of young warbling vireos. Canadian Journal of Zoology 62:1714-19.

Immelmann, K. (1969) Song development in the zebra finch and other estrildid finches. In: Bird vocalizations, ed. R. A. Hinde. Cambridge University Press.

(1979) Genetical constraints on early learning: A perspective from sexual imprinting in birds. In: Theoretical advances in behaviour genetics, ed. J. R. Royce. Sijthof \& Noordhof.

Jamieson, I. G. (1986) The functional approach to behavior: Is it useful? American Naturalist 127:195-208.

Jensen, D. D. (1961) Operationism and the question "Is this behavior learned or innate?" Behaviour 17:1-8.

(1970) Polythetic biopsychology: An alternative to behaviorism. In: Current issues in animal learning: A colloquium, ed. J. H. Reynierse. University of Nebraska Press.

(1987) Operationism, polytheticism, the biotemporal space, and the empirical integration of ethology, psychology, neuroscience, and sociobiology. Poster, XXth International Ethological Conference, Madison, Wis.

Jerne, N. (1967) Antibodies and learning: Selection versus instruction. In: The neurosciences, ed. G. C. Quarton, T. Melnechuck \& F. 0. Schmidt. Rockefeller University Press.

Johnston, T. D. (1981) Contrasting approaches to a theory of learning. Behavioral and Brain Sciences 4:125-73.

(1982) Learning and the evolution of developmental systems. In: Learning, development and evolution: Essays in evolutionary epistemology, ed. H. C. Plotkin. John Wiley.

(1984) Development and the origin of behavioral strategies. Behavioral and Brain Sciences 7:108-9.

(1985) Environmental constraints and the natural context of behavior: Grounds for an ecological approach to the study of infant perception. In: 
(1988b) Reply to Susan Oyama's review of Development, genetics, and psychology. Developmental Psychobiology 21:107-12.

Popper, K. (1959) The logic of scientific discovery. Basic Books.

Poulson, H. (1954) On the song of the linnet (Carduelis cannabina L.). Dansk Ornithologisk Forenings Tidsskrift 48:32-37.

Price, P. H. (1979) Developmental determinants of structure in zebra finch song. Journal of Comparative and Physiological Psychology 93:260-77.

Quinn, J. F. \& Dunham, A. E. (1983) On hypothesis testing in ecology and evolution. American Naturalist 122:602-17.

Quinn, W. G. \& Greenspan, R. J. (1984) Learning and courtship in Drosophila: Two stories with mutants. Annual Review of Neuroscience 7:67-93.

Ricker, J. \& Hirsch, J. (1985) Evolution of an instinct under long-term divergent selection for geotaxis in domesticated populations of Drosophila melanogaster. Journal of Comparative Psychology 99:380-90.

(1988a) Genetic changes occurring over 500 generations in lines of Drosophila melanogaster selected divergently for geotaxis. Behavior Genetics 18:13-25.

(1988b) Reversal of genetic homeostasis in laboratory populations of Drosophila melanogaster under long-term selection for geotaxis and estimates of gene correlates: Evolution of behavior-genetic system. Journal of Comparative Psychology 102:203-14.

Ricker, J., Hirsch, J., Holliday, M. \& Vargo, M. (1986) An examination of claims for classical conditioning as a phenotype in the genetic analysis of Diptera. In: Perspectives in behavior genetics, ed. J. L. Fuller \& E. C. Simmel. Erlbaum.

Rosen, D. E. \& Buth, D. G. (1980) Empirical evolutionary research versus neo-Darwinian speculation. Systematic Zoology 29:300-308

Rosenberg, A. (1985) The structure of biological science. Cambridge University Press

Rothenbuhler, W. C. (1967) Genetic and evolutionary considerations of social behavior of honeybees and some related insects. In: Behavior-genetic analysis, ed. J. Hirsch. McGraw-Hill.

Rothstein, S. I., Yokel, D. A. \& Fleischer, R. C. (1988) The agonistic and sexual functions of vocalizations of male brown-headed cowbirds, Molothrus ater. Animal Behaviour 36:73-86.

Rowley, I. \& Chapman, G. (1986) Cross-fostering, imprinting and learning in two sympatric species of cockatoo. Behaviour 96:1 - 16 .

Scheller, R. H. \& Axel, R. (1984) How genes control an innate behavior. Scientific American 250(3):54-62.

Scheller, R. H., Jackson, J. F., McAllister, L. B., Rothman, B. S., Mayeri, S. $\&$ Axel, R. (1983) A single gene encodes multiple neuropeptides mediating a stereotyped behavior. Cell 32(1):7-22.

Schleidt, W. M. (1985) Learning and the description of the environment. In: Issues in the ecological study of learning, ed. T. D. Johnston \& A. T. Pietrewicz. Erlbaum.

Schneirla, T. C. (1957) The concept of development in comparative psychology. In: The concept of development: An issue in the study of human behavior, ed. D. B. Harris. University of Minnesota Press.

(1965) Aspects of stimulation and organization in approach/withdrawal processes underlying vertebrate behavioral development. Advances in the Study of Behavior 1:1-74.

(1966) Behavioral development and comparative psychology. Quarterly Review of Biology 41:283-302.

Schoner, G. \& Kelso, J. A. S. (1988) Dynamic pattern generation in behavioral and neural systems. Science 239:1513-20.

Schutz, F. (1965) Sexuelle Pragung bei Anatiden. Zeitschrift fur Tierpsychologie 22:50-103.

Searcy, W. A. \& Marler, P. (1981) A test for responsiveness to song structure and programming in female sparrows. Science 213:926-28.

(1987) Response of sparrows to songs of deaf and isolation-reared males: Further evidence for innate auditory templates. Developmental Psychobiology 20:509-19.

Searcy, W. A., Marler, P. \& Peters, S. (1985) Songs of isolation-reared sparrows function in communication, but are significantly less effective than learned song. Behavioral Ecology and Sociobiology 17:223-29.

Segerstrale, U. (1986) Colleagues in conflict: An "in vivo" analysis of the sociobiology controversy. Biology and Philosophy 1:53-87.

Shatz, M. (1982) On mechanisms of language acquisition. In: Language acquisition: The state of the art, ed. E. Wanner \& L. R. Gleitman. Cambridge University Press.

Shepherd, J. M. (1983) Neurobiologia. Oxford University Press.

Shiovitz, K. A. (1975) The process of species-specific song recognition by the indigo bunting, Passerina cyanea, and its relationship to the organization of avian acoustical behavior. Behaviour 55:128-79.
Sidman, R. L., Green, M. C. \& Appel, S. H. (1965) Catalog of the neurological mutants of the mouse. Harvard University Press.

Silvern, L. E. (1984) Emotional-behavioral disorders: A failure of system functions. In: Malformations of development: Biological and psychological sources and consequences, ed. E. S. Gollin. Academic Press.

Skinner, B. F. (1957) Verbal behavior. Appleton-Century-Crofts. (1981) Selection by consequences. Science 213:501-4.

Slater, P. J. B., Eales, L. A. \& Clayton, N. S. (1988) Song learning in zebra finches (Taeniopygia guttata): Progress and prospects. Advances in the Study of Behavior 18:1-34.

Smotherman, W. P. \& Robinson, S. R. (1986) Environmental determinants of behaviour in the rat fetus. Animal Behaviour 34:1859-73.

Sober, E. (1980) Holism, individualism, and the units of selection. In: Proceedings of the Philosophy of Science Association Meetings, ed. P. Asquith \& R. Giere. Philosophy of Science Association.

(1984) The nature of selection: Evolutionary theory in philosophical focus. MIT Press.

Sokol, R. \& Sneath, P. (1963) Principles of numerical taxonomy. W. H. Freeman.

Sommerhoff, G. (1950) Analytical biology. Oxford University Press.

Sonnemann, P. \& Wander, S. (1979) Effects of crossfostering on the sexua imprinting of the female zebra finch. Zeitschrift fur Tierpsychologie 45:337-48.

Spitler-Nabors, K. J. \& Baker, M. C. (1987) Sexual display response of female white-crowned sparrows to normal, isolate and modified conspecific songs. Animal Behaviour 35:380-86.

Stent, G. (1981) Strength and weakness of the genetic approach to the development of the nervous system. In: Studies in developmental neurobiology, ed. W. M. Cowan. Oxford University Press.

ten Cate, C. (1982) Behavioural differences between zebra finch and Bengalese finch (foster)parents raising zebra finch offspring. Behaviour 81:152-72.

(1984) The influence of social relations on the development of species recognition in zebrafinch males. Behaviour 91:262-85.

(1985) Differences in the interactions between zebra finch and Bengalese finch parents with conspecific versus heterospecific young. Zeitschrift Tierpsychologie 67:58-68.

(1985a) On sex differences in sexual imprinting. Animal Behaviour 33:131017.

(1988) Behavioural development: Towards understanding processes. In: Perspectives in ethology. Vol. 8: Whither ethology?, ed. P. P. G. Bateson $\&$ P. H. Klopfer. Plenum Press.

ten Cate, C. \& Mug, G. (1984) The development of mate choice in female zebra finches. Behaviour 90:125-50.

Thelen, E. (1986) Treadmill-elicited stepping in seven-month-old infants. Child Development 57:1498-1506.

(in press a) Self-organization in developmental processes: Can systems approaches work? In: Systems in development: The Minnesota Symposium in Child Psychology, vol. 22, ed. M. Gunnar. Erlbaum.

(in press b) On the nature of developing motor systems and the transition from prenatal to postnatal life. In: Behavior of the fetus, ed. W. P. Smotherman \& S. R. Robinson. Telford Press.

Thelen, E., Kelso, J. A. S. \& Fogel, A. (1987) Self-organizing systems and infant motor development. Developmental Review 7:39-65.

Thompson, W. L. \& Rice, J. 0. (1970) Calls of the indigo bunting, Passerine cyanea. Zeitschrift fur Tierpsychologie 27:35-46.

Thorpe, W. H. (1958) The learning of song patterns by birds, with especial reference to the song of the chaffinch, Fringilla coelebs. Ibis 100:535-70. (1964) The isolate song of two species of Emberiza. Ibis 106:115-18.

Tinbergen, N. (1951) The study of instinct. Oxford University Press.

Toulmin, S. (1967) Neuroscience and human understanding. In: The neurosciences: A study program, ed. G. C. Quarton, T. Melnechuk \& F. 0 . Schmitt. The Rockefeller University Press.

Uexkull, J. von (1909/1985) Environment [Umwelt] and inner world of animals. In: Foundations of comparative ethology, ed. G. M. Burghardt. Van Nostrand Reinhold.

(1926) Theoretical biology. Harcourt Brace.

Vestal, B. M. \& Schnell, G. D. (1986) Influence of environmental complexity and space on social interactions of mice (Mus musculus and Peromyscus leucopus). Journal of Comparative Psychology 100:143-54.

Vince, M. A. (1979) Postnatal effects of prenatal sound stimulation in the guinea pig. Animal Behaviour 27:908-18.

Wallen, K. (1982) Influence of female hormonal state on rhesus sexual behavior varies with space for social interaction. Science 217:375-77.

Wallman, J. (1979) A minimal visual restriction experiment: Preventing chicks 
from seeing their feet affects later responses to mealworms. Developmental Psychobiology 12:391-97.

Wanner, E. \& Gleitman, L. R., eds. (1982) Language acquisition: The state of the art. Cambridge University Press.

Waser, M. S. \& Marler, P. (1977) Song learning in canaries. Journal of Comparative and Physiological Psychology 91:1-7.

Werker, J. F. \& Tees, R. C. (1984) Cross-language speech perception: Evidence for perceptual reorganization during the first year of life. Infant Behavior and Development 7:49-63.

Werner, E. E. \& Gilliam, J. F. (1984) The ontogenetic niche and species interactions in size-structured populations. Annual Review of Ecology and Systematics 15:393-425.

West, M. J. \& King, A. P. (1980) Enriching cowbird song by social deprivation. Journal of Comparative and Physiological Psychology 94:263-70.

(1985a) Learning by performing: An ecological theme for the study of vocal learning. In: Issues in the ecological study of learning, ed. T. D. Johnston \& A. T. Pietrewicz. Erlbaum.

(1985b) Studying dialects in songbirds: Finding the common ground. Behavioral and Brain Sciences 8:117-18.

(1987) Settling nature and nurture into an ontogenetic niche. Developmental Psychobiology 20:549-62.

(1987a) Coming to terms with the everyday language of comparative psychology. Nebraska Symposium on Motivation, ed. D. Leger. University of Nebraska Press.
(1988) Vocalizations of juvenile cowbirds evoke copulatory responses from females. Developmental Psychobiology.

West. M. J., King, A. P. \& Eastzer, D. H. (1981a) The cowbird: Reflections on development from an unlikely source. American Scientist 69:57-66.

(1981b) Validating the female bioassay of cowbird song: Relating differences in song potency to mating success. Animal Behaviour 29:490-501.

West, M. J., King, A. P., Eastzer, D. H. \& Staddon, J. E. R. (1979) A bioassay of isolate cowbird song. Journal of Comparative and Physiological Psychology 93:124-33.

Whitney, J. F. (1986) Effect of medial preoptic lesions on sexual behavior of female rats is determined by test situation. Behavioral Neuroscience 100:230-35.

Whitsett, J. M. \& Vandenbergh, J. G. (1978) Hormonal influences on brain and behavioral development. In: Studies on the development of behavior and the nervous system. Vol. 4: Early influences, ed. G. Gottlieb. Academic Press.

Wilkinson, R. (1980) Calls of nestling chaffinches, Fringilla coelebs: The use of two sound sources. Zeitschrift fir Tierpsychologie 54:346-56.

Williams, G. C. (1966) Adaptation and natural selection. Princeton University Press.

Yates, F. E., ed. (1987) Self-organizing systems: The emergence of order Plenum Press. 